\title{
U.S. Department of Energy FreedomCAR \& Vehicle Technologies Program Advanced Vehicle Testing Activity Hydrogen/CNG Blended Fuels Performance Testing in a Ford F-150
}

Don Karner James Francfort

November 2003

Idaho National Engineering and Environmental Laboratory Bechtel BWXT Idaho, LLC 


\title{
U.S. Department of Energy FreedomCAR \& Vehicle Technologies Program Advanced Vehicle Testing Activity
}

\section{Hydrogen/CNG Blended Fuels Performance Testing in a Ford F-150}

\author{
Don Karner ${ }^{a}$ \\ James Francfort ${ }^{b}$
}

November 2003

Idaho National Engineering and Environmental Laboratory Transportation Technology and Infrastructure Department Idaho Falls, Idaho 83415

Prepared for the

U.S. Department of Energy

Assistant Secretary for Energy Efficiency and Renewable Energy

Under DOE Idaho Operations Office

Contract DE-AC07-99ID13727

\footnotetext{
${ }^{a}$ Electric Transportation Applications

${ }^{\mathrm{b}}$ Principal Investigator, Idaho National Engineering and Environmental Laboratory
} 


\section{Disclaimer}

This document highlights work sponsored by agencies of the U.S. Government. Neither the U.S. Government nor any agency thereof, nor any of their employees, makes any warranty, express or implied, or assumes any legal liability or responsibility for the accuracy, completeness, or usefulness of any information, apparatus, product, or process disclosed, or represents that its use would not infringe privately owned rights. Reference herein to any specific commercial product, process, or service by trade name, trademark, manufacturer, or otherwise does not necessarily constitute or imply its endorsement, recommendation, or favoring by the U.S. Government or any agency thereof. The views and opinions of authors expressed herein do not necessarily state or reflect those of the U.S. Government or any agency thereof. 


\section{ABSTRACT}

Federal regulation requires energy companies and government entities to utilize alternative fuels in their vehicle fleets. To meet this need, several automobile manufacturers are producing compressed natural gas (CNG)-fueled vehicles. In addition, several converters are modifying gasoline-fueled vehicles to operate on both gasoline and CNG (Bifuel). Because of the availability of CNG vehicles, many energy company and government fleets have adopted $\mathrm{CNG}$ as their principle alternative fuel for transportation. Meanwhile, recent research has shown that blending hydrogen with CNG (HCNG) can reduce emissions from $\mathrm{CNG}$ vehicles. However, blending hydrogen with $\mathrm{CNG}$ (and performing no other vehicle modifications) reduces engine power output, due to the lower volumetric energy density of hydrogen in relation to CNG. Arizona Public Service (APS) and the U.S. Department of Energy's Advanced Vehicle Testing Activity (DOE AVTA) identified the need to determine the magnitude of these effects and their impact on the viability of using HCNG in existing CNG vehicles.

To quantify the effects of using various blended fuels, a work plan was designed to test the acceleration, range, and exhaust emissions of a Ford F-150 pickup truck operating on $100 \%$ CNG and blends of 15 and 30\% HCNG. This report presents the results of this testing conducted during May and June 2003 by Electric Transportation Applications (Task 4.10, DOE AVTA Cooperative Agreement DEFC36-00ID-13859). 


\section{CONTENTS}





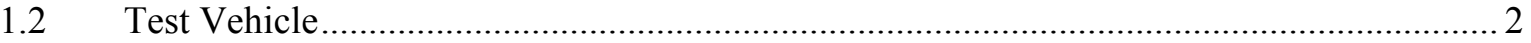



1.3.1 IM240 $\quad$.

1.3.2 $\quad$ FTP-75

$1.4 \quad$ Acceleration and Range Test Procedures ........................................................................ 3

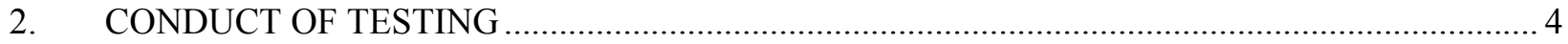

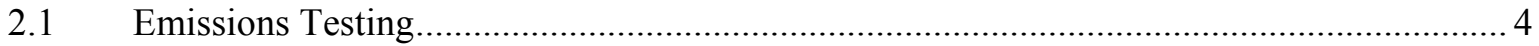

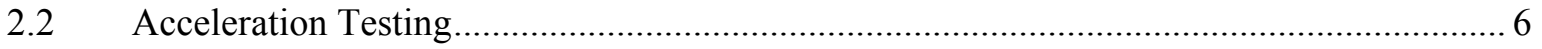

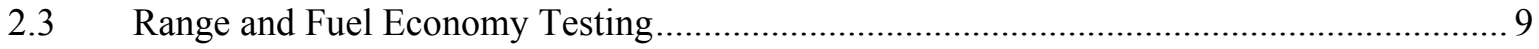

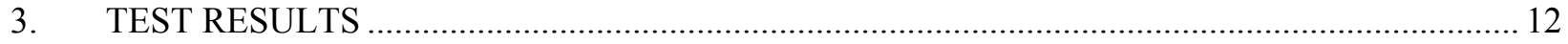

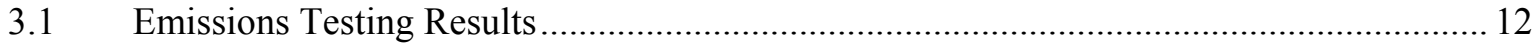



3.3 Range and Fuel Economy Test Results ....................................................................... 14

Attachment 1 - Hydrogen ICE Vehicle Acceleration Test Procedure ….................................................. 1

Attachment 2 - Hydrogen ICE Vehicle Constant Speed Fuel Economy Tests ......................................... 1

Attachment 3 - Hydrogen ICE Vehicle Acceleration Testing Data Sheets.............................................. 1

Attachment 4 - Hydrogen ICE Vehicle Constant Speed Fuel Economy Testing Data Sheets..................... 1

Attachment 5 - Summary Emission Test Data Sheets ........................................................................ 1 


\section{FIGURES}

Figure 1. Low-percentage blend Ford F-150 pickup. ....................................................................... 1

Figure 2. Low-percentage blend Ford F-150 engine compartment........................................................ 2

Figure 3. Speed versus distance for the F-150 test vehicle, using 100\% CNG...................................... 6

Figure 4. Speed versus distance for the F-150 test vehicle, using 15\% HCNG...................................... 7

Figure 5. Speed versus distance for the F-150 test vehicle, using 30\% HCNG....................................... 7

Figure 6. Speed versus time for the Ford F-150 test vehicle, using $100 \%$ CNG. ................................... 8

Figure 7. Speed versus time for the Ford F-150 test vehicle, using $15 \%$ HCNG. .................................. 8

Figure 8. Speed versus time for the Ford F-150 test vehicle, using 30\% HCNG. ................................. 9

Figure 10. Speed versus time for the Ford F-150 test vehicle range test, using 100\% CNG................... 10

Figure 11. Speed versus time for the Ford F-150 test vehicle range test, using 15\% HCNG.................. 11

Figure 12. Speed versus time for the Ford F-150 test vehicle range test, using 30\% HCNG................. 11

Figure 13. Average speed versus distance for F-150 test vehicle range test, $100 \% \mathrm{CNG}, 15 \% \mathrm{HCNG}$ and



Figure 14. Average speed versus time for F-150 test vehicle range test, $100 \% \mathrm{CNG}, 15 \% \mathrm{HCNG}$ and

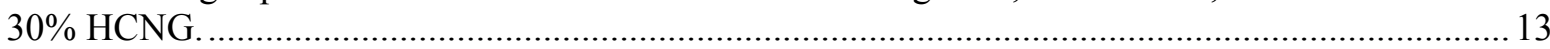

\section{TABLES}

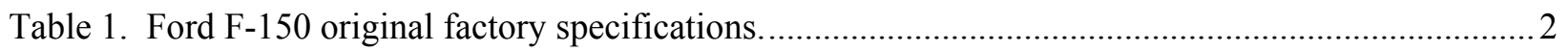

Table 2. California LEV II emission standards................................................................................. 3

Table 3. Fleet testing F-150 emissions test results (gram/mile) operating on 30\% HCNG...................... 4

Table 4. Gasoline-fueled F-150 emission test results (gram/mile) ........................................................ 5

Table 5. Percentage reduction in emissions (30\% HCNG fuel versus gasoline-fueled F-150). ................ 5

Table 6. Emissions test results (gram/mile) for blended HCNG fuels and 100\% CNG. ......................... 5

Table 7. Time to accelerate to $60 \mathrm{mph}$ for $100 \% \mathrm{CNG}, 15$ and $30 \%$ HCNG. ........................................ 9

Table 8. F-150 test vehicle range at a constant speed of $45 \mathrm{mph}$ for $100 \% \mathrm{CNG}, 15$ and 30\% HCNG.... 10

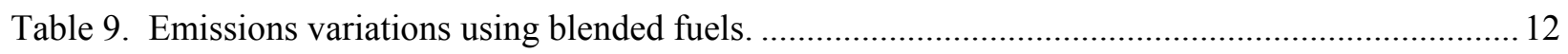

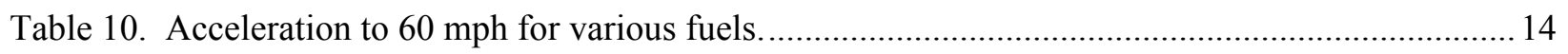

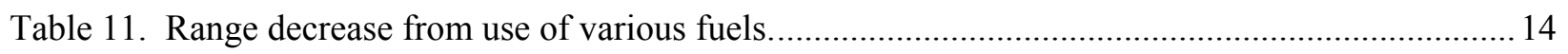




\section{ACRONYMS}

\begin{tabular}{|c|c|}
\hline APG & Arizona Proving Grounds \\
\hline APS & Arizona Public Service \\
\hline ATL & Automotive Testing Laboratories \\
\hline $\mathrm{CH}_{4}$ & Methane \\
\hline $\mathrm{CNG}$ & Compressed natural gas \\
\hline $\mathrm{CO}$ & Carbon monoxide \\
\hline $\mathrm{CO}_{2}$ & Carbon dioxide \\
\hline DOE AVTA & U.S. Department of Energy Advanced Vehicle Testing Activity \\
\hline ETA & Electric Transportation Applications \\
\hline FTP-75 & Federal Emissions Test Procedure \\
\hline gge & Gasoline gallon equivalent \\
\hline $\mathrm{HC}$ & Total hydrocarbons \\
\hline HCNG & Hydrogen blended with natural gas \\
\hline ICE & Internal combustion engine \\
\hline IM240 & Inspection and Maintenance Driving Cycle \\
\hline $\mathrm{kph}$ & Kilometers per hour \\
\hline LEV & Low-emission vehicles \\
\hline MDV & Medium duty vehicle \\
\hline mpg & Miles per gallon \\
\hline $\mathrm{mph}$ & Miles per hour \\
\hline $\mathrm{NMCH}$ & Nonmethane hydrocarbons \\
\hline NMOG & Nonmethane organic gases \\
\hline NOx & Oxides of nitrogen \\
\hline psi & Pounds per square inch \\
\hline psig & Pounds per square inch, gauge \\
\hline $\mathrm{kPa}$ & Kilopascals \\
\hline SULEV & Super ultra low-emission vehicle \\
\hline $\mathrm{EV}$ & Ultra low-emission vehicle \\
\hline
\end{tabular}




\section{Hydrogen/CNG-Blended Fuels Performance Testing in a Ford F-150}

\section{BACKGROUND}

\subsection{Test Program}

Federal regulation requires energy companies and government entities to utilize alternative fuels in their vehicle fleets. As a result, several automobile manufacturers are producing compressed natural gas (CNG)-fueled vehicles. In addition, several converters are modifying gasoline-fueled vehicles to operate on both gasoline and CNG (Bifuel). Because of the availability of CNG vehicles, many energy company and government fleets have adopted $\mathrm{CNG}$ as their principle alternative fuel for transportation. Meanwhile, recent research has shown that blending hydrogen with $\mathrm{CNG}(\mathrm{HCNG})$ can reduce emissions from $\mathrm{CNG}$ vehicles. However, blending hydrogen with CNG (and performing no other vehicle modifications) reduces engine power output, due to the lower volumetric energy density of hydrogen in relation to CNG. Arizona Public Service (APS) and the U.S. Department of Energy's (DOE's) Advanced Vehicle Testing Activity (AVTA) identified the need to determine the magnitude of these effects and their impact on the viability of using $\mathrm{HCNG}$ in existing $\mathrm{CNG}$ vehicles.

To perform this evaluation, a work plan was designed to test the acceleration, range, and exhaust emissions of a Ford F-150 pickup truck (Figure 1) operating on $100 \%$ CNG and blends of 15 and $30 \%$ HCNG. This work program was conducted by Electric Transportation Applications, as Task 4.10 under the DOE Cooperative Agreement DE-FC36-00ID-13859. The Ford F-150 was previously tested in fleet operation using a blend of 30\% HCNG (DOE Cooperative Agreement DE-FC36-00ID-13859, Task 4.6). Results of the previous Task 4.6 testing are documented in the report: Low Percentage Hydrogen/CNG Blend Ford F-150 Truck Operating Summary (INEEL/EXT-03-00008, September 2002).

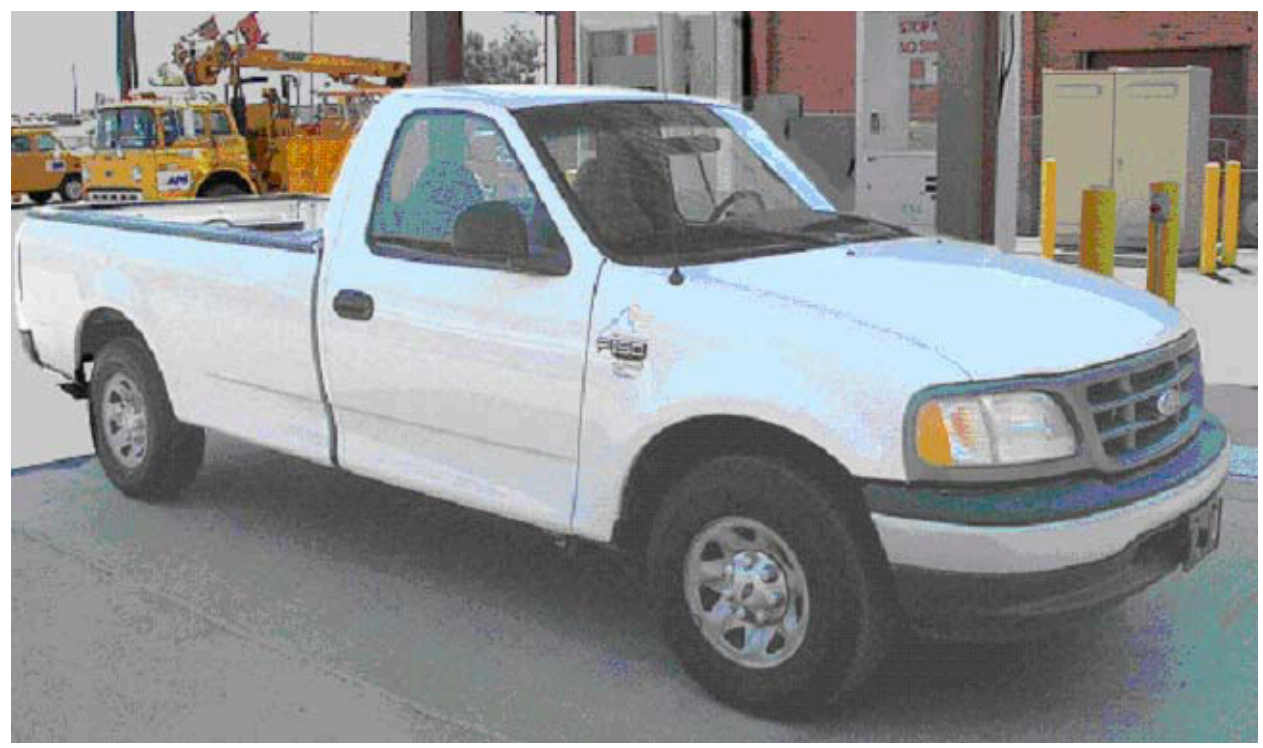

Figure 1. Low-percentage blend Ford F-150 pickup. 


\subsection{Test Vehicle}

The test vehicle is a model year 2000, F-150 regular cab pickup truck equipped with a factory CNG engine (Table 1) and 3600 psig carbon steel fuel tanks with an 85-liter capacity. It was modified by NRG Tech in Reno, Nevada to run on a blend of CNG and up to $30 \%$ hydrogen (by volume). NRG Tech modifications (Figure 2) include supercharging, ignition modifications, and exhaust gas recirculation. The F-150 was placed in service in the APS fleet in June 2001. Fleet testing of the vehicle was conducted from June 2001 through September 2002. Subsequent to the formal performance testing with blended fuels, the vehicle was again placed in the APS fleet. F-150 parametric performance testing with hydrogen/CNG-blended fuels was conducted in May and June 2003. At the beginning of this test program, the vehicle had accumulated 31,678 miles, operating with HCNG fuel.

Table 1. Ford F-150 original factory specifications.

\begin{tabular}{ll}
\hline Engine & $5.4 \mathrm{~L} \mathrm{~V} 8$ \\
Factory HP & $230 \mathrm{HP}$ \\
Curb weight & $5,170 \mathrm{lb}$ \\
GVWR & $7,650 \mathrm{lb}$ \\
\hline
\end{tabular}

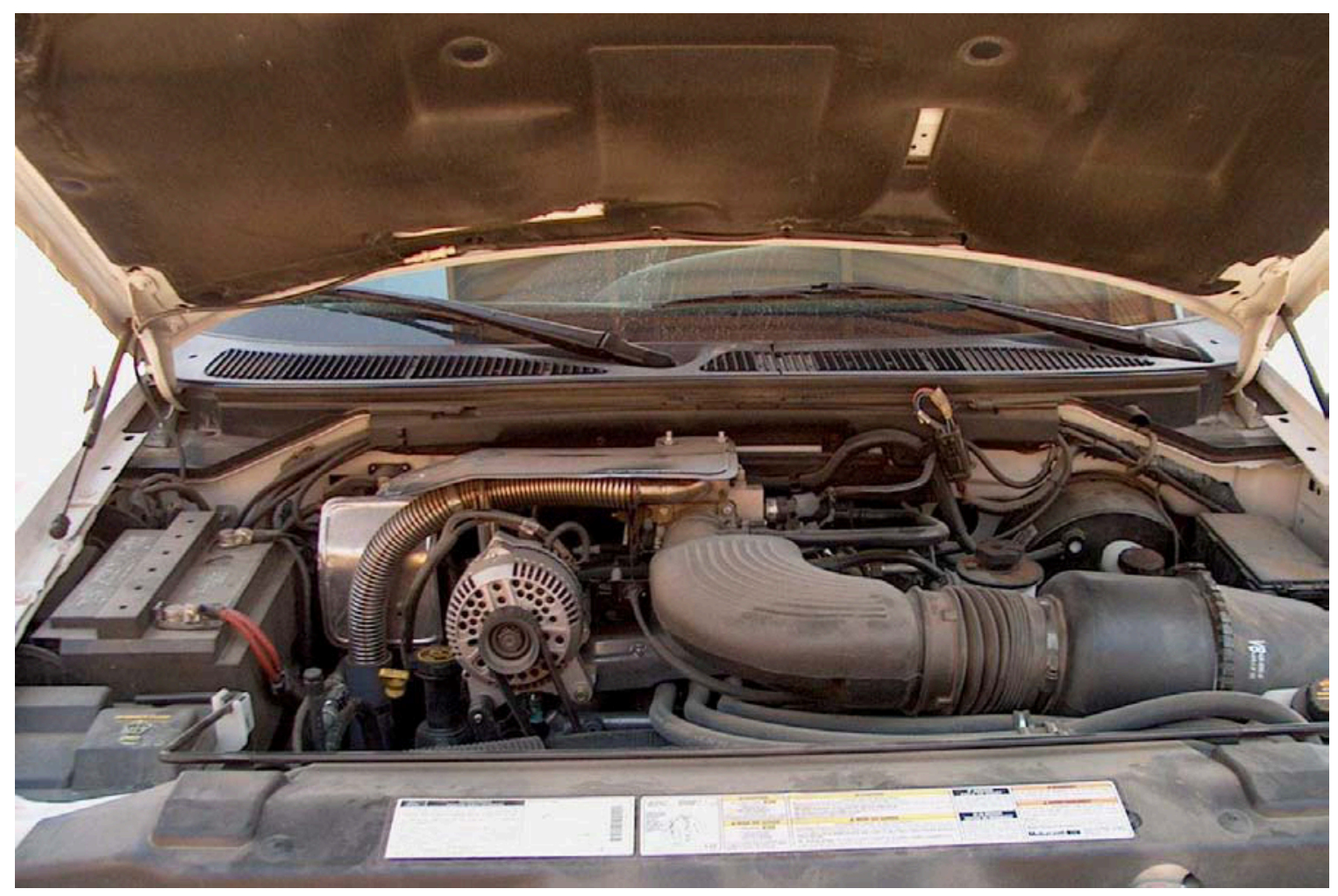

Figure 2. Low-percentage blend Ford F-150 engine compartment.

\subsection{Emission Test Procedures}

During the previous fleet testing (Task 4.6) of the Ford F-150, emissions from the test vehicle were periodically measured. Two different emission test procedures were performed on the vehicle, the IM240 and the FTP-75. 


\subsubsection{IM240}

The Inspection and Maintenance Driving Cycle (IM240) test is used by several states for emissions testing of light duty vehicles. The test consists of a single phase, which spans 240 seconds and 1.96 miles of travel; it reaches a top speed of $56.7 \mathrm{mph}$, at an average speed of $29.4 \mathrm{mph}$. The test fails to account for cold starts, when automobile emissions are typically the highest.

\subsubsection{FTP-75}

The Federal Test Procedure (FTP-75) is a more thorough emissions test than the IM240. The test consists of three phases, which span 1,874 seconds and 11.04 miles of travel, at an average speed of $21.2 \mathrm{mph}$. The three phases are cold start, transient, and hot start that occurs 10 minutes after completion of the transient phase.

Emissions tests performed under the current work program were conducted using the FTP-75 test cycle at the Automotive Testing Laboratories, Inc. (ATL) facilities, located in Mesa, Arizona. ATL is certified by the State of Arizona to conduct the Federal Test Procedure.

California emission standards are used in this report as a reference point for vehicle emissions. Currently, Low-Emission Vehicles I (LEV I) emission standards are in effect. However, a more stringent set of emission standards, LEV II, will come into effect in 2004. The California LEV II emission standards categorize emissions into the following groups: low-emission vehicles (LEVs), ultra lowemission vehicles (ULEVs), and super ultra low-emission vehicles (SULEVs). The standards are based on weight class and emissions are measured over the FTP-75 test. The F-150 test vehicle used for this work program is classified by California emission standards as an MDV3. ${ }^{\mathrm{c}}$ Some of the California emission standards for the MDV3 class are shown in Table 2.

Table 2. California LEV II emission standards.

\begin{tabular}{lccc}
\hline & $\begin{array}{c}\text { NMOG } \\
(\text { gram/mile })\end{array}$ & $\begin{array}{c}\text { CO } \\
(\text { gram/mile })\end{array}$ & $\begin{array}{c}\text { NOx } \\
(\text { gram/mile })\end{array}$ \\
\hline LEV & 0.09 & 4.2 & 0.07 \\
ULEV & 0.055 & 2.1 & 0.07 \\
SULEV & 0.01 & 1 & 0.02 \\
\hline
\end{tabular}

$\mathrm{NMOG}=$ nonmethane organic gases.

$\mathrm{CO}=$ carbon monoxide.

$\mathrm{NOx}=$ oxides of nitrogen.

\subsection{Acceleration and Range Test Procedures}

Hydrogen internal combustion engine (ICE) test procedures were developed to conduct acceleration and range testing of the F-150 test vehicle, fueled using 100\% CNG and blends of 15 and $30 \%$ HCNG. The acceleration test procedure (Attachment 1) requires that the vehicle be accelerated from rest to a speed of $100 \mathrm{mph}$, and speed versus time data are collected. The hydrogen ICE range test procedure (Attachment 2) requires that the vehicle be operated at a constant speed of $45 \mathrm{mph}$, and distance versus time data are collected.

\footnotetext{
${ }^{\mathrm{c}} \mathrm{MDV}=$ medium duty vehicle; MDV3 is the class of MDVs with a test weight between 5751 and 8500 lb. Test weight by the California definition is analogous to the federal definition of adjusted loaded vehicle weight (ALVW); Test weight $=(\mathrm{curb}$ weight + GVWR)/2.
} 


\section{CONDUCT OF TESTING}

\subsection{Emissions Testing}

Emissions from the F-150 were measured at ATL using both FTP-75 and IM240 test cycles during the June 2001 through September 2002 vehicle fleet testing (Task 4.6). During this test, the F-150 was fueled exclusively with a blend of $30 \% \mathrm{HCNG}$. The vehicle was tested several times to validate the results. As Table 3 shows, carbon monoxide emissions from the low percentage blend F-150 averaged 0.26 gram $/$ mile over the FTP-75 tests, well under the California SULEV standard of $1 \mathrm{gram} / \mathrm{mile}$. Nitrogen oxide emissions averaged 0.078 gram/mile, near the California ULEV standard of 0.07 . However, the first $\mathrm{NO}_{\mathrm{x}}$ testing result (0.063) was under the 0.07 standard, which is based on emissions when a vehicle is new. Non-methane organic gases (NMOG) were not measured.

To provide an additional point of reference for F-150 emissions test results, emissions testing of a randomly selected Ford F-150 equipped with a factory gasoline engine was also conducted at ATL (Table 4).

Table 3. Fleet testing F-150 emissions test results (gram/mile) operating on $30 \%$ HCNG.

\begin{tabular}{|c|c|c|c|c|c|c|c|}
\hline Test Date & Mileage & NMHC & $\mathrm{CH}_{4}$ & $\mathrm{HC}$ & $\mathrm{CO}$ & $\mathrm{NO}_{\mathrm{X}}$ & $\mathrm{CO}_{2}$ \\
\hline \multicolumn{8}{|l|}{ FTP-75 } \\
\hline $5 / 2 / 2001$ & 1592 & 0.011 & 0.075 & 0.094 & 0.237 & 0.063 & 440.606 \\
\hline $5 / 3 / 2001$ & 1613 & 0.019 & 0.084 & 0.118 & 0.249 & 0.094 & 441.442 \\
\hline $5 / 4 / 2001$ & 1636 & 0.024 & 0.082 & 0.121 & 0.267 & 0.094 & 437.370 \\
\hline $5 / 8 / 2001$ & 1657 & 0.017 & 0.099 & 0.133 & 0.257 & 0.084 & 439.940 \\
\hline $6 / 14 / 2001$ & 2148 & 0.028 & 0.091 & 0.136 & 0.223 & 0.104 & 435.899 \\
\hline $8 / 30 / 2001$ & 3890 & 0.028 & 0.074 & 0.116 & 0.348 & 0.051 & 442.515 \\
\hline $8 / 31 / 2001$ & 3915 & 0.028 & 0.067 & 0.107 & 0.210 & 0.053 & 437.009 \\
\hline Average & & 0.022 & 0.081 & 0.117 & 0.255 & 0.078 & 439.254 \\
\hline \multicolumn{8}{|l|}{ IM240 } \\
\hline $5 / 2 / 2001$ & 1592 & 0.062 & 0.050 & 0.124 & 0.135 & 0.040 & 392.720 \\
\hline $5 / 3 / 2001$ & 1625 & 0.008 & 0.042 & 0.057 & 0.118 & 0.025 & 402.205 \\
\hline $5 / 4 / 2001$ & 1647 & 0.014 & 0.054 & 0.078 & 0.146 & 0.023 & 410.147 \\
\hline $5 / 8 / 2001$ & 1670 & 0.016 & 0.069 & 0.098 & 0.101 & 0.022 & 411.302 \\
\hline $8 / 30 / 2001$ & 3901 & 0.014 & 0.054 & 0.078 & 0.077 & 0.089 & 397.635 \\
\hline $8 / 30 / 2001$ & 3903 & 0.016 & 0.028 & 0.049 & 0.125 & 0.051 & 402.614 \\
\hline $8 / 31 / 2001$ & 3928 & 0.013 & 0.045 & 0.066 & 0.101 & 0.019 & 397.634 \\
\hline $8 / 31 / 2001$ & 3931 & 0.013 & 0.026 & 0.045 & 0.095 & 0.033 & 396.020 \\
\hline Average & & 0.019 & 0.046 & 0.074 & 0.112 & 0.037 & 401.285 \\
\hline
\end{tabular}

$\mathrm{NMHC}=$ nonmethane hydrocarbons

$\mathrm{CH}_{4}=$ methane

$\mathrm{HC}=$ total hydrocarbons

$\mathrm{CO}=$ carbon monoxide

$\mathrm{NO}_{\mathrm{x}}=$ oxides of nitrogen

$\mathrm{CO}_{2}=$ carbon dioxide 
Table 4. Gasoline-fueled F-150 emission test results (gram/mile).

\begin{tabular}{cccccccc}
\hline Test & Vehicle & \multicolumn{7}{c}{ Emission Species } \\
\cline { 3 - 8 } Date & Mileage & NMHC & $\mathrm{CH}_{4}$ & $\mathrm{HC}$ & $\mathrm{CO}$ & $\mathrm{NO}_{\mathrm{X}}$ & $\mathrm{CO}_{2}$ \\
\hline FTP-75 & & & & & & & \\
$6 / 20 / 2001$ & 23497 & 0.122 & 0.013 & 0.136 & 1.644 & 0.170 & 620.7 \\
$6 / 21 / 2001$ & 23519 & 0.107 & 0.011 & 0.119 & 1.457 & 0.163 & 623.0 \\
Average & & 0.115 & 0.012 & 0.128 & 1.551 & 0.167 & 621.9 \\
IM240 & & & & & & & \\
6/20/2001 & 23509 & 0.015 & 0.008 & 0.023 & 0.127 & 0.565 & 585.172 \\
$6 / 21 / 2001$ & 23531 & 0.006 & 0.011 & 0.017 & 0.046 & 0.440 & 578.728 \\
Average & & 0.011 & 0.010 & 0.020 & 0.087 & 0.503 & 581.95 \\
\hline
\end{tabular}

$\mathrm{NMHC}=$ nonmethane Hydrocarbons

$\mathrm{CH}_{4}=$ methane

$\mathrm{HC}=$ total hydrocarbons

$\mathrm{CO}=$ carbon monoxide

$\mathrm{NO}_{\mathrm{x}}=$ oxides of nitrogen

$\mathrm{CO}_{2}=$ carbon dioxide

Table 5 illustrates the emissions comparison between the average emissions of the F-150 during fleet testing at 30\% HCNG (Table 3) and the random gasoline-fueled F-150 (Table 4). Reductions were achieved for all emission species except for methane, which is typical of vehicles operating on CNG.

Table 5. Percentage reduction in emissions (30\% HCNG fuel versus gasoline-fueled F-150).

\begin{tabular}{cccc}
\hline $\mathrm{HC}$ & $\mathrm{CO}$ & $\mathrm{NO}_{\mathrm{X}}$ & $\mathrm{CO}_{2}$ \\
\hline $7.6 \%$ & $53.4 \%$ & $29.4 \%$ \\
\hline $\mathrm{HC}=$ total hydrocarbons. & & \\
$\mathrm{CO}=$ carbon monoxide. & & \\
$\mathrm{NO}_{\mathrm{x}}=$ oxides of nitrogen. & & \\
$\mathrm{CO}_{2}=$ carbon dioxide. & &
\end{tabular}

The baseline of data obtained from the previous F-150 emissions testing during the fleet testing (Tables 3 and 4) was supplemented in the current work program by conducting additional FTP-75 emissions testing for the F-150 test vehicle using fuels of 100\% CNG, 15 and 30\% HCNG (Table 6). Each time fuel was changed in the test vehicle, it was driven at least 100 miles using the new fuel to allow the engine management computer to make any automatic adjustments necessary to optimize use of the new fuel. The FTP-75 test cycle emissions testing was conducted by ATL using the procedures certified by the State of Arizona.

Table 6. Emissions test results (gram/mile) for blended HCNG fuels and 100\% CNG.

\begin{tabular}{cccccccc}
\hline Fuel & Vehicle & \multicolumn{5}{c}{ Emission Species (gram/mile) } \\
\cline { 3 - 8 } Blend & Mileage & $\mathrm{NMHC}$ & $\mathrm{CH}_{4}$ & $\mathrm{HC}$ & $\mathrm{CO}$ & $\mathrm{NO}_{\mathrm{X}}$ & $\mathrm{CO}_{2}$ \\
\hline $\mathrm{CNG}$ & 30,045 & 0.023 & 0.128 & 0.173 & 0.567 & 0.110 & 473.1 \\
$15 \% \mathrm{HCNG}$ & 29,915 & 0.025 & 0.132 & 0.179 & 0.467 & 0.124 & 452.2 \\
$30 \% \mathrm{HCNG}$ & 28,814 & 0.013 & 0.138 & 0.175 & 0.423 & 0.126 & 448.1 \\
\hline $\mathrm{CO}=$ carbon monoxide & \multicolumn{6}{c}{$\mathrm{NMHC}^{2}$ nonmethane Hydrocarbons } \\
$\mathrm{NO}_{\mathrm{x}}=$ oxides of nitrogen & \multicolumn{5}{c}{$\mathrm{CH}_{4}=$ methane } \\
$\mathrm{CO}_{2}=$ carbon dioxide & \multicolumn{7}{c}{$\mathrm{HC}=$ total hydrocarbons. }
\end{tabular}




\subsection{Acceleration Testing}

Acceleration testing of the F-150 was conducted at DaimlerChrysler's Arizona Proving Grounds (APG) in accordance with the Hydrogen ICE (Internal Combustion Engine) Vehicle Acceleration Test Procedures (Attachment 1), for fuels of $100 \%$ CNG, and blends of 15 and 30\% HCNG. Tests were performed using a 2.4-mile-long straight track at the APG. For each of the three blends of fuel, two sets of acceleration runs were conducted. Each set consisted of one acceleration run in each direction (east and west) on the straight track. Data sheets from these tests (12 runs total) are presented in Attachment 3. Results of acceleration testing conducted with the F-150 test vehicle are presented as speed versus distance in Figures 3, 4, and 5 and speed versus time in Figures 6, 7, and 8 for each fuel type. Table 7 presents the times to accelerate to $60 \mathrm{mph}$ for each fuel type.

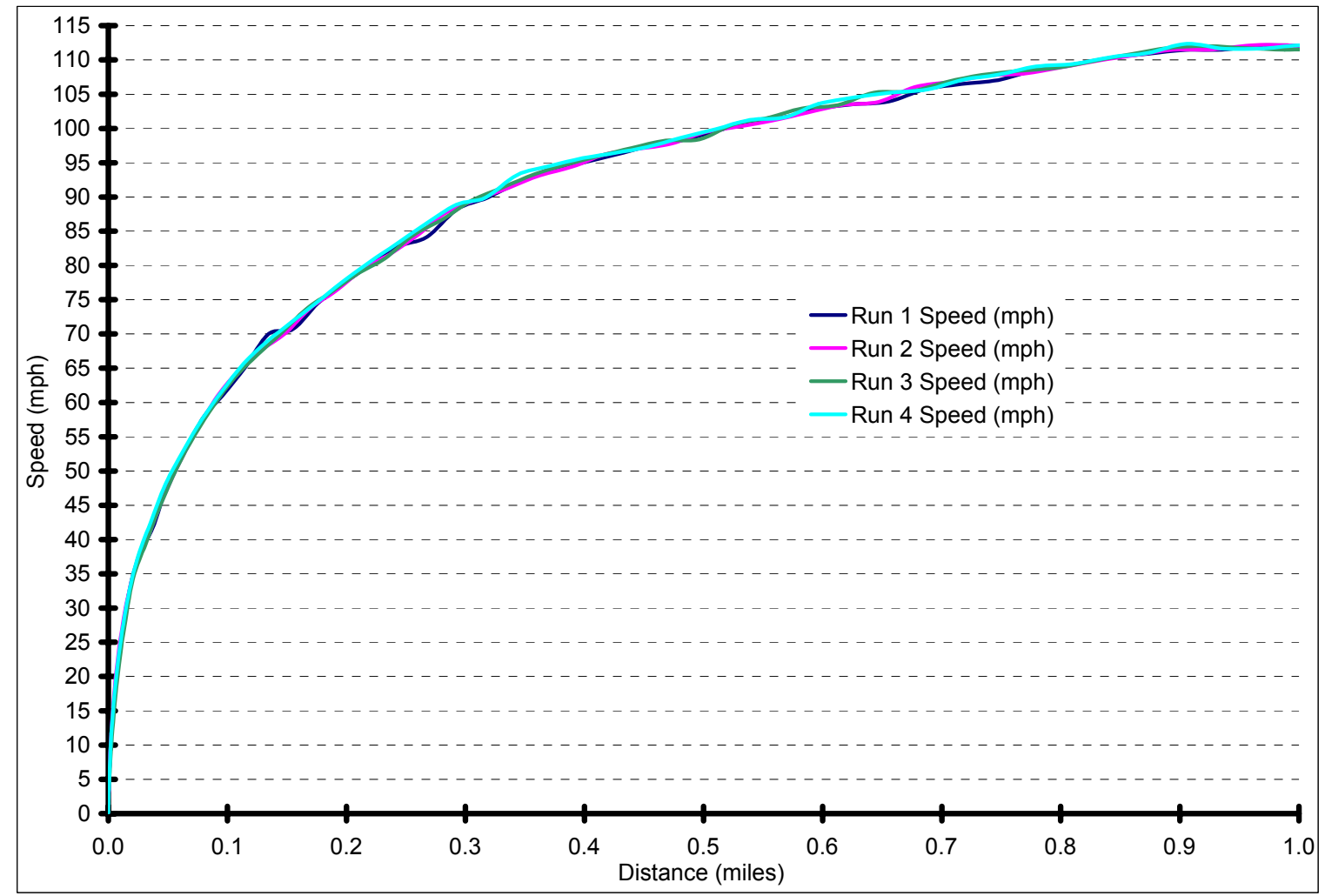

Figure 3. Speed versus distance for the F-150 test vehicle, using 100\% CNG. 


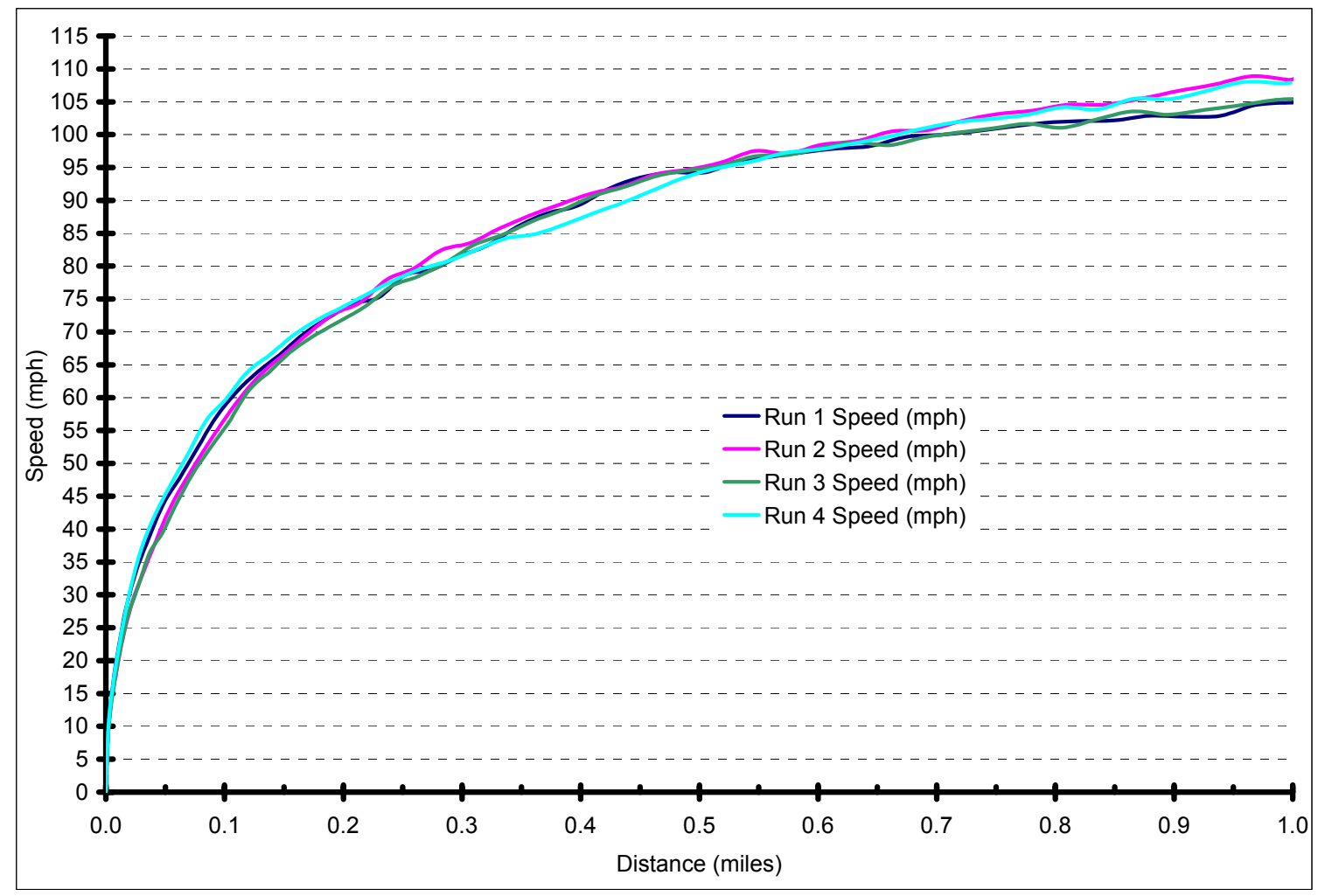

Figure 4. Speed versus distance for the F-150 test vehicle, using 15\% HCNG.

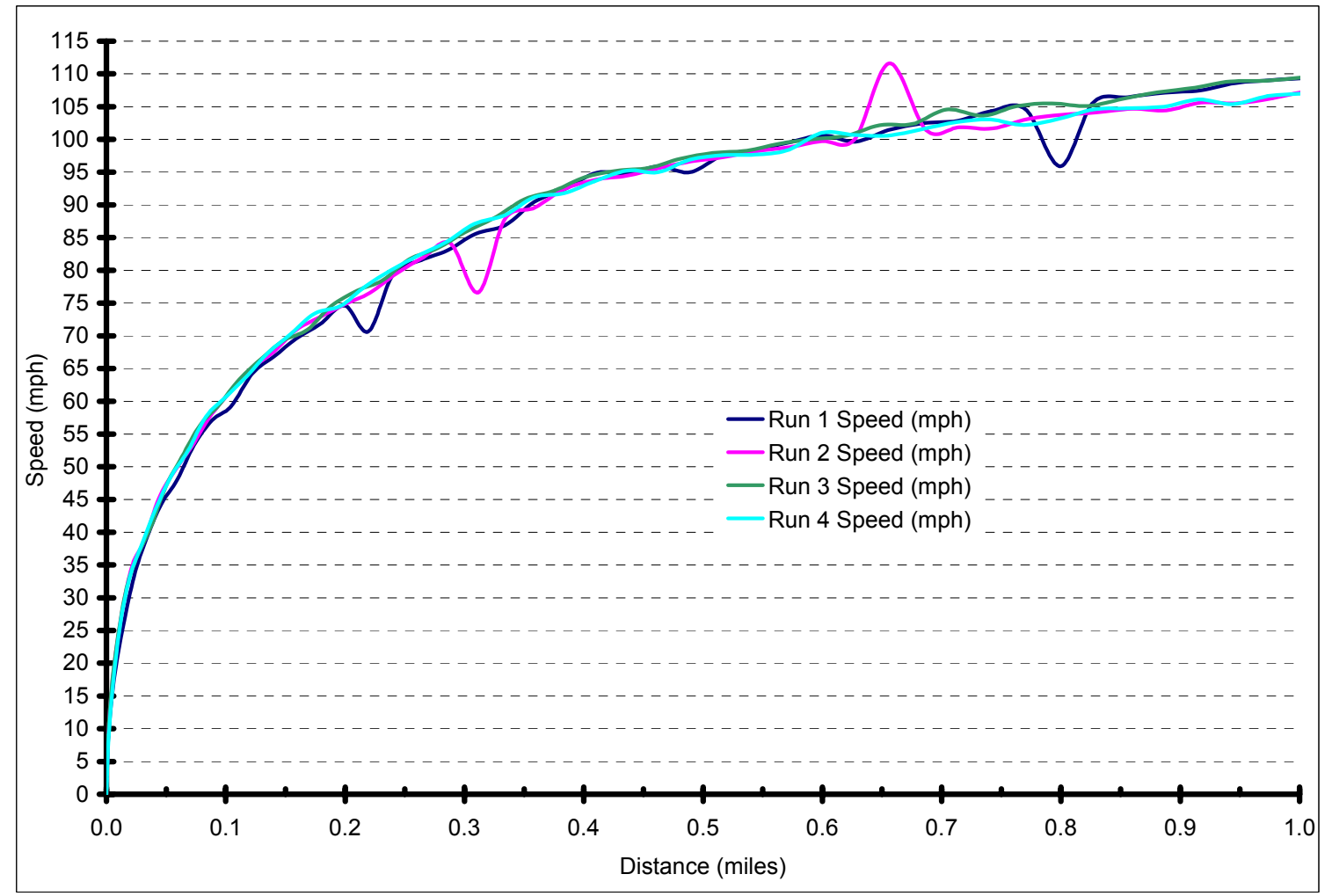

Figure 5. Speed versus distance for the F-150 test vehicle, using 30\% HCNG. 


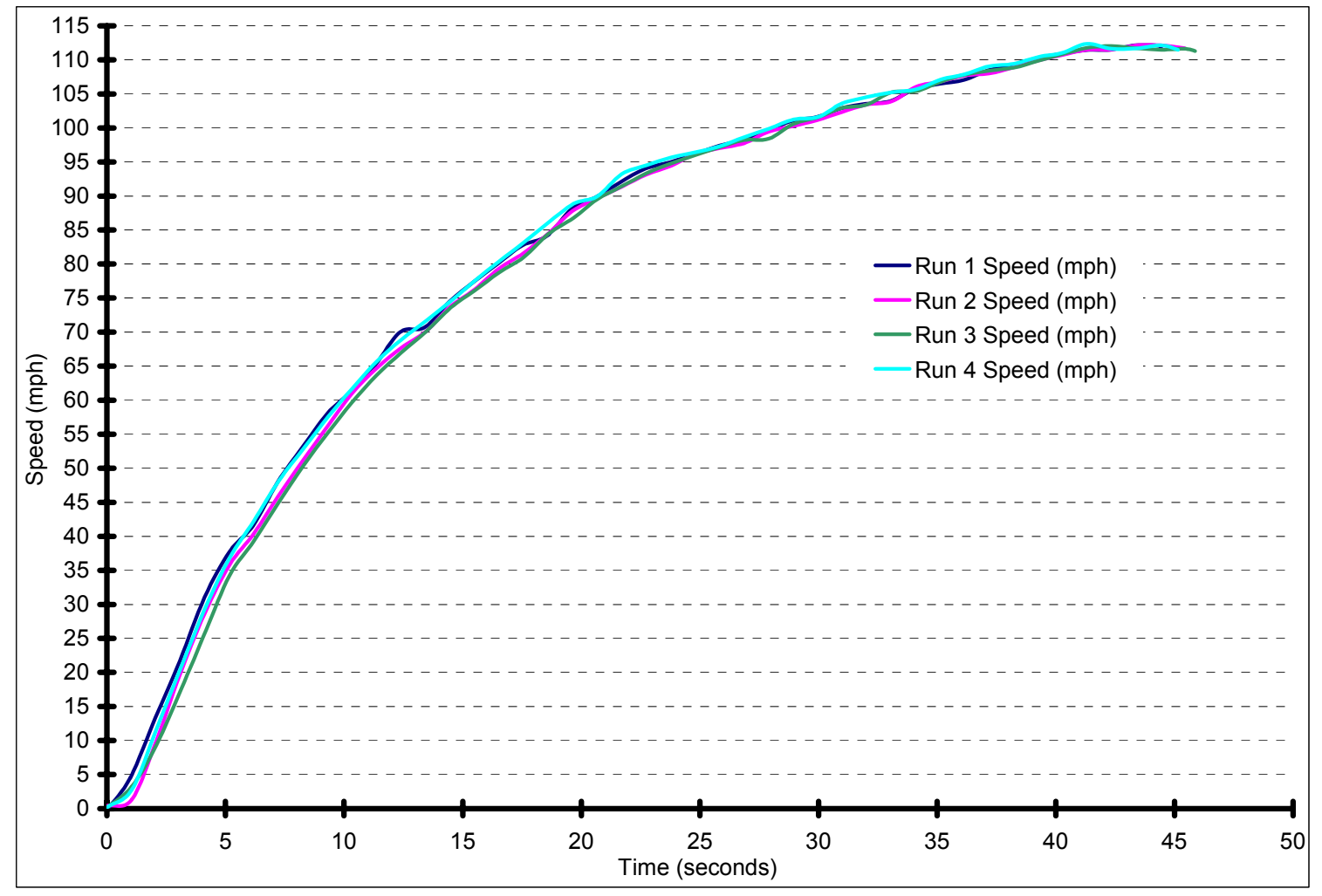

Figure 6. Speed versus time for the Ford F-150 test vehicle, using 100\% CNG.

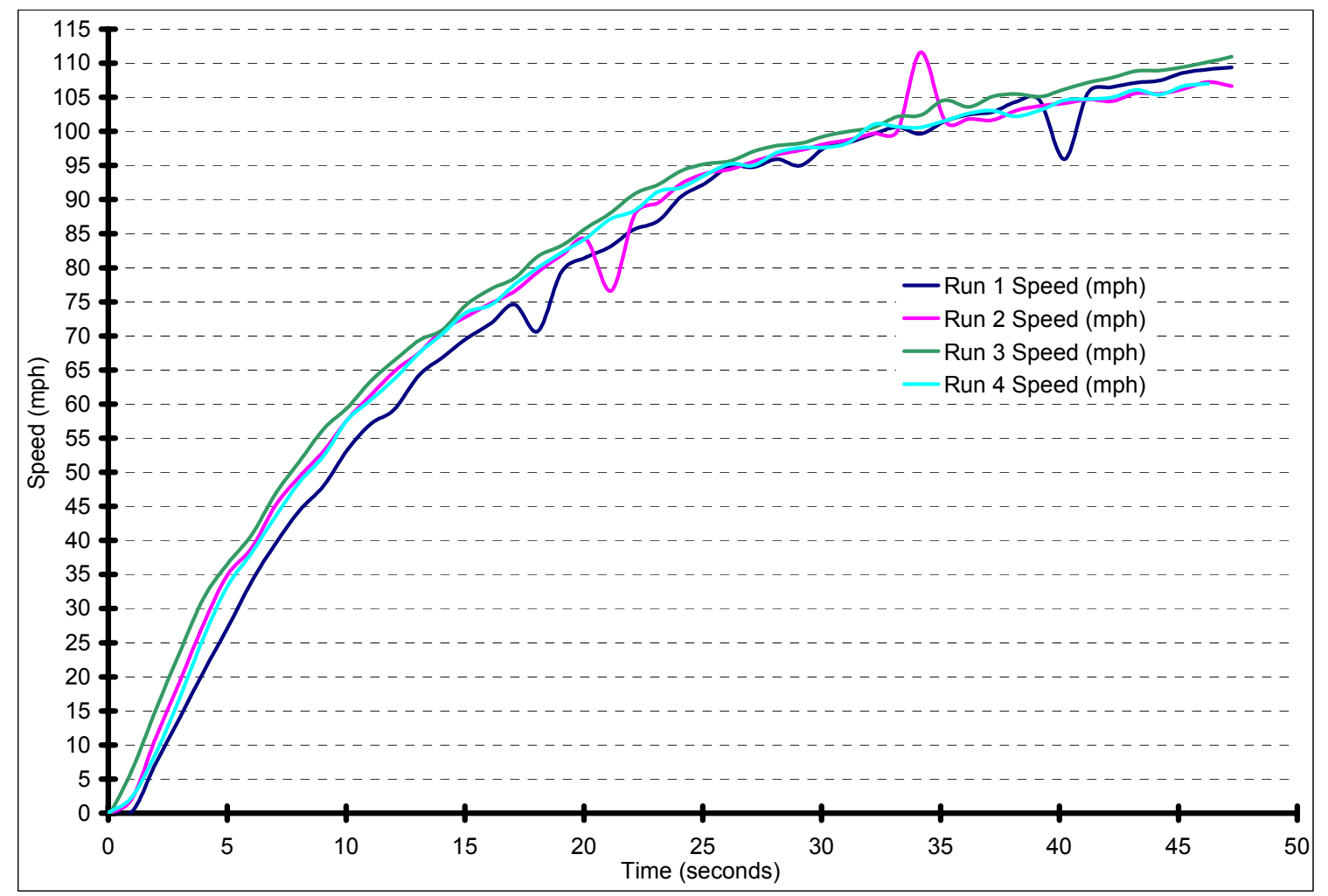

Figure 7. Speed versus time for the Ford F-150 test vehicle, using 15\% HCNG. 


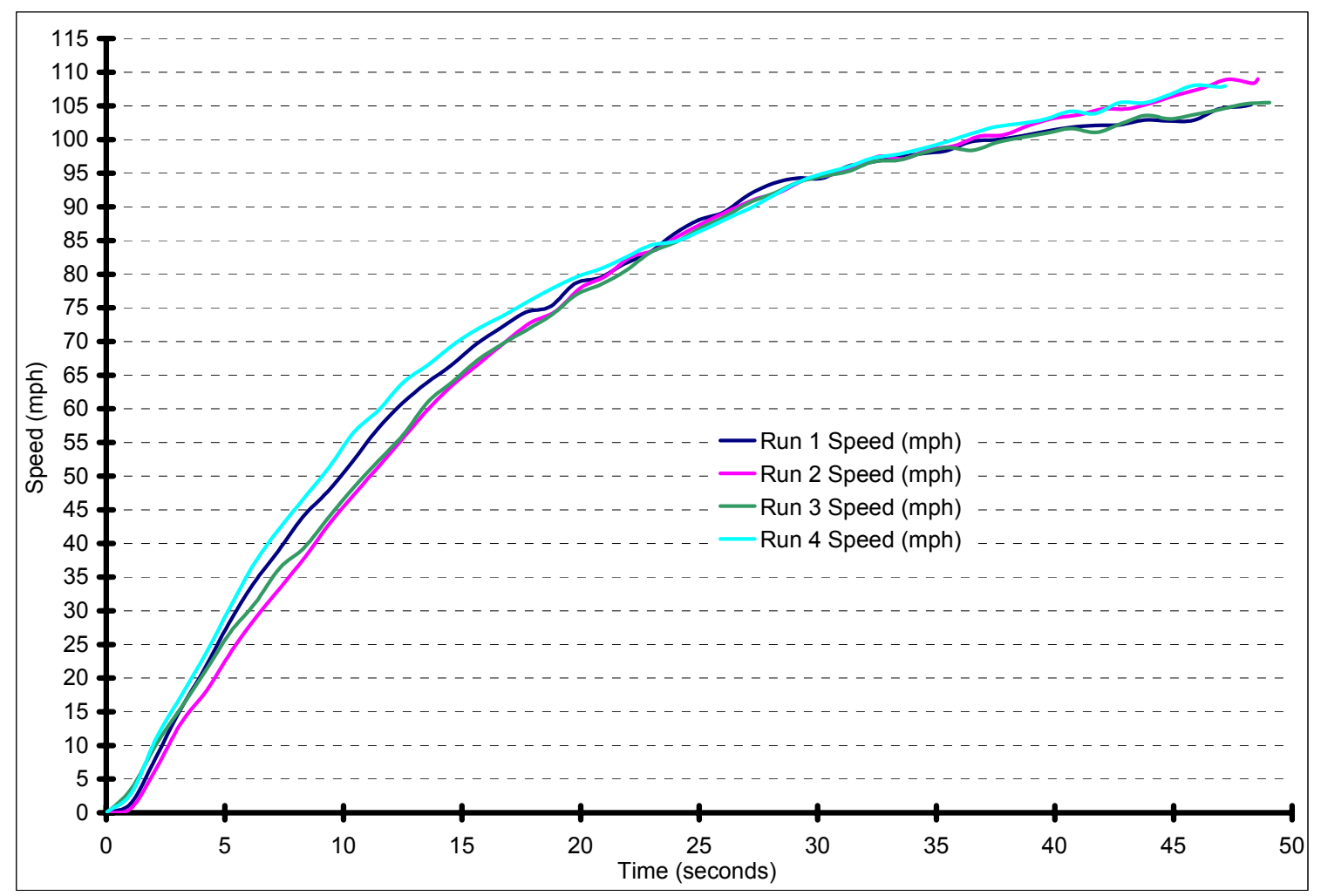

Figure 8. Speed versus time for the Ford F-150 test vehicle, using 30\% HCNG.

Table 7. Time to accelerate to $60 \mathrm{mph}$ for $100 \% \mathrm{CNG}, 15$ and $30 \%$ HCNG.

\begin{tabular}{ccc}
\hline Fuel Blend & Vehicle Mileage & Time to $60 \mathrm{mph}$ \\
\hline $100 \% \mathrm{CNG}$ & 32,452 & 10.10 \\
$15 \% \mathrm{HCNG}$ & 31,943 & 10.97 \\
$30 \% \mathrm{HCNG}$ & 31,679 & 12.68 \\
\hline
\end{tabular}

\subsection{Range and Fuel Economy Testing}

The range of the F-150 test vehicle was also tested at the APG (Figure 9), in accordance with the Hydrogen ICE Vehicle Constant Speed Fuel Economy Tests Procedures presented in Attachment 2, for $100 \% \mathrm{CNG}$ and blends of 15 and 30\% HCNG. Tests were performed at a constant speed of $45 \mathrm{mph}$, using the 4.2-mile-long high-speed oval track at the APG. The vehicle was driven 60 miles on each fuel and the amount of fuel used was determined through the mathematical relationship between pressure, temperature, and mass for a perfect gas. From these calculations, the fuel economy in gasoline gallon equivalents (gge) was determined (see Table 8). Using the fuel economy and the capacity of the fuel tanks (85 liters) filled to 3,600 psig, the range of the F-150 test vehicle for each type of fuel was calculated, as shown in Table 8. Data sheets from these tests are presented in Attachment 4. Speed versus time testing graphs are presented in Figures 10, 11, and 12 for each fuel type. Speed was controlled manually by the driver, as the vehicle was not equipped with cruise control. Spikes in vehicle speed are the result of data acquisition system noise; they do not represent actual speed deviations. 


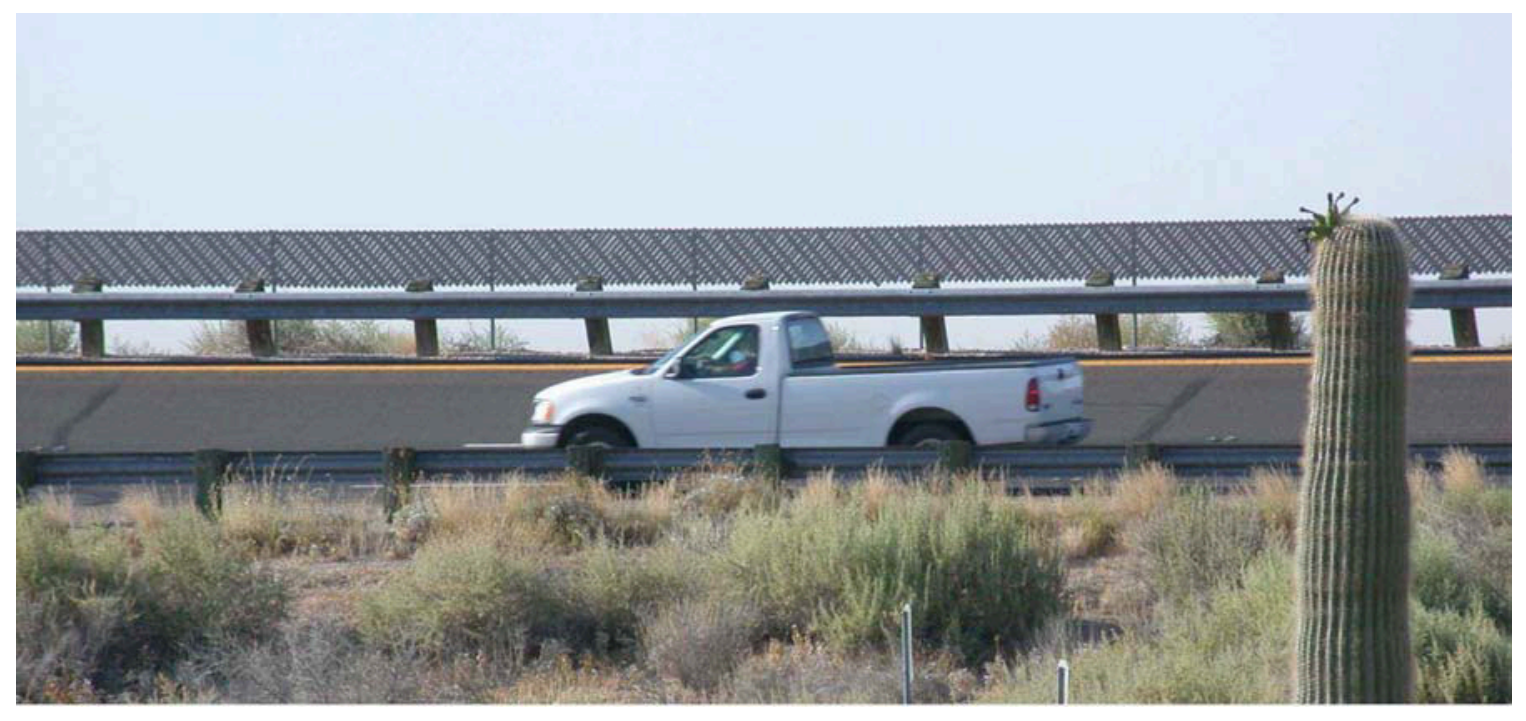

Figure 9. Vehicle range testing at the Arizona Proving Grounds.

Table 8 . F-150 test vehicle range at a constant speed of $45 \mathrm{mph}$ for $100 \% \mathrm{CNG}, 15$ and $30 \% \mathrm{HCNG}$.

\begin{tabular}{cccc}
\hline Fuel Blend & Vehicle Mileage & Fuel Economy (miles/gge) & Range (miles) \\
\hline CNG & 32,465 & 23.3 & 122 \\
$15 \%$ HCNG & 31,951 & 22.6 & 110 \\
$30 \%$ HCNG & 31,769 & 23.5 & 102 \\
\hline
\end{tabular}

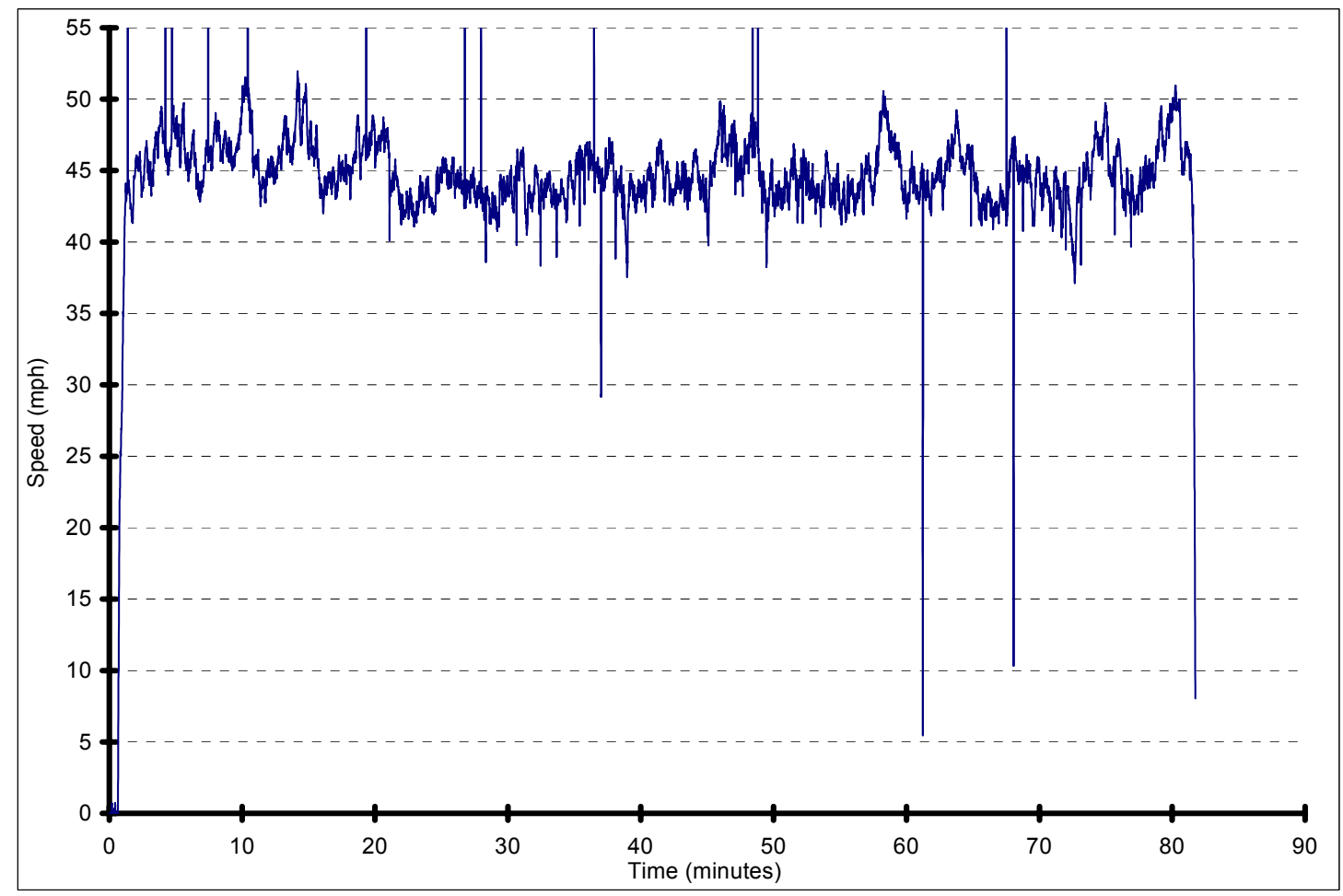

Figure 10. Speed versus time for the Ford F-150 test vehicle range test, using 100\% CNG. 


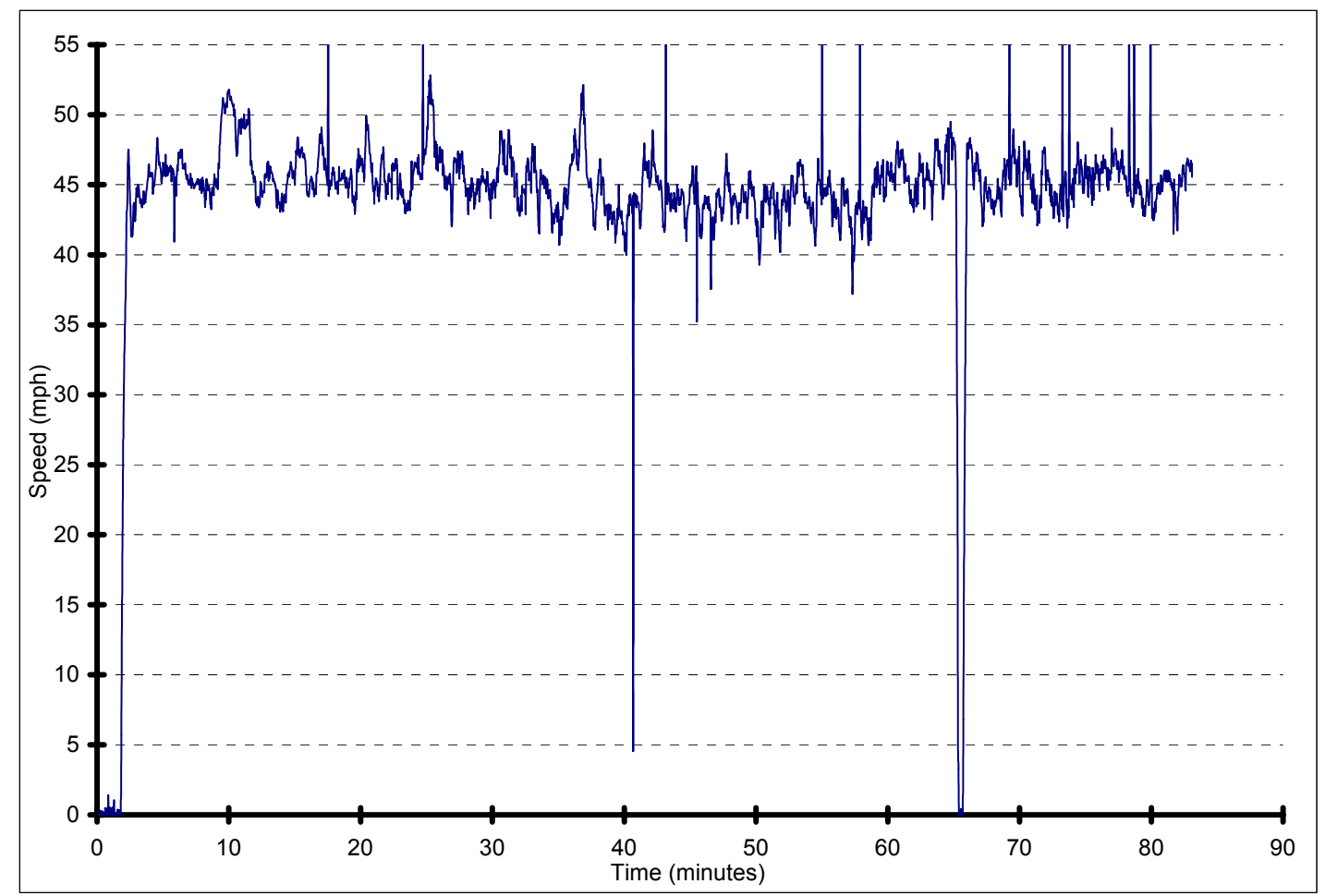

Figure 11. Speed versus time for the Ford F-150 test vehicle range test, using $15 \%$ HCNG.

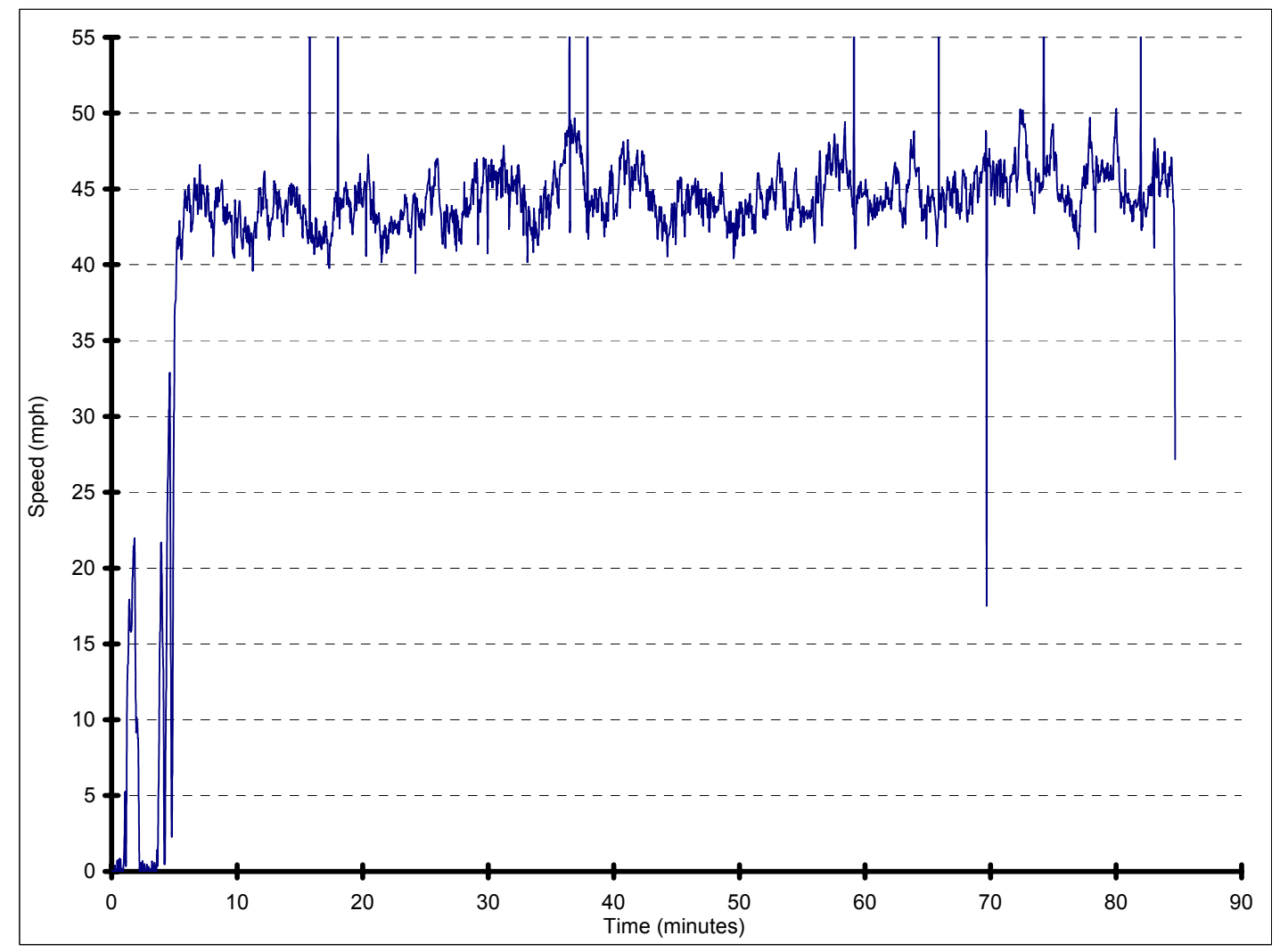

Figure 12. Speed versus time for the Ford F-150 test vehicle range test, using 30\% HCNG. 


\section{TEST RESULTS}

\subsection{Emissions Testing Results}

Exhaust emissions using 100\% CNG, and 15 and 30\% HCNG (Table 6) showed significant emission reductions over gasoline (Table 4) in $\mathrm{NMHC}, \mathrm{CO}, \mathrm{NO}_{\mathrm{X}}$, and $\mathrm{CO}_{2}$. However, $\mathrm{CH}_{4}$ and $\mathrm{HC}$ increased with the introduction of the methane-based CNG. Percentage changes are shown in Table 9. Attachment 5 summarizes the test results from Automotive Testing Laboratories.

Table 9. Emissions variations using blended fuels; comparison of the results found in Tables 4 and 6.

\begin{tabular}{lcccccc}
\hline & \multicolumn{7}{c}{ Percentage Change in Emission Species } \\
\cline { 2 - 7 } Fuel Type & NMHC & $\mathrm{CH}_{4}$ & $\mathrm{HC}$ & $\mathrm{CO}$ & $\mathrm{NO}_{\mathrm{X}}$ & $\mathrm{CO}_{2}$ \\
\hline Gasoline & Base & Base & Base & Base & Base & Base \\
CNG & -80 & +967 & +35 & -63 & -34 & -24 \\
$15 \%$ HCNG & -78 & +1000 & +40 & -70 & -26 & -27 \\
$30 \%$ HCNG & -89 & +1050 & +37 & -73 & -25 & -28 \\
\hline
\end{tabular}

$\mathrm{NMHC}=$ nonmethane hydrocarbons

$\mathrm{CH}_{4}=$ methane

$\mathrm{HC}=$ total hydrocarbons

$\mathrm{CO}=$ carbon monoxide

$\mathrm{NOx}=$ oxides of nitrogen

$\mathrm{CO}_{2}=$ carbon dioxide

Much of the reductions in $\mathrm{CO}, \mathrm{NO}_{\mathrm{X}}$, and $\mathrm{CO}_{2}$ emissions are achieved by switching from gasoline to $\mathrm{CNG}$. Additional $\mathrm{CO}$ reductions are achieved with higher percentage blends of hydrogen in CNG.

However, $\mathrm{NO}_{\mathrm{X}}$ increases with the higher-percentage blends. Note that the $\mathrm{NO}_{\mathrm{X}}$ levels measured in the current work program are significantly higher than those measured during the fleet operation of the F-150 test vehicle using a $30 \%$ blend of hydrogen in CNG. The fleet testing was conducted with between 1,500 and 4,000 miles on the vehicle. Testing in the current work program was conducted with the vehicle use near 30,000 miles. Aging of the catalytic converter was probably the cause of the increased $\mathrm{NO}_{\mathrm{X}}$ emissions.

Based on these results, it is apparent that reductions in $\mathrm{CO}$ and $\mathrm{CO}_{2}$ emissions can be achieved by blending hydrogen with $\mathrm{CNG}$ for use in $\mathrm{CNG}$ fleets. These emission reductions come at some cost in terms of increased $\mathrm{CH}_{4}$ and $\mathrm{HC}$ emissions and reduced vehicle acceleration and range. However, even at $15 \% \mathrm{HCNG}$, the performance reductions do not have a significant impact on vehicle drivability and offer an additional $10 \%$ decrease in $\mathrm{CO}$ and $\mathrm{CO}_{2}$ emissions.

\subsection{Acceleration Testing Results}

As expected, the performance (in terms of acceleration [Figures 12 and 13] and range) of the F-150 test vehicle degrades with increasing amounts of hydrogen in the fuel. However, much of the performance loss results from the initial switch from a liquid fuel (gasoline) to a gaseous fuel (CNG), as shown in Table 10. The degradation in acceleration resulting from use of hydrogen in the fuel does not have a significant impact on the drivability until blends approaching 30\% hydrogen are used. At a blend of $15 \%$ HCNG, the F-150 test vehicle acceleration was within $10 \%$ of that with the vehicle operating on $100 \%$ CNG (Table 10). 


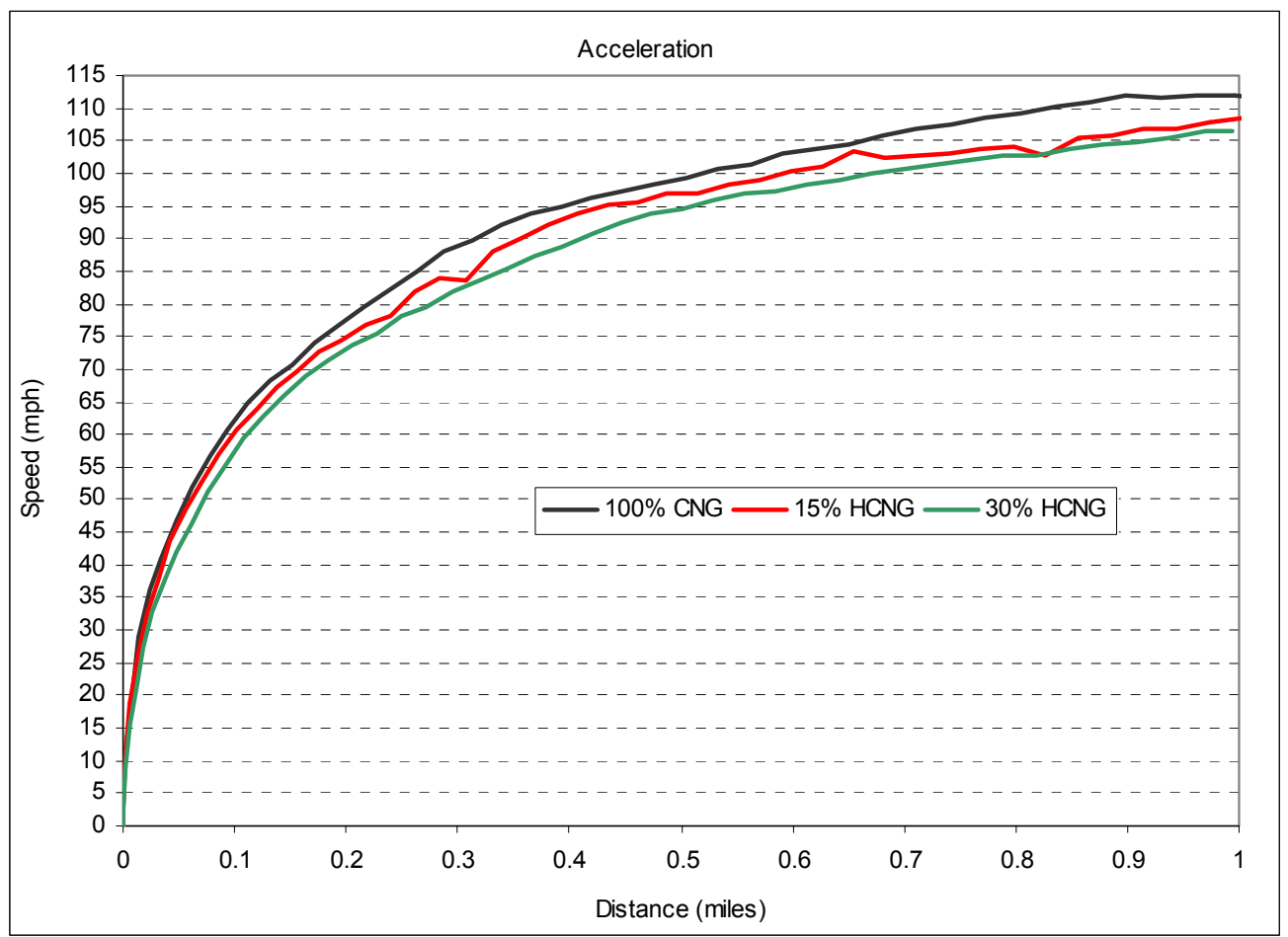

Figure 13. Average speed versus distance for F-150 test vehicle range test, $100 \% \mathrm{CNG}, 15 \% \mathrm{HCNG}$ and $30 \% \mathrm{HCNG}$.

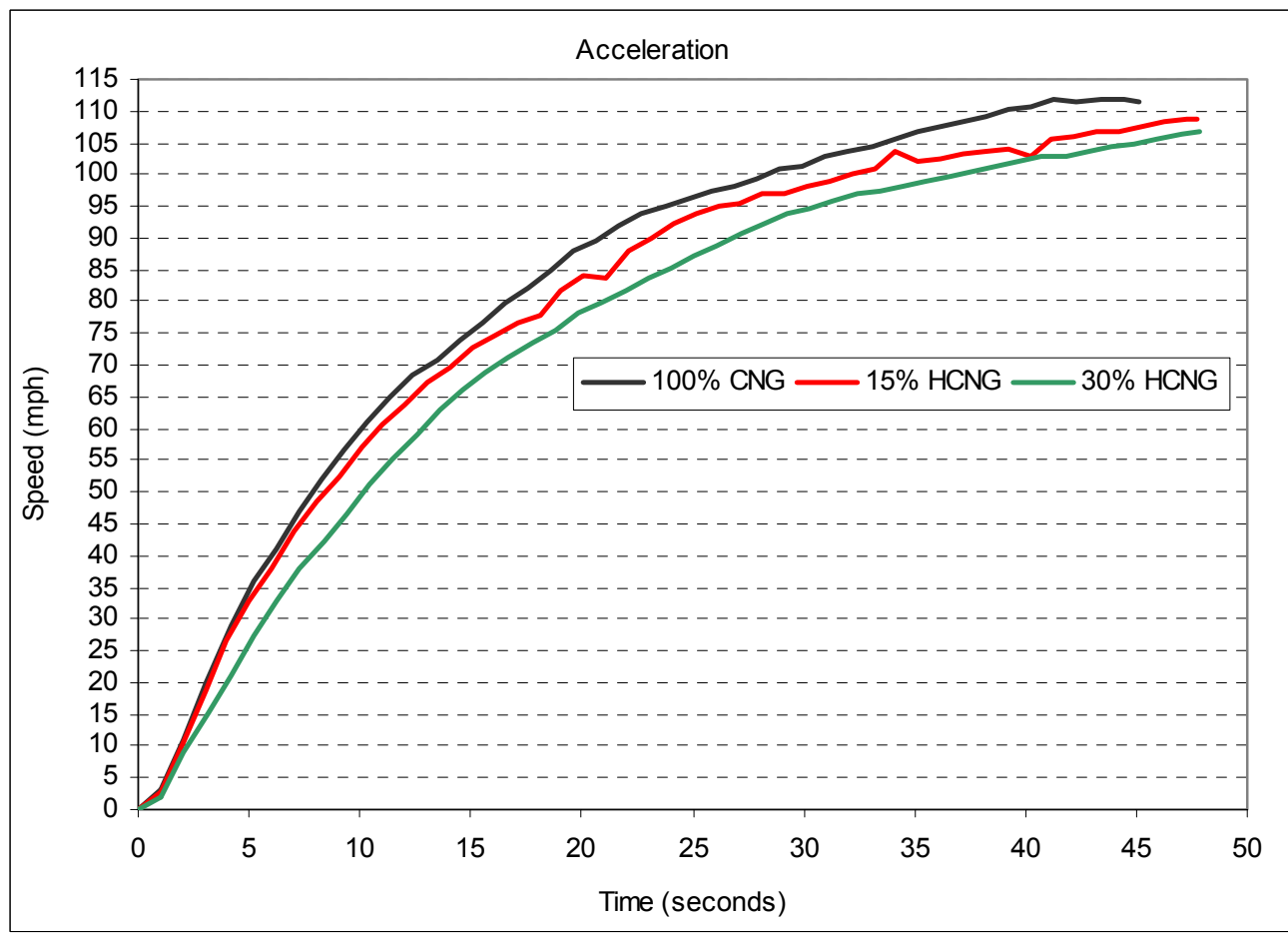

Figure 14. Average speed versus time for F-150 test vehicle range test, 100\% CNG, 15\% $\mathrm{HCNG}$ and $30 \% \mathrm{HCNG}$. 
Table 10. Acceleration to $60 \mathrm{mph}$ for various fuels.

\begin{tabular}{|c|c|c|c|}
\hline $\begin{array}{c}\text { Fuel } \\
\text { Blend }\end{array}$ & $\begin{array}{l}\text { Time to } 60 \mathrm{mph} \\
\text { (seconds) }\end{array}$ & $\begin{array}{l}\text { Degradation from CNG } \\
\text { F-150 }\end{array}$ & $\begin{array}{l}\text { Degradation from Gasoline } \\
\text { F-150 }\end{array}$ \\
\hline Gasoline $^{1}$ & $8.6^{(1)}$ & --- & Base \\
\hline CNG & 10.10 & Base & $17.4 \%$ \\
\hline $15 \% \mathrm{HCNG}$ & 10.97 & $8.6 \%$ & $27.6 \%$ \\
\hline $30 \% \mathrm{HCNG}$ & 12.68 & $25.5 \%$ & $47.4 \%$ \\
\hline
\end{tabular}

${ }^{1} 2001$ Ford F-150 with 5.4L V-8 engine and automatic transmission, as reported by edmunds.com.

Degradation of acceleration can be remedied by either increasing the amount of fuel and air entering the engine cylinders, or by directly injecting hydrogen into the cylinder to avoid the displacement of air by the hydrogen fuel. However, this requires additional vehicle modifications, which does not appear to be economically practical for introducing blended fuel into existing CNG fleets.

\subsection{Range and Fuel Economy Test Results}

As shown in Table 11, degradation of vehicle range was significant with the $30 \% \mathrm{HCNG}$ fuel. The decrease is based on the lower energy content of hydrogen when compared to $\mathrm{CNG}$ on a volumetric basis. The decrease in range between $100 \%$ CNG and $30 \%$ HCNG would require a $16.4 \%$ increase in onboard fuel storage to maintain vehicle range similar to that achievable with $100 \% \mathrm{CNG}$. In the case of the F-150 test vehicle, this would require the addition of a 14-liter fuel tank. With a fuel of $15 \% \mathrm{HCNG}$, the range degradation was less than $10 \%$, which should have a negligible impact on vehicle utility in fleet operation.

Table 11. Range decrease from use of various fuels.

\begin{tabular}{rcc}
\hline Fuel Blend & Range (miles) & Decrease from CNG \\
\hline CNG & 122 & Base \\
$15 \%$ HCNG & 110 & $9.8 \%$ \\
$30 \%$ HCNG & 102 & $16.4 \%$ \\
\hline
\end{tabular}

Note that no significant change in efficiency (within the accuracy of the test methods) was noted for the fuels tested. Fuel economy for the constant speed of $45 \mathrm{mph}$ range test was $23.3 \mathrm{mile} / \mathrm{gge}$ for $100 \% \mathrm{CNG}, 22.6 \mathrm{mile} / \mathrm{gge}$ for $15 \% \mathrm{HCNG}$, and $23.5 \mathrm{mile} / \mathrm{gge}$ for $30 \% \mathrm{HCNG}$. 
Attachment 1 - Hydrogen ICE Vehicle Acceleration Test Procedure ETA-YTP001

Revision 0

Effective May 15, 2003

Implementation of SAE Standard J1666 AUG99

Prepared by

Electric Transportation Applications 


\section{Appendix 1}

\section{ETA-YTP001 \\ Revision 0}

Effective May 15, 2003

\section{Implementation of SAE Standard J1666 AUG99}

\section{"Hydrogen ICE Vehicle Acceleration Test Procedure"}

$$
\begin{gathered}
\text { Prepared by } \\
\text { Electric Transportation } \\
\text { Applications }
\end{gathered}
$$

Prepared by:

Approved by:
Date:

Date: 


\section{ATTACHMENT 1 \\ Procedure ETA-YTP001 \\ Revision 0}

\section{TABLE OF CONTENTS}

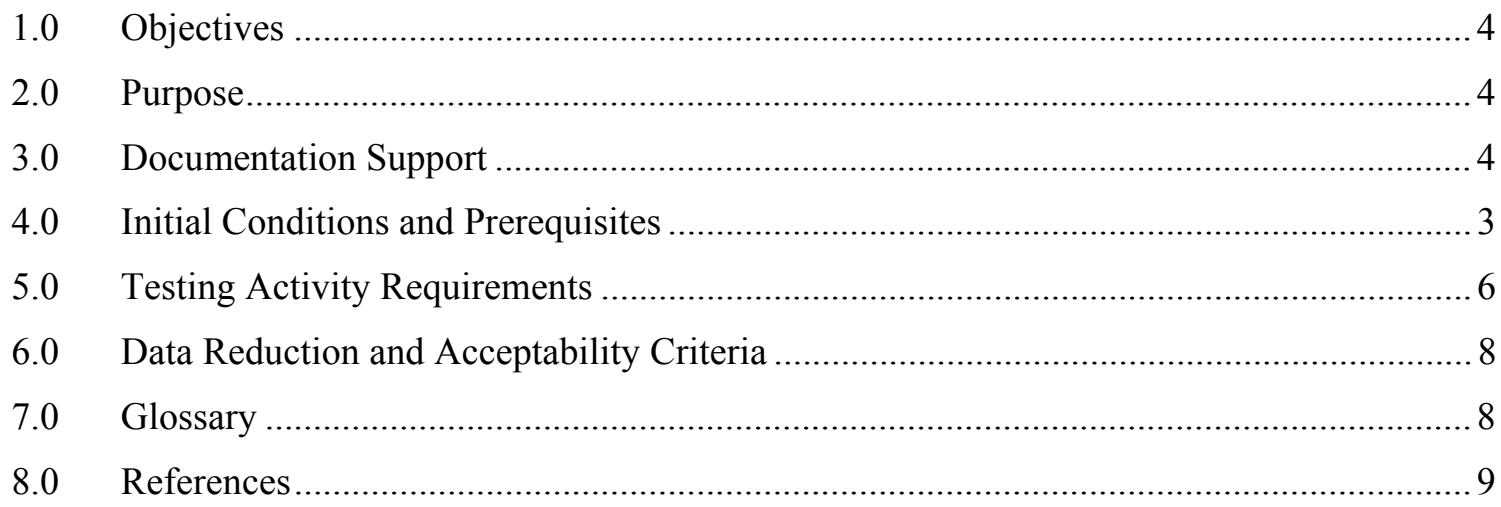

Appendix A - Acceleration to a Pre-Determined Speed ........................................................... 10

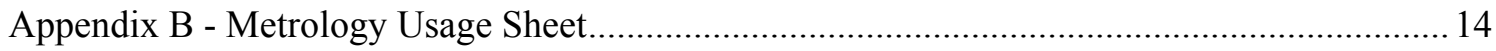

Page 3, (c) 2003. Electric Transportation Applications. All rights reserved. 


\section{Hydrogen ICE Vehicle Acceleration Test Procedure}

\subsection{Objective}

The objective of this procedure is to identify proper methods for the control of acceleration testing pursuant to the requirements of SAE J1666 AUG99, "Electric Vehicle Acceleration, Gradeability and Deceleration Test Procedure", as such methods are applied to hydrogen fueled internal combustion engine powered (ICE) Vehicles (HFVs). These methods are not meant to supersede those of the testing facility, those specifically addressed by SAE Test Standards, nor of any regulatory agency who may have or exercise control over the covered activities.

\subsection{Purpose}

The purpose of this procedure is to identify acceptable methods for the implementation of an acceleration test. SAE-J1666 AUG99 establishes uniform procedures for testing electric vehicles. Testing conducted in accordance with this procedure is similar to that identified in SAE J1666 AUG99, with the exception of using an internal combustion powered vehicle. This procedure collects and retains test data as specified in the "HFV America Technical Requirements."

\subsection{Documentation}

Documentation addressed by this procedure shall be consistent, easy to understand, easy to read and readily reproducible. This documentation shall contain enough information to "stand alone"; that is, be self-contained to the extent that all individuals qualified to review it could be reasonably expected to reach a common conclusion, without the need to review additional documentation. Review and approval of test documentation shall be in accordance with ETA-YAC004, "Review of Test Results." Storage and retention of records during and following testing activities shall be completed as described in Procedure ETA-YAC001, "Control, Close-out and Storage of Documentation."

\subsection{Initial Conditions and Prerequisites}

Prior to conduct of any portion of the testing, the following initial conditions and prerequisites shall be met. Satisfactory completion of these items should be verified as complete and recorded on the Test Data Sheet.

4.1 Personnel conducting testing under this procedure shall be familiar with the requirements of this procedure, and when applicable the appropriate SAE Test Instructions, Administrative Control Procedures, and be certified by the Program Manager, Test Manager or specific Test Engineer prior to commencing any testing activities.

4.2 All documentation required to complete the testing shall be completed, approved and issued (past it's effective date) prior to commencing the testing it addresses.

\subsection{Test Conditions}

4.3.1 The test road must be an open course consisting of dry, clean and smooth roads not exceeding $1.0 \%$ grade. Tests shall be run in pairs in opposite directions on the test road. 


\section{ATTACHMENT 1 \\ Procedure ETA-YTP001 \\ Revision 0}

4.3.2 Ambient temperature during road testing shall be within the range of $50^{\circ} \mathrm{F}$ to $100^{\circ} \mathrm{F}\left(5^{\circ} \mathrm{C}\right.$ to $\left.38^{\circ} \mathrm{C}\right)$ - Note this is a deviation from SAE J1666 AUG99.

4.3.3 The average wind speed at the test site during the test shall not exceed 10 $\mathrm{mph}(16 \mathrm{~km} / \mathrm{h})$. Wind gusts shall not exceed $20 \mathrm{mph}(32 \mathrm{kph})$ during the test.

\subsection{Test Vehicle Preparation}

4.4.1 The vehicle should have accumulated a minimum of 2,000 miles $(3,200$ $\mathrm{km})$ of operation prior to test. At least $1,000(1,600 \mathrm{~km})$ of these miles must have been driven at speeds above $40 \mathrm{mph}(64 \mathrm{kph})$.

4.4.2 Tires shall have been operated for at least 100 miles $(160 \mathrm{~km})$ prior to test and shall have at least $75 \%$ of the tread remaining and in good condition. Tires provided with the vehicle shall be the standard tire offered by the vehicle manufacturer, and shall be inflated to the manufacturer's (placard) recommended cold inflation pressures prior to test. This pressure shall not exceed the maximum allowable pressure imprinted upon the tire's sidewall.

4.4.3 Vehicle shall be tested in its normal configuration with normal appendages (mirrors, bumpers, hubcaps, etc.).

4.4.4 Vehicles shall be tested at curb weight plus 332 pounds. - Note this is a deviation from SAE J1666 AUG99. Consideration should be given to how adding instrumentation will affect the test weight and balance of the vehicle.

4.4.5 Normal manufacturer's recommended lubricants shall be employed.

4.5 The following data shall be collected during conduct of the various tests specified by this procedure suing an onboard Data Acquisition System (DAS). Overall error in recording or indicating instruments shall not exceed $\pm 2 \%$ of the maximum value of the variable being measured, unless otherwise excepted and noted. Periodic calibration shall be performed and documented to ensure compliance with this requirement.

\subsubsection{Vehicle speed versus time;}

\subsubsection{Distance versus time;}

4.6 Environmental conditions during the testing shall be recorded and include, at a minimum, the following:

\subsubsection{Range of ambient temperature during the test;}

4.7.2 Range of wind velocity during the test;

4.7.3 Range of wind direction during the test.

Bounding values shall be recorded in Appendix A.

4.7 A description of the test route, road surface type and condition (SAE J688, "Truck Ability Prediction Procedure"), and lengths and grades of test route, shall be recorded in Appendix A. 


\section{ATTACHMENT 1 \\ Procedure ETA-YTP001 \\ Revision 0}

4.8 The date and starting and ending times shall be recorded in Appendix A

4.9 The starting and ending vehicle odometer readings shall be recorded in Appendix A.

4.10 The type of fuel used for the test shall be recorded in Appendix A.

\section{NOTE}

When switching fuels, the vehicle shall be operated for a minimum of 20 miles under varying load conditions to allow the fuel management system to adapt to the new fuel.

4.11 All instrumentation used in the test shall be listed on Appendix B, attached to the test data sheets/results, and shall include the following information:

\subsubsection{Manufacturer}

4.12.2 Model Number

4.12.3 Serial Number

4.12.4 Last Calibration date

4.12.5 Next Calibration date

4.12 The speed-time measuring device and other necessary equipment shall be installed so that they do not hinder vehicle operation or alter the operating characteristics of the vehicle. Mounting will nominally be at the rear of the vehicle.

4.13 Any deviation from the test procedure, and the reason for the deviation, shall be recorded in accordance with ETA-YAC002.

4.14 All documentation required to complete the testing shall be completed, approved and issued prior to commencing the testing it addresses.

4.15 During data reduction, the time to specific speeds and the speed at a distance of one mile shall be determined and recorded.

\subsection{Test Activity Requirements}

This section selectively implements portions of SAE J1666 AUG99 to determine vehicle acceleration on a level road

\section{NOTE}

Activities necessary to complete the test are identified in the following sections. All items shall be completed, whether they are required by J1666 or not. Any section which cannot be completed shall be so annotated, along with the appropriate justification in accordance with ETA-YAC002, "Control of Test Conduct," on Appendix A.

\section{NOTE}

In this section, vehicles will be tested twice, with each test consisting of two acceleration runs (one in each direction on the test road).

5.1 Record information concerning the vehicle being tested in Appendix A.

Page 6, (c) 2003. Electric Transportation Applications. All rights reserved. 


\section{ATTACHMENT 1

5.2 Instrument the vehicle to obtain, at a minimum, the data identified in Section 4.6. Calibrate the fifth wheel, as necessary.

5.3 Determine the maximum speed to be achieved and record this value in Appendix A.

5.4 Adjust the vehicle's cold tire pressures to match the manufacturer's placard value, or the maximum cold inflation pressure imprinted upon the tire's sidewall, whichever is less.

5.5 Operate the vehicle for a minimum of 10 miles to allow the engine and fluids to reach operating temperature.

5.6 Record time of test commencement and the vehicle's odometer reading on Appendix A and start the onboard DAS. Accessories shall not be used during testing activities.

\section{NOTE}

At least the last 3000 feet of the track for this test shall be straightaway.

5.7 From a standing start, accelerate the vehicle at its maximum attainable acceleration or the manufacturer's maximum permissible acceleration rate(s) (whichever is less) until the target speed has been exceeded or the vehicle has traveled one mile, whichever occurs first. Note the speed achieved and the time required to achieve it on Appendix A. [If the data is being accumulated into a DAS, this data may be transcribed subsequent to the data download.]

5.8 Reverse the direction of travel on the test track.

5.9 The maximum time interval between the completion of the acceleration portion of one run to the beginning of the next successive run shall not exceed 5 minutes. Record elapsed time on Appendix A. [If the data is being accumulated into a DAS, this time interval may be transcribed subsequent to the data download.]

5.10 From a standing start, accelerate the vehicle at its maximum attainable acceleration or the manufacturer's maximum permissible acceleration rate(s) (whichever is less) until the target speed has been exceeded or the vehicle has traveled one mile, whichever occurs first. Note the speed achieved and the time required to achieve it on Appendix A. [If the data is being accumulated into a DAS, this data may be transcribed subsequent to the data download.]

5.11 Record completion of this test portion on Appendix A and reverse the direction of travel on the test track.

5.12 From a standing start, accelerate the vehicle at its maximum attainable acceleration or the manufacturer's maximum permissible acceleration rate(s) (whichever is less) until the target speed has been exceeded or the vehicle has traveled one mile, whichever occurs first. Note the speed achieved and the time required to achieve it in Appendix A. [If the data is being accumulated into a DAS, this data may be transcribed subsequent to the data download.]

5.13 Reverse the direction of travel on the test track.

5.14 The maximum time interval between the completion of the acceleration portion of one run to the beginning of the next successive run shall not exceed 5 minutes.

Page 7, (c) 2003. Electric Transportation Applications. All rights reserved. 


\section{ATTACHMENT 1 \\ Procedure ETA-YTP001 \\ Revision 0}

Record elapsed time on Appendix A. [If the data is being accumulated into a DAS, this time interval may be transcribed subsequent to the data download.]

5.15 From a standing start, accelerate the vehicle at its maximum attainable acceleration or the manufacturer's maximum permissible acceleration rate(s) (whichever is less) until the target speed has been exceeded or the vehicle has traveled one mile, whichever occurs first. Note speed achieved and time required to achieve in Appendix A.

5.16 Record completion of this test section in Appendix A.

\subsection{Data Reduction and Acceptability Criteria}

6.1 The requirements for data reduction are specifically addressed in Section 9 of SAE J1263. Refer to that standard for these techniques.

6.2 Acceptability requirements are presented in Section 9.4 of SAE J1634.

6.3 Distribution, retention and destruction of all test documents shall be in accordance with the requirements identified in Procedure ETA-YAC001, "Control, Close-out and Storage of Documentation."

\subsection{Glossary}

7.1 Curb Weight - The total weight of the vehicle including fuel tanks, lubricants and other expendable supplies, but excluding the driver, passengers, and other payloads.

7.2 Effective Date - The date, after which a procedure has been reviewed and approved, that the procedure can be utilized in the field for official testing.

7.3 Fifth Wheel - A calibrated mechanical instrument used to measure a vehicle's speed and distance independent of the vehicles on-board systems.

7.4 Gross Vehicle Weight Rating - The maximum design loaded weight of the vehicle specified by the manufacturer.

7.5 Initial Conditions - Conditions that shall exist prior to an event occurring.

7.6 Prerequisites - Requirements that shall be met or resolved prior to an event occurring.

7.7 Program Manager - As used in this procedure, the individual within Electric Transportation Applications responsible for oversight of the HFV America Performance Test Program. [Subcontract organizations may have similarly titled individuals, but they are not addressed by this procedure.]

7.8 Shall - Items which require adherence without deviation. Shall statements identify binding requirements. A go, no-go criterion.

7.9 Should - Items which require adherence if at all possible. Should statements identify preferred conditions.

7.10 Test Director - The individual within Electric Transportation Applications responsible for all testing activities associated with the HFV America Performance Test Program.

Page 8, (c) 2003. Electric Transportation Applications. All rights reserved. 


\section{ATTACHMENT 1 \\ Procedure ETA-YTP001 \\ Revision 0}

7.11 Test Director's Log - A daily diary kept by the Test Director, Program Manager, Test Manager or Test Engineer to document major activities and decisions that occur during the conduct of a Performance Test Evaluation Program. This log is normally a running commentary, utilizing timed and dated entries to document the days activities. This log is edited to develop the Daily Test Log published with the final report for each vehicle.

7.12 Test Engineer - The individual(s) assigned responsibility for the conduct of any given test. [Each contractor/subcontractor should have at least one individual filling this position. If so, they shall be responsible for adhering to the requirements of this procedure.]

7.13 Test Manager - The individual within Electric Transportation Applications responsible for the implementation of the test program for any given vehicle(s) being evaluated to the requirements of the HFV America Performance Test Program. [Subcontract organizations may have similarly titled individuals, but they are not addressed by this procedure.]

\subsection{References}

8.1 SAE Recommended Practice - "Electric Vehicle Acceleration, Gradeability, and Deceleration Test Procedure" SAE J1666, AUG99

8.2 "HFV America Technical Requirements," dated May 15, 2001

8.3 ETA-YAC001, "Control, Close-out and Storage of Documentation"

8.4 ETA-YAC002, "Control of Test Conduct"

8.5 ETA-YAC004, "Review of Test Results"

8.6 ETA-YAC005, "Qualifications, Certifications \& Training of Test Personnel"

8.7 ETA-YAC006, "Vehicle Verification"

8.8 ETA-YAC007, "Control of Measuring and Test Equipment"

8.9 ETA-YTP004, "Constant Speed Range Test"

8.10 ETA-YTP011, "Receipt Inspection"

Page 9, (c) 2003. Electric Transportation Applications. All rights reserved. 


\section{APPENDIX-A \\ Hydrogen ICE Vehicle Acceleration to a \\ Pre-Determined Speed Test Data Sheet \\ (Page 1 of 4)}

VIN Number:

\begin{tabular}{|c|c|c|}
\hline \multirow{3}{*}{\begin{tabular}{|l|} 
Project No.: \\
Root File No.: \\
Test Driver: \\
\end{tabular}} & & Test Date(s): \\
\hline & & \\
\hline & (Initials) & \\
\hline Test Engineer: & (Initials) & \\
\hline
\end{tabular}

\section{Vehicle Setup}

\begin{tabular}{||l|l|l|l|l||}
\hline \multicolumn{7}{|c||}{ VEHICLE WEIGHTS AS TESTED WITH DRIVER \& INSTRUMENTATION } \\
(Curb weight plus 332 pounds)
\end{tabular}

\section{Track/Weather Conditions}

\begin{tabular}{|c|c|c|}
\hline Test Track Location: & Track Grade: & $\%$ \\
\hline Ambient Temperature (initial): & \multicolumn{2}{|l|}{ Ambient Temperature (final): } \\
\hline Track Temperature (initial): & \multicolumn{2}{|l|}{ Track Temperature (final): } \\
\hline Wind Velocity (initial): & \multicolumn{2}{|c|}{ Wind Velocity (final): $\quad{ }_{(<10 \mathrm{mph} \text { or } 16 \mathrm{~km} / \mathrm{h})}$} \\
\hline Wind Direction (initial): & Wind Direction (completion): & $\circ$ \\
\hline
\end{tabular}

Page 10, (C) 2003. Electric Transportation Applications. All rights reserved. 


\section{ATTACHMENT 1 \\ Procedure ETA-YTP001 \\ Revision 0}

\section{APPENDIX-A}

\section{Hydrogen ICE Vehicle Acceleration to a \\ Pre-Determined Speed Test Data Sheet \\ (Page 2 of 4)}

VIN Number:

\begin{tabular}{|c|c|c|c|}
\hline Sequence No: 1 & File No.: & & Direction of Travel: \\
\hline \multicolumn{2}{|l|}{ Time (initial): } & \multicolumn{2}{|l|}{ Time (final): } \\
\hline \multicolumn{2}{|l|}{ Odometer (initial): } & \multicolumn{2}{|l|}{ Odometer (final): } \\
\hline \multicolumn{3}{|c|}{ Vehicle Fuel (\% Hydrogen by Volume): } & $\% \mathrm{H}_{2}$ \\
\hline \multicolumn{4}{|c|}{ Comments (initials/date): } \\
\hline Sequence No: 2 & File No.: & & Direction of Travel: \\
\hline \multicolumn{2}{|l|}{ Time (initial): } & \multicolumn{2}{|l|}{ Time (final): } \\
\hline \multicolumn{2}{|l|}{ Odometer (initial): } & \multicolumn{2}{|l|}{ Odometer (final): } \\
\hline Vehicle Fuel $(\% \mathrm{H})$ & ogen by Volume): & & $\% \mathrm{H}_{2}$ \\
\hline \multicolumn{4}{|c|}{ Comments (initials/date): } \\
\hline
\end{tabular}

Page 11, (C) 2003. Electric Transportation Applications. All rights reserved. 


\section{APPENDIX-A}

\section{Hydrogen ICE Vehicle Acceleration to a Pre-Determined Speed Test Data Sheet (Page 3 of 4)}

VIN Number:

\begin{tabular}{|c|c|c|c|}
\hline Sequence No: 3 & File No.: & & Direction of Travel: \\
\hline \multicolumn{2}{|l|}{ Time (initial): } & \multicolumn{2}{|l|}{ Time (final): } \\
\hline \multicolumn{2}{|l|}{ Odometer (initial): } & \multicolumn{2}{|l|}{ Odometer (final): } \\
\hline \multicolumn{3}{|c|}{ Vehicle Fuel (\% Hydrogen by Volume): } & $\% \mathrm{H}_{2}$ \\
\hline \multicolumn{4}{|c|}{ Comments (initials/date): } \\
\hline Sequence No: 4 & File No.: & & Direction of Travel: \\
\hline \multicolumn{2}{|l|}{ Time (initial): } & \multicolumn{2}{|l|}{ Time (final): } \\
\hline \multicolumn{2}{|l|}{ Odometer (initial): } & \multicolumn{2}{|l|}{ Odometer (final): } \\
\hline Vehicle Fuel (\% H) & ogen by Volume): & & $\% \mathrm{H}_{2}$ \\
\hline \multicolumn{4}{|c|}{ Comments (initials/date): } \\
\hline
\end{tabular}

Page 12, () 2003. Electric Transportation Applications. All rights reserved. 


\section{APPENDIX-A}

\section{Hydrogen ICE Vehicle Acceleration to a Pre-Determined Speed Test Data Sheet \\ (Page 4 of 4)}

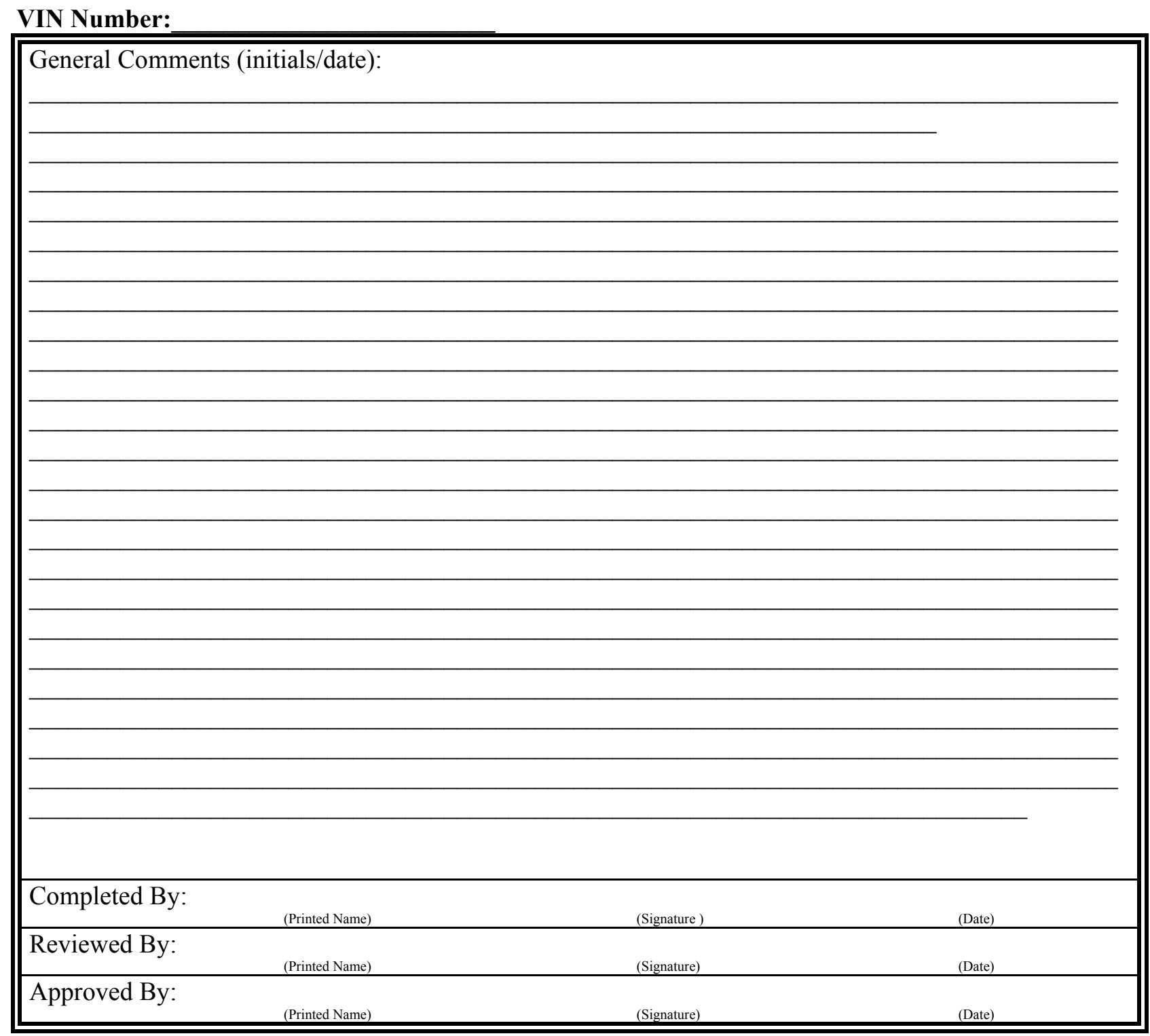

Page 13, (C) 2003. Electric Transportation Applications. All rights reserved. 
APPENDIX-B

\section{Vehicle Metrology Setup Sheets}

(Page 1 of 1)

VIN Number:

\begin{tabular}{|c|c|c|}
\hline Instrument/Device: & Calibration Due Date: & Initials / Date: \\
\hline Fifth Wheel S/N: & & \\
\hline Fifth Wheel Calibrator S/N: & & \\
\hline DAS S/N: & & \\
\hline DAS Set-up Sheet S/N & & \\
\hline Tire Pressure Gauge S/N: & & \\
\hline Misc: & & \\
\hline Misc: & & \\
\hline Misc: & & \\
\hline Misc: & & \\
\hline Comments (initials/date): & & \\
\hline Completed By: & (Signature ) & (Date) \\
\hline (Printed Name) & (Signature) & (Date) \\
\hline
\end{tabular}

Page 14, (c) 2003. Electric Transportation Applications. All rights reserved. 


\title{
Attachment 2 - Hydrogen ICE Vehicle Constant Speed Fuel Economy Tests
}

\author{
ETA-YTP002 \\ Revision 0 \\ Effective May 15, 2003 \\ Prepared by \\ Electric Transportation Applications
}

Page 1. (C) 2003, Electric Transportation Applications. All rights reserved. 


\title{
Appendix 2
}

\section{ETA-YTP002 \\ Revision 0}

Effective May 15, 2003

\section{Hydrogen ICE Vehicle Constant Speed Fuel Economy Tests}

\author{
Prepared by \\ Electric Transportation Applications
}

Prepared by:

Bill Short

Approved by:

Don Karner
Date:

Date: 


\section{TABLE OF CONTENTS}

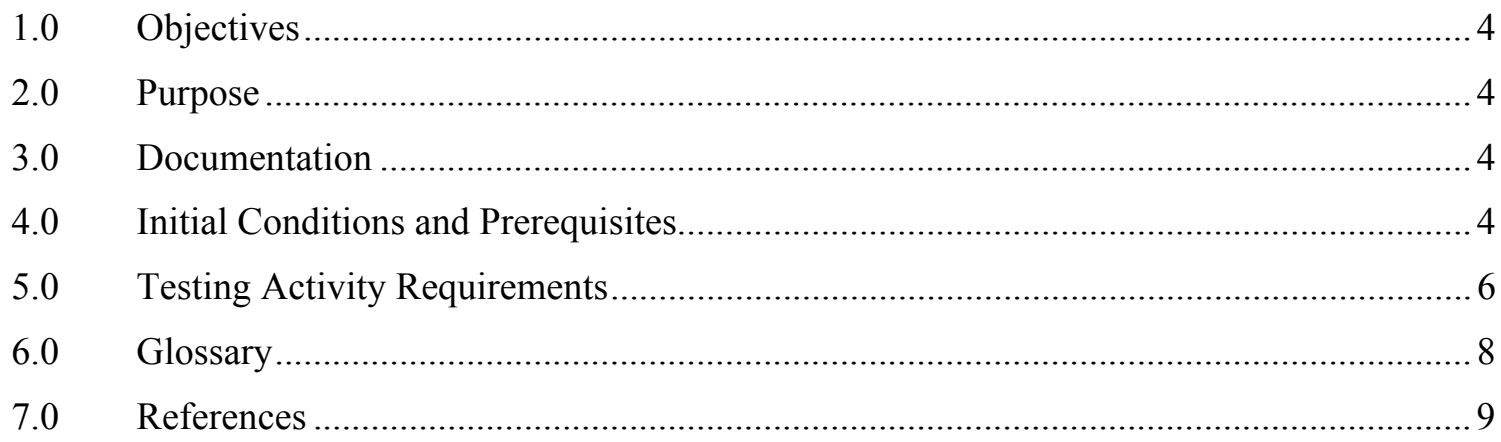

Appendix A - 45 mph Constant Speed Range Test Data Sheet.................................................. 10

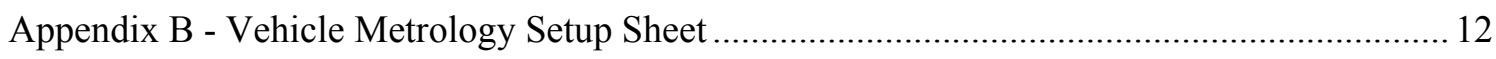

Appendix C - Fuel Use Calculation Using ETA-YTP002 (Fuel Use Calculator) ........................ 13

Page 3, (c) 2003. Electric Transportation Applications. All rights reserved. 


\section{Attachment 2 \\ Procedure ETA-YTP002 \\ Revision 0}

\subsection{Objective}

The objective of this procedure is to identify proper methods for the control of constant speed fuel economy testing, pursuant to SAE-J1082 JUN95. These methods are not meant to supersede those of the testing facility, those specifically addressed by SAE Test Standards, nor of any regulatory agency who may have or exercise control over the covered activities.

\subsection{Purpose}

The purpose of this procedure is to identify acceptable methods for the implementation of a constant speed range test. SAE J1082 JUN95 establishes uniform procedures for testing internal combustion vehicle fuel economy. Testing conducted in accordance with this procedure is similar to that identified in SAE J1082 JUN95, with the exception of using a constant speed driving schedule. This procedure shall collect and retain test data as specified in the HFV America Technical Requirements.

\subsection{Documentation}

Documentation addressed by this procedure shall be consistent, easy to understand, easy to read and readily reproducible. This documentation shall contain enough information to "stand alone"; that is, be self-contained to the extent that all individuals qualified to review it could be reasonably expected to reach a common conclusion, without the need to review additional documentation. Review and approval of test documentation shall be in accordance with ETA-YAC004, "Review of Test Results." Storage and retention of records during and following testing activities shall be completed as described in Procedure ETA-YAC001, "Control, Close-out and Storage of Documentation."

\subsection{Initial Conditions and Prerequisites}

Prior to conduct of any portion of the testing, the following initial conditions and prerequisites shall be met. Satisfactory completion of these items shall be verified as complete and recorded on the Vehicle Test Data Sheet.

4.1 Personnel conducting testing under this procedure shall be familiar with the requirements of this procedure, and when applicable the appropriate SAE Test Instructions, Administrative Control Procedures, and be certified by the Program Manager, Test Manager or specific Test Engineer prior to commencing any testing activities.

4.2 All documentation required to complete the testing shall be completed, approved and issued (past it's effective date) prior to commencing the testing it addresses.

4.3 Test Conditions

4.3.1 The test road must be a closed course consisting of dry, clean and smooth roads not exceeding $1.0 \%$ grade

4.3.2 Ambient temperature during road testing shall be within the range of $50^{\circ} \mathrm{F}$ to $100^{\circ} \mathrm{F}\left(-1^{\circ} \mathrm{C}\right.$ to $\left.38^{\circ} \mathrm{C}\right)-$ Note this is a deviation from SAE J1082 JUN95.

Page 4, (c) 2003. Electric Transportation Applications. All rights reserved. 


\section{Attachment 2 \\ Procedure ETA-YTP002 \\ Revision 0}

4.3.3 The average wind speed at the test site during the test shall not exceed 10 $\mathrm{mph}(16 \mathrm{~km} / \mathrm{h})$. Wind gusts shall not exceed $20 \mathrm{mph}(32 \mathrm{kph})$ during the test.

4.4 Test Vehicle Preparation

4.4.1 The vehicle should have accumulated a minimum of 2,000 miles $(3,200$ $\mathrm{km})$ of operation prior to test. At least $1,000(1,600 \mathrm{~km})$ of these miles must have been driven at speeds above $40 \mathrm{mph}(64 \mathrm{kph})$.

4.4.2 Tires shall have been operated for at least 100 miles $(160 \mathrm{~km})$ prior to test and shall have at least $75 \%$ of the tread remaining and in good condition. Tires provided with the vehicle shall be the standard tire offered by the vehicle manufacturer, and shall be inflated to the manufacturer's (placard) recommended cold inflation pressures prior to test. This pressure shall not exceed the maximum allowable pressure imprinted upon the tire's sidewall.

4.4.3 Vehicle shall be tested in its normal configuration with normal appendages (mirrors, bumpers, hubcaps, etc.).

4.4.4 Vehicles shall be tested at curb weight plus 332 pounds. - Note this is a deviation from SAE J1082 JUN95. Consideration should be given to how adding instrumentation will affect the test weight and balance of the vehicle.

4.4.5 Normal manufacturer's recommended lubricants shall be employed.

4.5 The following data shall be collected during conduct of the test specified by this procedure. Overall error in recording or indicating instruments shall not exceed $\pm 2 \%$ of the maximum value of the variable being measured. Periodic calibration shall be performed and documented to ensure compliance with this requirement.

4.5.1 Fuel pressure and fuel temperature prior to testing

4.5.2 Vehicle speed versus time

4.5.3 Distance versus time

4.5.4 Fuel pressure and fuel temperature after testing

Vehicle speed and distance versus time data shall be collected using an onboard Data Acquisition System (DAS).

4.6 Environmental conditions during the testing shall be recorded and include, at a minimum, the following:

4.6.1 Range of ambient temperature during the test;

4.6.2 Range of wind velocity during the test;

4.6.3 Range of wind direction during the test.

Bounding values shall be recorded in Appendix A.

4.7 Verify that Procedures ETA-YAC006, "Vehicle Verification," and ETAYTP011, "Receipt Inspection," have been completed. This requirement shall be waived if the vehicle is being tested outside the HFV America Program.

Page 5, (c) 2003. Electric Transportation Applications. All rights reserved. 


\section{Attachment 2 \\ Procedure ETA-YTP002 \\ Revision 0}

4.8 A description of the test route, road surface type and condition (SAE J688, "Truck Ability Prediction Procedure"), and lengths and grades of test route, shall be recorded in Appendix A.

4.9 The date and starting and ending times shall be recorded in Appendix A

4.10 The starting and ending vehicle odometer readings shall be recorded in Appendix A.

4.11 The type of fuel used for the test shall be recorded in Appendix A.

\section{NOTE}

When switching fuels, the vehicle shall be operated for a minimum of 20 miles under varying load conditions to allow the fuel management system to adapt to the new fuel.

4.12 All instrumentation used in the test shall be listed on Appendix B, attached to the test data sheets/results, and shall include the following information:

\subsubsection{Manufacturer}

4.12.2 Model Number

4.12.3 Serial Number

4.12.4 Last Calibration date

4.12.5 Next Calibration date

4.13 The speed-time measuring device and other necessary equipment shall be installed so that they do not hinder vehicle operation or alter the operating characteristics of the vehicle. Mounting will nominally be at the rear of the vehicle.

4.14 Any deviation from the test procedure, and the reason for the deviation, shall be recorded in accordance with ETA-YAC002.

4.15 All documentation required to complete the testing shall be completed, approved and issued prior to commencing the testing it addresses.

4.16 During data reduction, the actual distance traveled and the corresponding fuel consumption shall be determined.

4.17 Each Fuel Economy Test shall be terminated when the specific requirements of section 5.9 have been reached. However, if the manufacturer's instructions provide guidance about when to stop driving the vehicle, this guidance shall take precedence in all circumstances.

\subsection{Testing Activities Requirements}

\subsection{Range at $45 \mathrm{mph}$ Constant Speed}

The purpose of this section is to determine fuel economy with the vehicle loaded at curb weight plus 332 pounds, and operated at a constant $45 \mathrm{mph}$.

This testing shall be completed subject to the initial conditions and prerequisites stated in Section 4 of this procedure.

Page 6, (c) 2003. Electric Transportation Applications. All rights reserved. 


\section{Attachment 2 \\ Procedure ETA-YTP002 \\ Revision 0}

\section{NOTE}

All steps shall be completed in the order written. Deviations from any step or requirement shall have the approval of the Program Manager or Test Manager in accordance with Procedure ETA-YAC002, "Control of Test Conduct."

5.1 Record information concerning the vehicle being tested in Appendix A.

5.2 Instrument the vehicle to obtain, at a minimum, the data identified in Section 4.5. Calibrate the fifth wheel, as necessary.

5.3 Record fuel pressure and temperature of the fuel tank to be used for constant speed fuel economy testing after soaking the vehicle for 6 hours in a constant temperature area. Tank temperature shall be measured by a thermocouple attached to the tank exterior approximately mid tank (long dimension). The temperature of the tank shall be within $1^{\circ} \mathrm{C}$ of the air temperature in the immediate vicinity of the tank and the air temperature approximately four (4) feet from the tank. Isolate the fuel tank to be used for constant speed fuel economy testing until commencement of step 5.7.

5.4 Adjust the vehicle's cold tire pressures to match the manufacturer's placard value, or the maximum cold inflation pressure imprinted upon the tire's sidewall, whichever is less.

5.5 Operate the vehicle for a minimum of 10 miles to allow the engine and fluids to reach operating temperature.

5.6 Switch the vehicle fuel supply to the tank isolated in step 5.3. Record time of test commencement and the vehicle's odometer reading on Appendix A and start the onboard DAS. Accessories shall not be used during testing activities.

5.7 From a standing start, accelerate the vehicle under its own power to a speed of 45 $m p h \pm 1 \mathrm{mph}(72 \mathrm{~km} / \mathrm{h} \pm 1.6 \mathrm{~km} / \mathrm{h})$.

5.8 Each time the vehicle passes the lap marker, record the odometer reading. Each reading shall be recorded in the smallest increment displayed by its respective indicator.

\section{NOTE}

All vehicle's tested will be operated in accordance with the requirements of the Manufacturer's operating manuals/instruction cards/placards. Should the manufacturer's requirements for stopping the vehicle be met prior to reaching the criteria in Step 5.9, the test shall be terminated. The Official Range will be the range achieved at that point, regardless of remaining capability.

5.9 Maintain this speed without interruption until the vehicle travels at least 60 miles $(100 \mathrm{~km})$.

5.10 Pull the vehicle off to the side of the test track Record the final odometer reading and time on Appendix A. (This may be recorded via a DAS).

5.11 The vehicle shall not be driven more than 0.3 miles or $0.5 \%$ of the test distance, whichever is greater, prior to completing step 5.12. As an alternative, the fuel

Page 7, (c) 2003. Electric Transportation Applications. All rights reserved. 


\section{Attachment 2 \\ Procedure ETA-YTP002 \\ Revision 0}

tank used for the constant speed range test may be isolated and the vehicle driven using a supplemental fuel supply.

5.12 Record fuel pressure and temperature of the fuel tank to be used for constant speed fuel economy testing after soaking the vehicle for 6 hours in a constant temperature area. Tank temperature shall be measured by a thermocouple attached to the tank exterior approximately mid tank (long dimension). The temperature of the tank shall be within $1^{\circ} \mathrm{C}$ of the air temperature in the immediate vicinity of the tank and the air temperature approximately four (4) feet from the tank.

5.13 Calculate the quantity (moles) of fuel consumed using the following formula.

$\Delta n=\left(P_{\text {initial }} * V_{\text {initial }}\right) /\left(\zeta * R * T_{\text {initial }}\right)-\left(P_{\text {final }} * V_{\text {final }} / \zeta * R * T_{\text {final }}\right)$

where;

$$
\begin{aligned}
& \mathrm{R}=\text { Universal Gas Constant } \\
& \zeta=\text { Compressibility Factor }
\end{aligned}
$$

5.14 Calculate the quantity (gge) of fuel consumed using the following formula.

$$
Q=\Delta n * E M W / A C C
$$

where;

$$
\begin{aligned}
& \text { EMW }=\text { Effective Molecular Weight of the fuel } \\
& \text { ACC }=\text { Average Conversion Constant for the fuel }
\end{aligned}
$$

5.15 Calculate the constant speed fuel economy (miles/gge) using the following formula.

$$
F E=\left(O D O M E T E R_{\text {initial }}-O D O M E T E R_{\text {final }}\right) / Q
$$

5.16 For convenience and accuracy, the equations used in Sections 5.13 through 5.15 have been incorporated into a MicroSoft Excel ${ }^{\circledR}$ spreadsheet. The file name for this spreadsheet is "ETA-YTP002 (Fuel Use Calculator)" and is marked as Revision 0. A sample print from this spreadsheet is attached as Appendix C.

\subsection{GLOSSARY}

6.1 Curb Weight - The total weight of the vehicle including fuel tanks, lubricants and other expendable supplies, but excluding the driver, passengers, and other payloads.

6.2 Effective Date - The date, after which a procedure has been reviewed and approved, that the procedure can be utilized in the field for official testing.

6.3 Fifth Wheel - A calibrated instrument used to measure a vehicle's speed and distance independent of the vehicles on-board systems.

6.4 Gross Vehicle Weight Rating (GVWR) - The maximum design loaded weight of the vehicle specified by the manufacturer.

6.5 Initial Conditions - Conditions that shall exist prior to an event occurring.

Page 8, (c) 2003. Electric Transportation Applications. All rights reserved. 


\section{Attachment 2 \\ Procedure ETA-YTP002 \\ Revision 0}

6.6 Prerequisites - Requirements that must be met or resolved prior to an event occurring.

6.7 Program Manager - As used in this procedure, the individual within Electric Transportation Applications responsible for oversight of the HFV America Performance Test Program. [Subcontract organizations may have similarly titled individuals, but they are not addressed by this procedure.]

6.8 Shall - This word is used to indicate an item which requires adherence without deviation. Shall statements identify binding requirements. A go, no-go criterion.

6.9 Should - This word is used to identify an item which requires adherence if at all possible. Should statements identify preferred conditions.

6.10 Test Director - The individual within Electric Transportation Applications responsible for all testing activities associated with the HFV America Performance Test Program.

6.11 Test Director's Log - A daily diary kept by the Test Director, Program Manager, Test Manager or Test Engineer to document major activities and decisions that occur during the conduct of a Performance Test Evaluation Program. This log is normally a running commentary, utilizing timed and dated entries to document the day's activities. This log is edited to develop the Daily Test Log published with the final report for each vehicle.

6.12 Test Engineer - The individual(s) assigned responsibility for the conduct of any given test. [Each contractor/subcontractor should have at least one individual filling this position. If so, they shall be responsible for adhering to the requirements of this procedure.]

6.13 Test Manager - The individual within Electric Transportation Applications responsible for the implementation of the test program for any given vehicle(s) being evaluated to the requirements of the HFV America Performance Test Program. [Subcontract organizations may have similarly titled individuals, but they are not addressed by this procedure.]

\subsection{REFERENCES}

7.1 HFV America Vehicle Technical Specifications

7.2 ETA-YAC001, Revision 0 - "Control, Close-out and Storage of Documentation"

7.3 ETA-YAC002, Revision 0 - "Control of Test Conduct"

7.4 ETA-YAC004, Revision 0 - "Review of Test Results"

7.5 ETA-YAC006, Revision 0 - "Vehicle Receipt"

7.6 ETA-YAC007, Revision 0 - "Control of Measuring and Test Equipment"

7.7 ETA-YTP002, Revision 0 - "Implementation of SAE Standard J1666 May 93, Electric Vehicle Acceleration, Gradeability and Deceleration Test Procedure"

7.8 ETA-YTP011, Revision 0 - "Receipt Verification"

7.9 SAE Standard J1082 JUN95

7.10 SAE Standard J1515 JUN95

Page 9, (c) 2003. Electric Transportation Applications. All rights reserved. 


\section{APPENDIX-A \\ 45 mph Constant Speed Fuel Economy Test Data Sheet (Page 1 of 2)}

VIN Number:

\begin{tabular}{|c|c|c|}
\hline Project No.: & & Test Date(s): \\
\hline \multicolumn{3}{|l|}{ Root File No.: } \\
\hline Test Driver: & (Initials) & \\
\hline Test Engineer: & (Initials) & \\
\hline
\end{tabular}

\section{Vehicle Setup}

\begin{tabular}{|c|c|c|c|c|}
\hline \multicolumn{5}{|c|}{$\begin{array}{l}\text { VEHICLE WEIGHTS AS TESTED WITH DRIVER \& INSTRUMENTATION } \\
\text { (Test Weight is Curb Weight plus } 332 \text { pounds) }\end{array}$} \\
\hline Left Front: & Right Front: & Total Front: & Percent Front: & $\%$ \\
\hline $\begin{array}{l}\text { Left Rear: } \\
\quad(\mathrm{lbs} \text { or } \mathrm{kg})\end{array}$ & Right Rear: & Total Rear: & Percent Rear: & $\%$ \\
\hline & & \multicolumn{2}{|l|}{ Total Weight: } & \\
\hline \multicolumn{5}{|c|}{$\begin{array}{l}\text { INSTALLED TIRES } \\
\text { (Placard or sidewall whichever is less) }\end{array}$} \\
\hline \multicolumn{5}{|c|}{ Preparation Area Temperature: } \\
\hline \multicolumn{2}{|c|}{ Left Front } & \multicolumn{3}{|c|}{ Right Front } \\
\hline Pressure: & & Pressure: & & \\
\hline \multicolumn{2}{|c|}{ Left Rear } & \multicolumn{3}{|c|}{ Right Rear } \\
\hline Pressure: & & Pressure: & & \\
\hline
\end{tabular}

\section{Track/Weather Conditions}

\begin{tabular}{|c|c|c|}
\hline Test Track Location: & Track Grade: & $\%$ \\
\hline Ambient Temperature (initial): & \multicolumn{2}{|l|}{ Ambient Temperature (final): } \\
\hline Track Temperature (initial): & \multicolumn{2}{|l|}{ 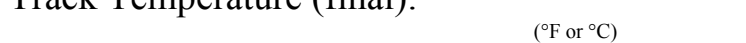 } \\
\hline Wind Velocity (initial): & \multicolumn{2}{|c|}{$(<10 \mathrm{mph}$ or $16 \mathrm{kmh})$} \\
\hline Wind Direction (initial): & Wind Direction (completion): & $\circ$ \\
\hline
\end{tabular}


APPENDIX-A

\section{5 mph Constant Speed Fuel Economy Test Data Sheet}

(Page 2 of 2)

VIN Number

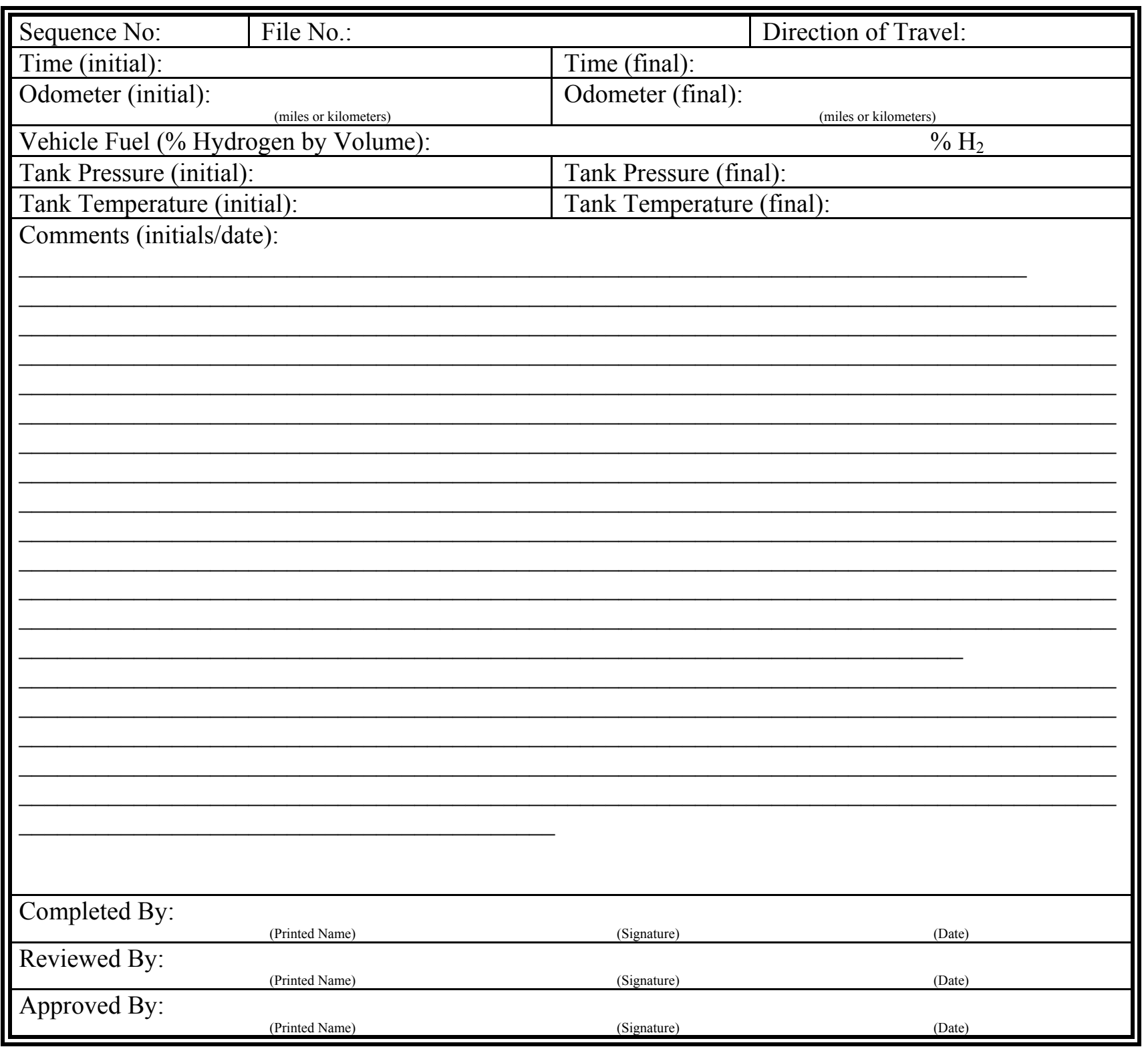

Page 11, () 2003. Electric Transportation Applications. All rights reserved. 


\section{APPENDIX-B}

Revision 0

\section{Vehicle Metrology Setup Sheets \\ (Page 1 of 1)}

VIN Number:

\begin{tabular}{|c|c|c|}
\hline Instrument/Device: & Calibration Due Date: & Initials / Date: \\
\hline Fifth Wheel S/N: & & \\
\hline Fifth Wheel Calibrator $\mathrm{S} / \mathrm{N}$ : & & \\
\hline DAS S/N: & & \\
\hline DAS Set-up Sheet $\mathrm{S} / \mathrm{N}$ & & \\
\hline kWh Meter S/N: & & \\
\hline Shunt $\mathrm{S} / \mathrm{N}$ : & & \\
\hline Tire Pressure Gauge $\mathrm{S} / \mathrm{N}$ : & & \\
\hline Fuel Pressure Gauge S/N: & & \\
\hline Fuel Temperature Meter $\mathrm{S} / \mathrm{N}$ : & & \\
\hline Misc: & & \\
\hline Misc: & & \\
\hline Comments (initials/date): & & \\
\hline Completed By: & & \\
\hline Reviewed By (QA): & (Signature) & (Date) \\
\hline (Printed Name) & (Signature) & (Date) \\
\hline Approved By: & (Signature) & (Date) \\
\hline
\end{tabular}

Page 12, () 2003. Electric Transportation Applications. All rights reserved. 


\section{Attachment 2 \\ Procedure ETA-YTP002 \\ Revision 0}

\section{APPENDIX-C \\ Fuel Use Calculation Using \\ Spreadsheet ETA-YTP002 (Fuel Use Calculator)}

\section{SAMPLE}

File Name: ETA-YTP002 (Fuel Use Calculator)

Calculations for Fuel Economy

\begin{tabular}{|lr|}
\hline Assumptions & \\
\hline Assumed LHV for $\mathrm{H} 2$ & $51,608 \mathrm{Btu} / \mathrm{lb}(\mathrm{LHV})$ \\
Assumed LHV for $\mathrm{CH} 4$ & $21,480 \mathrm{Btu} / \mathrm{lb}$ (LHV) \\
Assumed curve fit of $\mathrm{Z}$ for $\mathrm{H} 2$ (pressure in $\mathrm{psi} Z=2 \mathrm{E}-12 \mathrm{P}^{\wedge} 3+2 \mathrm{E}-8 \mathrm{P}^{\wedge} 2+1 \mathrm{E}-5 \mathrm{P}+.9974$ \\
Assumed curve fit of $\mathrm{Z}$ for $\mathrm{CH} 4$ (pressure in $\mathrm{pZ}=3 \mathrm{E}-8 \mathrm{P}^{\wedge} 2-1 \mathrm{E}-4 \mathrm{P}+.9914$ \\
\hline
\end{tabular}

$\begin{array}{rr}\text { Test Number } & \text { ETA-06-002 } \\ \text { Test Date } & 6 / 3 / 2003 \\ \text { Test Engineer } & \text { B.S. }\end{array}$ Assumed curve fit of $Z$ for $\mathrm{CH} 4$ (pressure in $\mathrm{pZ}=3 \mathrm{E}-8 \mathrm{P}^{\wedge} 2-1 \mathrm{E}-4 \mathrm{P}+.9914$

\section{Input Parameters}

Input Gasoline Energy per Gallon Input Molar Percentage H2

Input Tank Volume

Input Initial Pressure

Input Initial Temperatue

Input Final Pressure

Input Final Temperature

Input Distance Traveled

\section{Output Parameters}

Initial Gasoline Gallons Equivalen

Final Gasoline Gallons Equivalent

Gasoline Gallons Equivalent Used

Miles Per Gasoline Gallon Equival

Claculations

H2 Mass Percentage

Initial Pressure

$\mathrm{Z}$ for $\mathrm{H} 2$

$\mathrm{Z}$ for $\mathrm{CH} 4$

Molar Ratio $(\mathrm{H} 2 / \mathrm{CH} 4)$

Pressure Ratio $(\mathrm{H} 2 / \mathrm{CH} 4)$

Partial Pressure of $\mathrm{H} 2$

Partial Pressure of $\mathrm{CH} 4$

Total Initial Pound Moles

Initial H2 Weight

Initial $\mathrm{CH} 4$ Weight

Initial Energy of $\mathrm{H} 2$

Initial Energy of $\mathrm{CH} 4$

Initial Total Energy

Final Pressure

$\mathrm{Z}$ for $\mathrm{H} 2$

$\mathrm{Z}$ for $\mathrm{CH} 4$

Molar Ratio $(\mathrm{H} 2 / \mathrm{CH} 4)$

Pressure Ratio $(\mathrm{H} 2 / \mathrm{CH} 4)$

Partial Pressure of $\mathrm{H} 2$

Partial Pressure of $\mathrm{CH} 4$

Total Final Pound Moles

Initial H2 Weight

Final $\mathrm{CH} 4$ Weight

Final Energy of $\mathrm{H} 2$

Final Energy of $\mathrm{CH} 4$

Final Total Energy
122,000 Btu/gallon (LHV)

$0.3 \%$

85 liters

3220 psig

81.0 Fahrenheit 541.0 Rankine

1520 psig

74.1 Fahrenheit 534.1 Rankine

60 Miles

$3.92 \mathrm{GGE}$

1.65 GGE

2.27 GGE

26.48 Miles per GGE

$0.050847 \%$

1.021526

3220 psig $\quad 465796.8 \mathrm{psf}$

0.918415

0.428571

0.476687

$1044.189 \mathrm{psi} \quad 150363.2 \mathrm{psf}$

$2190.511 \mathrm{psi} \quad 315433.6 \mathrm{psf}$

1.760966

$1.05658 \mathrm{lbs}$

$19.72282 \mathrm{lbs}$

$54527.97 \mathrm{Btu}$

$423646.2 \mathrm{Btu}$

478174.2 Btu

1520 psig
1.006308
0.885032
0.428571
0.487299
$502.8294 \mathrm{psi}$
$1031.871 \mathrm{psi}$
0.742973
$0.445784 \mathrm{lbs}$
$8.321302 \mathrm{lbs}$
$23006.02 \mathrm{Btu}$
$178741.6 \mathrm{Btu}$
$201747.6 \mathrm{Btu}$

966 Perfect gas partial pressure (used for calculating $Z$ ) 2254 Perfect gas partial pressure (used for calculating $Z$ )

220996.8 psf

$72407.43 \mathrm{psf}$ $148589.4 \mathrm{psf}$
456 Perfect gas partial pressure (used for calculating $Z$ ) 1064 Perfect gas partial pressure (used for calculating Z)

Page 13, (C) 2003. Electric Transportation Applications. All rights reserved. 


\title{
Attachment 3 - Hydrogen ICE Vehicle Acceleration Testing Data Sheets
}

\author{
Test Data Sheets Form \\ Conduct of ETA-YTP001, Revision 0 \\ Implementation of \\ SAE Standard J1666 AUG99
}




\section{APPENDIX-A \\ Hydrogen ICE Vehicle Acceleration to a Pre-Determined Speed Test Data Sheet (Page 1 of 4)}

VIN Number: IFTPF 17 m 8 YKB 39272

\begin{tabular}{|c|c|}
\hline Project No: $E \mid A-06-25-01$ & Test Date(s): $\quad 6 / 25 / 0 B$ \\
\hline \multicolumn{2}{|l|}{ Root File No.: } \\
\hline Test Driver: Bsiel She 4 & 6125103 \\
\hline Test Engineer: & $6 / 25 / 03$ \\
\hline
\end{tabular}

\section{Vehicle Setup}

\begin{tabular}{|c|c|c|c|}
\hline \multicolumn{4}{|c|}{$\begin{array}{l}\text { VEHICLE WEIGHTS AS TESTTD WITH DRIVER \& INSTRUMENTATION } \\
\text { (Curb weight plus } 332 \text { pounds) }\end{array}$} \\
\hline Left Front: $1363 \mathrm{lbs}$ & Right Front: $144 \mid \underset{\text { (las or kg) }}{\mid 4 .}$. & 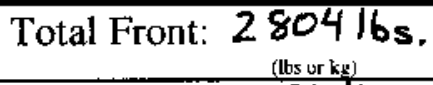 & Percent Front:53.7\% \\
\hline Left Rear: $122816 \mathrm{~s}$. & 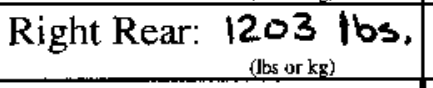 & Total Rear: 243 l los & Percent Rear: $46.3 \%$ \\
\hline & & \multicolumn{2}{|c|}{ Total Weight: $\quad 5235$ /6s } \\
\hline \multicolumn{4}{|c|}{$\begin{array}{c}\text { INSTALLED TIRES } \\
\text { (Placard or sidewall whichever is less) }\end{array}$} \\
\hline \multicolumn{4}{|c|}{ Preparation Area Temperature: } \\
\hline \multicolumn{2}{|c|}{ Left Front } & \multicolumn{2}{|c|}{ Right Front } \\
\hline Pressure: 65 psi & & 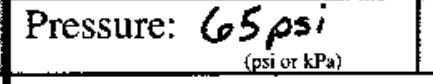 & \\
\hline \multicolumn{2}{|c|}{ Left Rear } & \multicolumn{2}{|c|}{ Right Rear } \\
\hline Pressure: 65 psi & & Pressure: $65 \operatorname{pssi}_{(\mathrm{ps} \mathrm{K} \mathrm{ka})}$ & \\
\hline
\end{tabular}

Track/Weather Conditions

\begin{tabular}{|c|c|}
\hline Test Track Location: $\infty \subset A P G$ & Track Grade: \pm 1 (Wilhin $\mid \%)$ \\
\hline Ambient Temperature (initial): $\quad 72.3^{\circ} \mathrm{F}$ & Ambient Temperature (final): \\
\hline Track Temperature (initial): & Track Temperature (final): \\
\hline Wind Velocity (initial): & Wind Velocity (final): \\
\hline Wind Direction (initial): & Wind Direction (completion): $\quad 31^{4}$ \\
\hline
\end{tabular}




\section{APPENDIX-A \\ Hydrogen ICE Vehicle Acceleration to a Pre-Determined Speed Test Data Sheet (Page 2 of 4)}

VIN Number:IFTPF $17 m$ \&YK B 39272

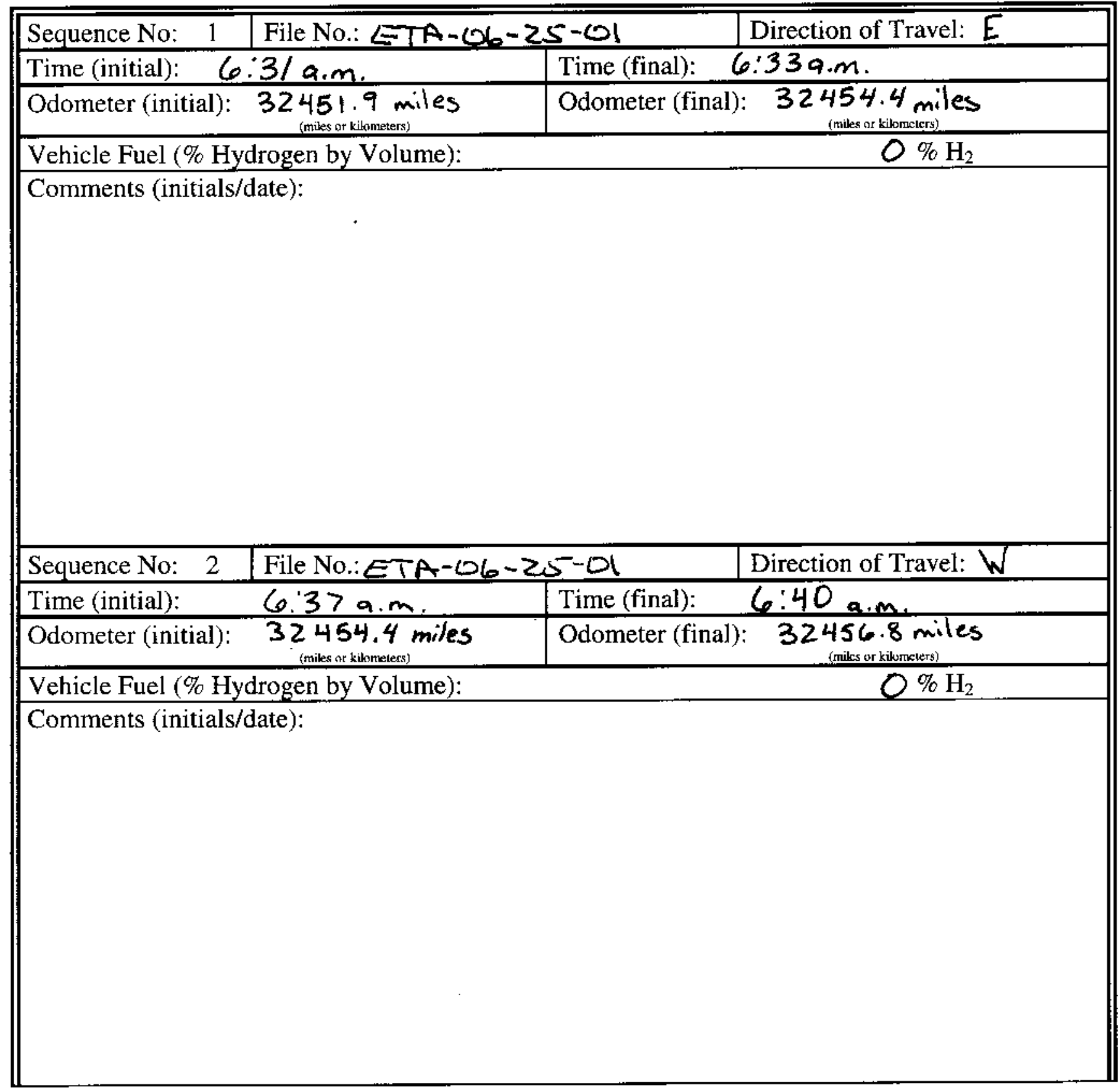




\section{APPENDIX-A \\ Hydrogen ICE Vehicle Acceleration to a Pre-Determined Speed Test Data Sheet (Page 3 of 4)}

VIN Number: IFTPF 17 M 8 YKB 39272

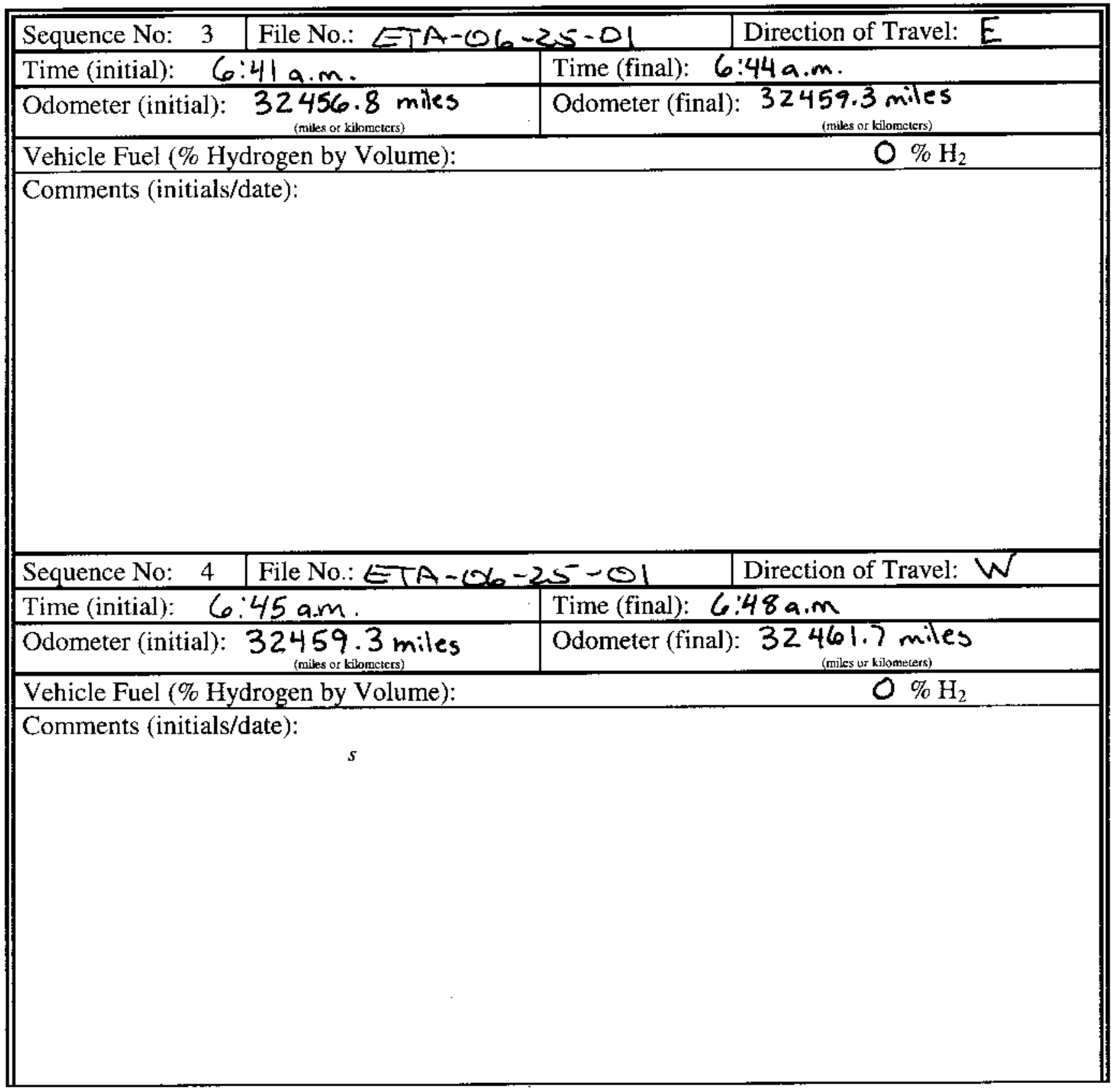

(C)2003 Clectric $_{\text {ransportation Applications All Rights Reserved }}$ 


\section{APPENDIX-A}

Hydrogen ICE Vehicle Acceleration to a Pre-Determined Speed Test Data Sheet (Page 4 of 4)

\section{VIN Number:IfTPF 17 m8 YK B 39272}

General Comments (initials/date):

Completed By: Bill Short

Reviewed By: PRiLarnes

Approved By: DßBllariner

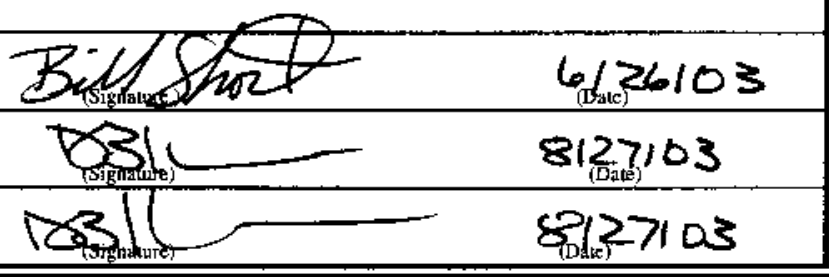

APPENDIX-B

(C2003 Cloctric $\eta_{\text {ransportation Applications All Rights Reserved }}$ 


\section{Vehicle Metrology Setup Sheets}

(Page 1 of 1)

VIN Number: IFTPFI7M8YKB39272

\begin{tabular}{|c|c|c|}
\hline $\begin{array}{r}\text { Fifth Wheel S/N: } \\
01359 \\
\end{array}$ & $5-19-04$ & $6 / 26 / 03$ \\
\hline Fifth Wheel Calibrator S/N: & not applicable & 6.26103 \\
\hline DAS S/N: & not appliable & $6 / 26 / 03$ \\
\hline DAS Set-up Sheet S/N & not appli & $6 / 26 / 03$ \\
\hline Tire Pressure Gauge S/N: & not applicable & $6 / 26 / 03$ \\
\hline Misc: & & \\
\hline Misc: & & \\
\hline Misc: & & \\
\hline Mise: & & \\
\hline Comments (initials/date): & & \\
\hline Completed By: Bill Short & & $6 / 26 / 03$ \\
\hline$W_{B} K_{a}$ & & 8127103 \\
\hline
\end{tabular}




\section{APPENDIX-A \\ Hydrogen ICE Vehicle Acceleration to a Pre-Determined Speed Test Data Sheet (Page 1 of 4)}

VIN Number: IFTPF 17 M 8 YKB 39272

\begin{tabular}{|c|c|}
\hline Project No.: $E T A \cdot 06-|1-0|$ & Test Date(s): $6 / 11 / 03$ \\
\hline \multicolumn{2}{|l|}{ Root File No.: } \\
\hline Test Driver: Bild Shot & $6 / 11 / 03$ \\
\hline Test Engineer: & $6 / 4 l / O 3$ \\
\hline
\end{tabular}

\begin{tabular}{|c|c|c|c|}
\hline \multicolumn{4}{|l|}{ Vehicle Setup } \\
\hline \multicolumn{4}{|c|}{$\begin{array}{l}\text { VEHCLE WEIGHTS AS TESTED WTH DRIVER \& NSTRUMENTATTON } \\
\text { (Cub weight plus } 332 \text { pounds) }\end{array}$} \\
\hline Left Front: $1363 \mathrm{lbs}$. & Right Front: 1441 los & Total Front: $2804 \mathrm{lbs}$ & Percent Front: 53.7\% \\
\hline Lefl Rear: 1228 Ibs & Right Rear: 1203 lbs & Total Rear: 2431 lbs & Percent Rear:46.3\% \\
\hline & & \multicolumn{2}{|c|}{ Total Weight: $5235 \mathrm{lbs}$} \\
\hline \multicolumn{4}{|c|}{$\begin{array}{l}\text { MSTAUTED TIRES } \\
\text { (Placaro or sidewall whicheyer is less) }\end{array}$} \\
\hline \multicolumn{2}{|c|}{ Preparation Area Temperature: } & & \\
\hline \multicolumn{2}{|c|}{ Left Front } & \multicolumn{2}{|c|}{ Right Front } \\
\hline 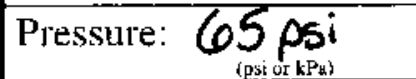 & 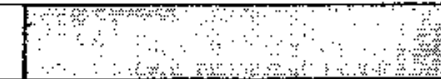 & Pressure: 65 psi & \\
\hline \multicolumn{2}{|c|}{ Left Rear } & \multicolumn{2}{|c|}{ Right Rear } \\
\hline Pressure: 65 psi & $\sqrt{8}$ & Pressure: $6 \underset{(\text { psi or } \mathrm{pPa} \text {. }}{5 \mathrm{pi}}$ & \\
\hline
\end{tabular}

Track/Weather Conditions

\begin{tabular}{|c|c|}
\hline \multicolumn{2}{|c|}{ Test Track Location: DCAPCS Straushtaway } \\
\hline Ambient Temperature (initial): & Ambient Temperature (final): \\
\hline Track Temperature (initial): & Track Temperature (final): \\
\hline Wind Velocity (initial): & Wind Velocity (final): \\
\hline Wind Direction (initial): & Wind Direction (completion): \\
\hline
\end{tabular}




\section{APPENDIX-A}

Hydrogen ICE Vehicle Acceleration to a Pre-Determined Speed Test Data Sheet (Page 2 of 4)

VIN Number:IFTPFI7M8YKB39272

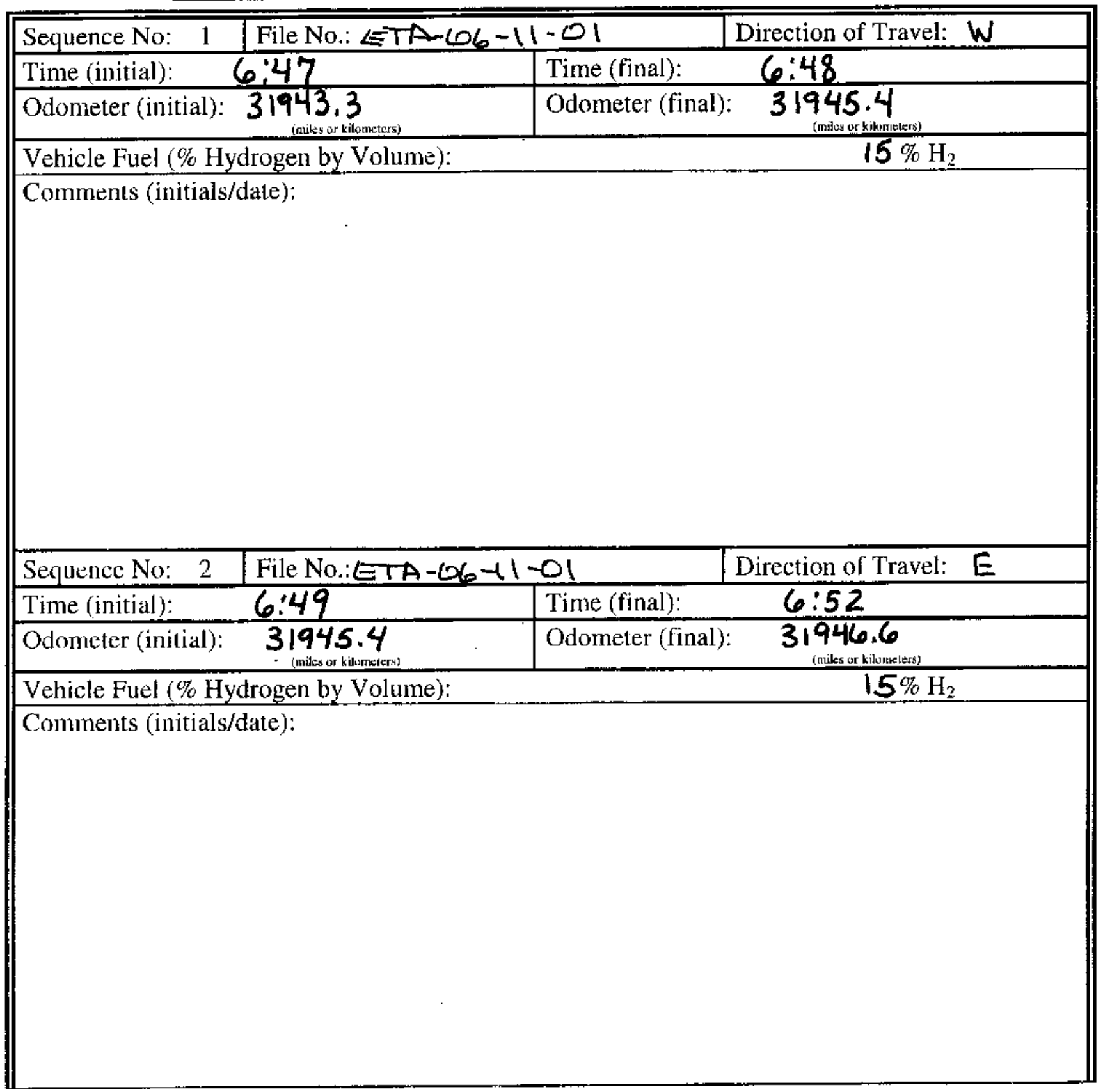




\section{APPENDIX-A \\ Hydrogen ICE Vehicle Acceleration to a Pre-Determined Speed Test Data Sheet (Page 3 of 4)}

VIN Number: IFTPF17m8YKB 39272

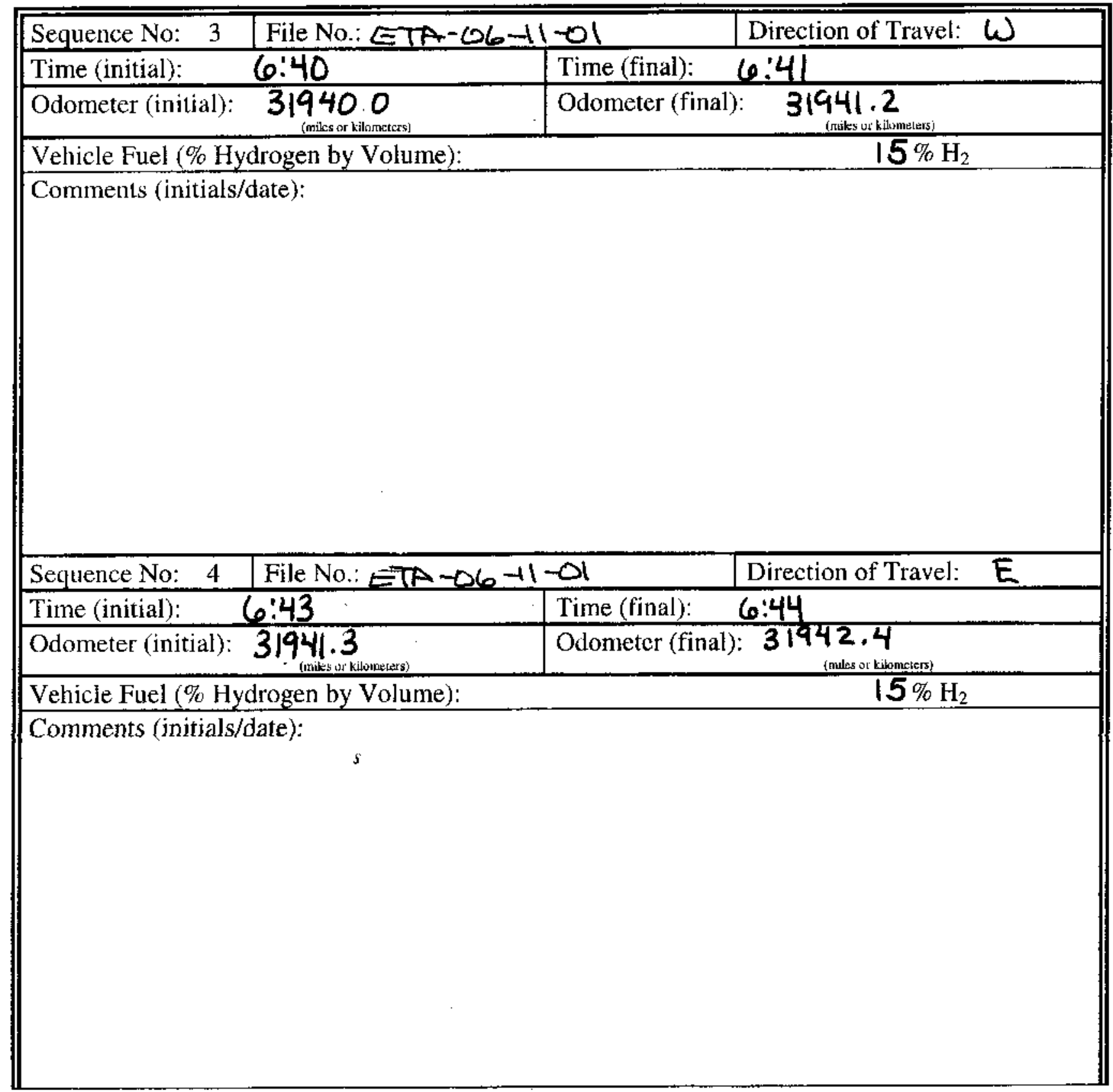




\section{APPENDIX-A \\ Hydrogen ICE Vehicle Acceleration to a Pre-Determined Speed Test Data Sheet (Page 4 of 4)}

VIN Number:IFTPF17 M8YKB39 272

General Comments (initials/date):

Completed By:

Reviewed By:

Approved By:

\section{APPENDIX-B}


Proc :dure ETA-YTP001 Revision 0

\section{Vehicle Metrology Setup Sheets \\ (Page 1 of 1)}

VIN Number: IFTPFI7M8YKB39272

\begin{tabular}{|c|c|c|}
\hline $\begin{aligned} & \text { Fifth Wheel S/N: } 01359 \\
&\end{aligned}$ & $5-19-04$ & $6 / 12 / 03$ \\
\hline Fifth Wheel Calibrator $\mathrm{S} / \mathrm{N}$ : & not applicable & $6 / 12 / 03$ \\
\hline DAS S/N: & notapslicable & $6 / 12 / 03$ \\
\hline DAS Set-up Sheet $\mathrm{S} / \mathrm{N}$ & not apolicable & $6 / 12 / 03$ \\
\hline Tire Pressure Gauge $\mathrm{S} / \mathrm{N}$ : & not applicable & $6 / 12 / 03$ \\
\hline Mise: & & \\
\hline Misc: & & \\
\hline Misc: & & \\
\hline Misc: & & \\
\hline Comments (initials/date): & & \\
\hline 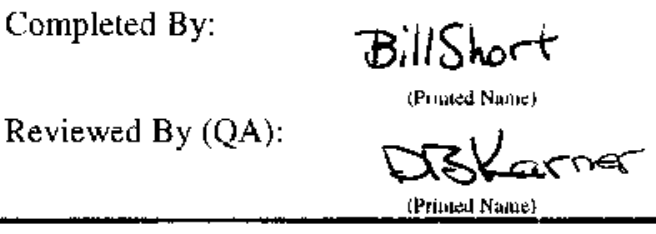 & naure) & $\begin{array}{l}6 / 12 / 03 \\
8127 / 03 \\
\text { (Dake) }\end{array}$ \\
\hline
\end{tabular}






\section{APPENDIX-A \\ Hydrogen ICE Vehicle Acceleration to a Pre-Determined Speed Test Data Sheet (Page 1 of 4)}

VIN Number: IFTPFI7M8YK B 39272

\begin{tabular}{|c|c|}
\hline Project No.: ETA-05-21-01 & Test Date(s): $5-21-03$ \\
\hline \multicolumn{2}{|l|}{ Root File No.: } \\
\hline Test Driver: William Short $\omega_{\text {(Initulst }} S$ & $5121 / 03$ \\
\hline Test Engineer: & $5 / 21 / 03$ \\
\hline
\end{tabular}

Vehicle Setup

\begin{tabular}{|c|c|c|c|}
\hline \multicolumn{4}{|c|}{$\begin{array}{l}\text { VEHCLE WUGHS AS TESTED WTH DRIVER \& NSURUMENTANION } \\
\text { (Curb weigh plus } 332 \text { pounds) }\end{array}$} \\
\hline Left Front: $/ 36316 \mathrm{~s}$ & Right Front: $144 / 16 \mathrm{~s}$ & Total Front: $280416 \mathrm{~s}$ & Percent Front: $\mathbf{5 3 . 7 \%}$ \\
\hline L.eft Rear: 1228 rbs & Right Rear: 1203 ibs & Total Rear: 2431165 & Percent Rear. $46.3 \%$ \\
\hline & & Total Weight: 5235 & of \\
\hline \multicolumn{4}{|c|}{$\begin{array}{l}\text { INSTALED TIRES } \\
\text { (Placard or sidewall whichever is less) }\end{array}$} \\
\hline \multicolumn{4}{|c|}{ Preparation Area Temperature: } \\
\hline \multicolumn{2}{|c|}{ Left Front } & \multicolumn{2}{|c|}{ Right Front } \\
\hline Pressure: $\quad 65$ & & Pressure: $\quad 65$ & \\
\hline \multicolumn{2}{|c|}{ Left Rear } & \multicolumn{2}{|c|}{ Right Rear } \\
\hline Pressure: $\quad 605$ & 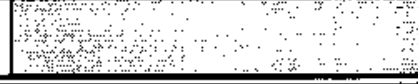 & Pressure: & \\
\hline
\end{tabular}

Track/Weather Conditions

\begin{tabular}{|c|c|c|}
\hline Test Track Location: $D<A P C=$ strais & Track Grade: $\quad \pm 1 \%$ & $\%$ \\
\hline Ambient Temperature (initial): $\quad 91.2$ & Ambient Temperature (final): 91.7 & \\
\hline Track Temperature (initial): $\quad 109.4$ & Track Temperature (final): & \\
\hline $\begin{array}{lc}\text { Wind Velocity (initial): } & 9.9 \\
& 9.9\end{array}$ & Wind Velocity (final): & \\
\hline Wind Direction (initial): & Wind Direction (completion): & 0 \\
\hline
\end{tabular}

(C2003 8 sctric $7_{\text {ratispurtulion }} A_{p p}$ lications All Rights Reserved 


\section{APPENDIX-A \\ Hydrogen ICE Vehicle Acceleration to a Pre-Determined Speed Test Data Sheet (Page 2 of 4)}

VIN Number:IFTPFI/7m8YkB39272

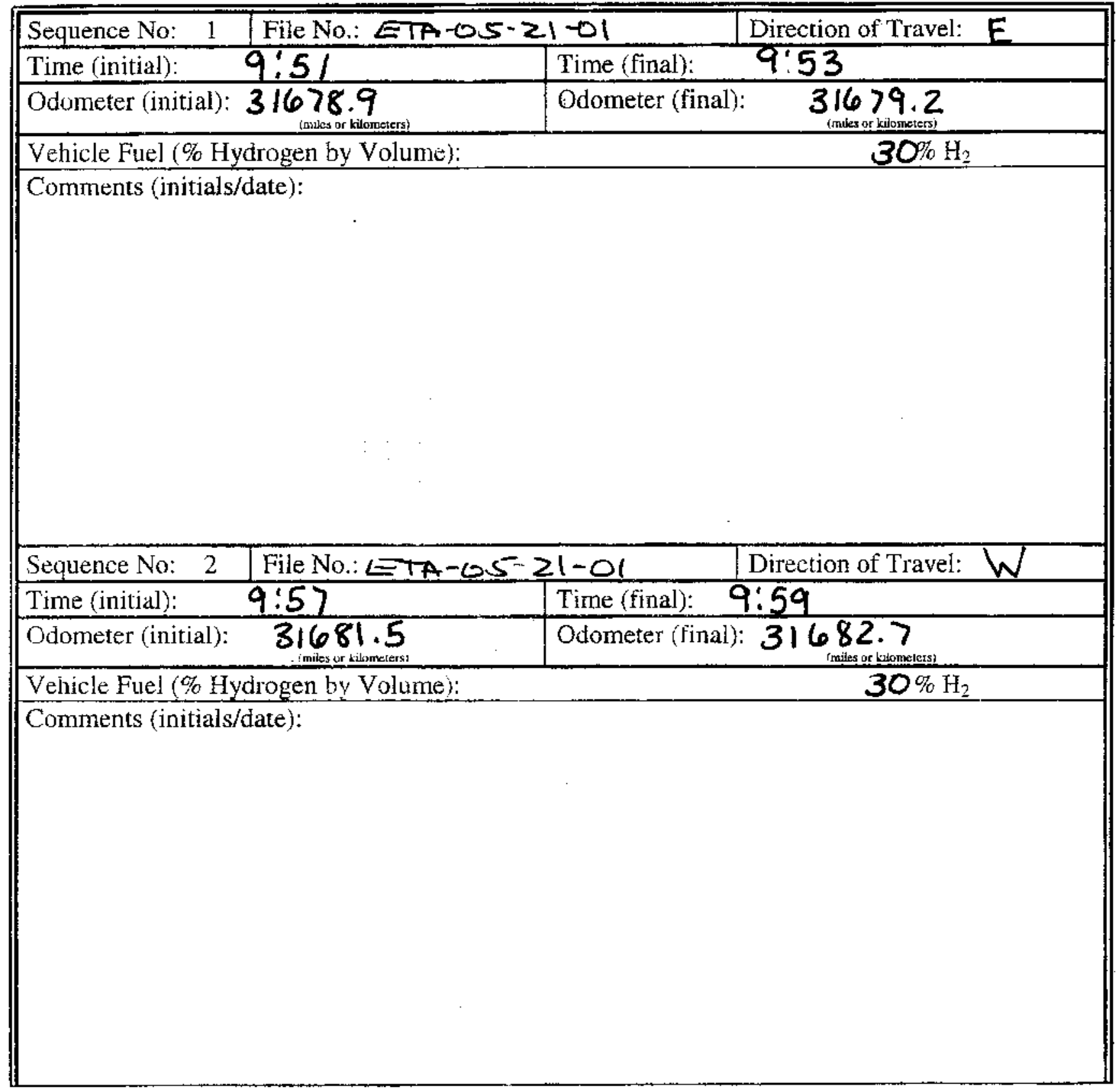




\section{APPENDIX-A \\ Hydrogen ICE Vehicle Acceleration to a Pre-Determined Speed Test Data Sheet (Page 3 of 4)}

VIN Number:IfTPF 17 m8YKB39272

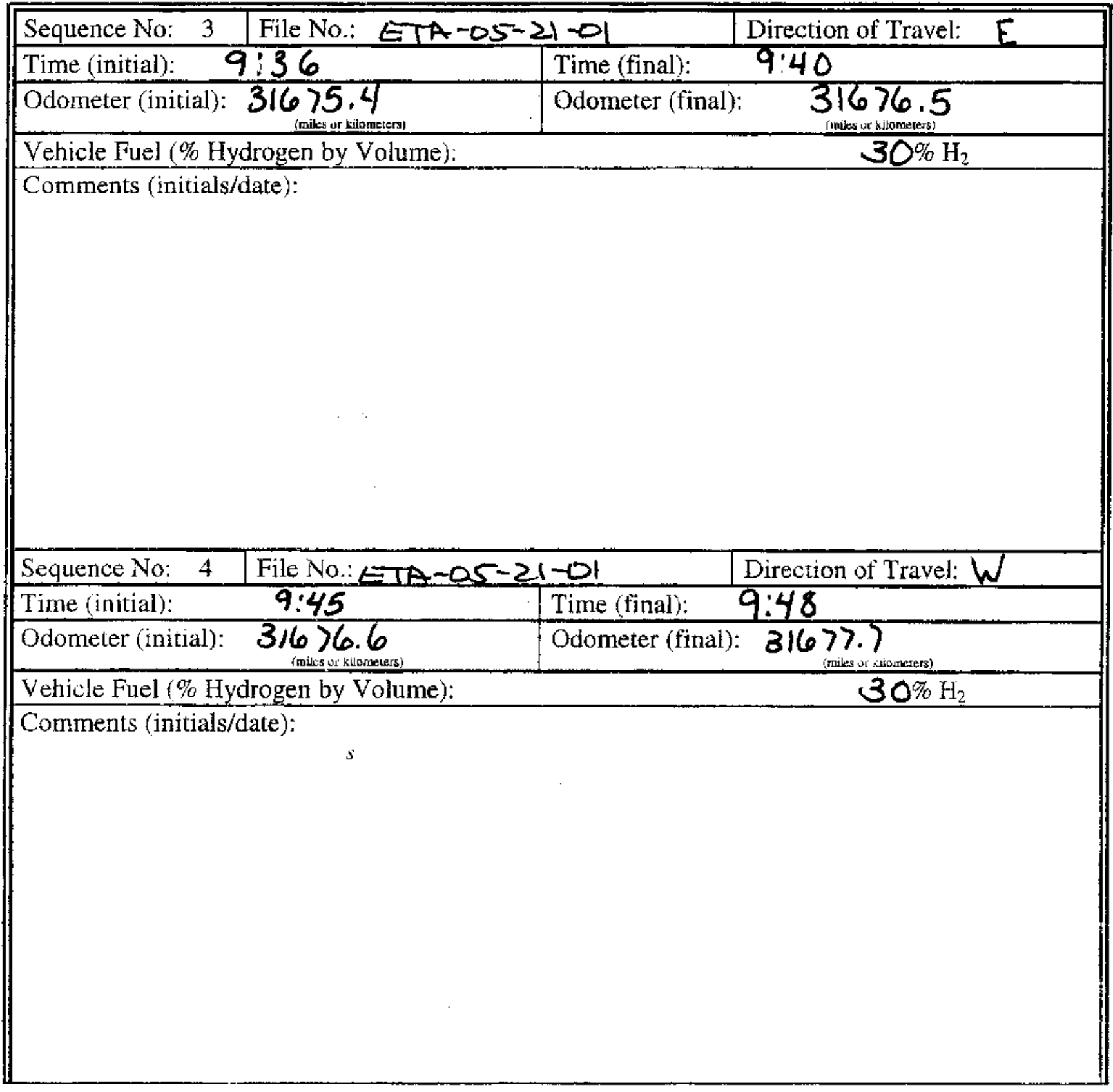




\section{APPENDIX-A \\ Hydrogen ICE Vehicle Acceleration to a Pre-Determined Speed Test Data Sheet (Page 4 of 4)}

VIN Number:IFTPF $17 \mathrm{m8YKB} 39272$

General Comments (initials/date):

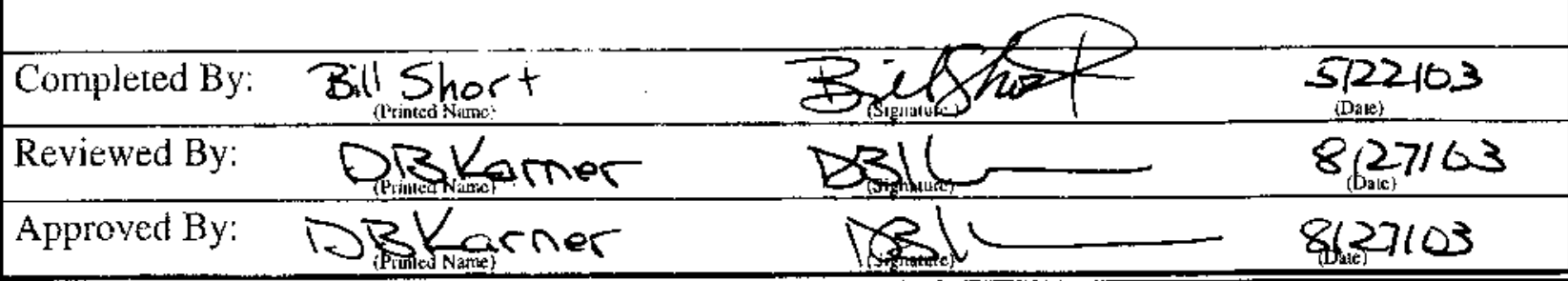

APPENDIX-B

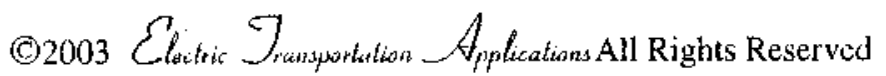


Proc:dure ETA-YTP001 Revision 0

\section{Vehicle Mifrology Setup Sheets}

(Page 1 of 1)

VIN Number: IFTPF/7M8YKB39272

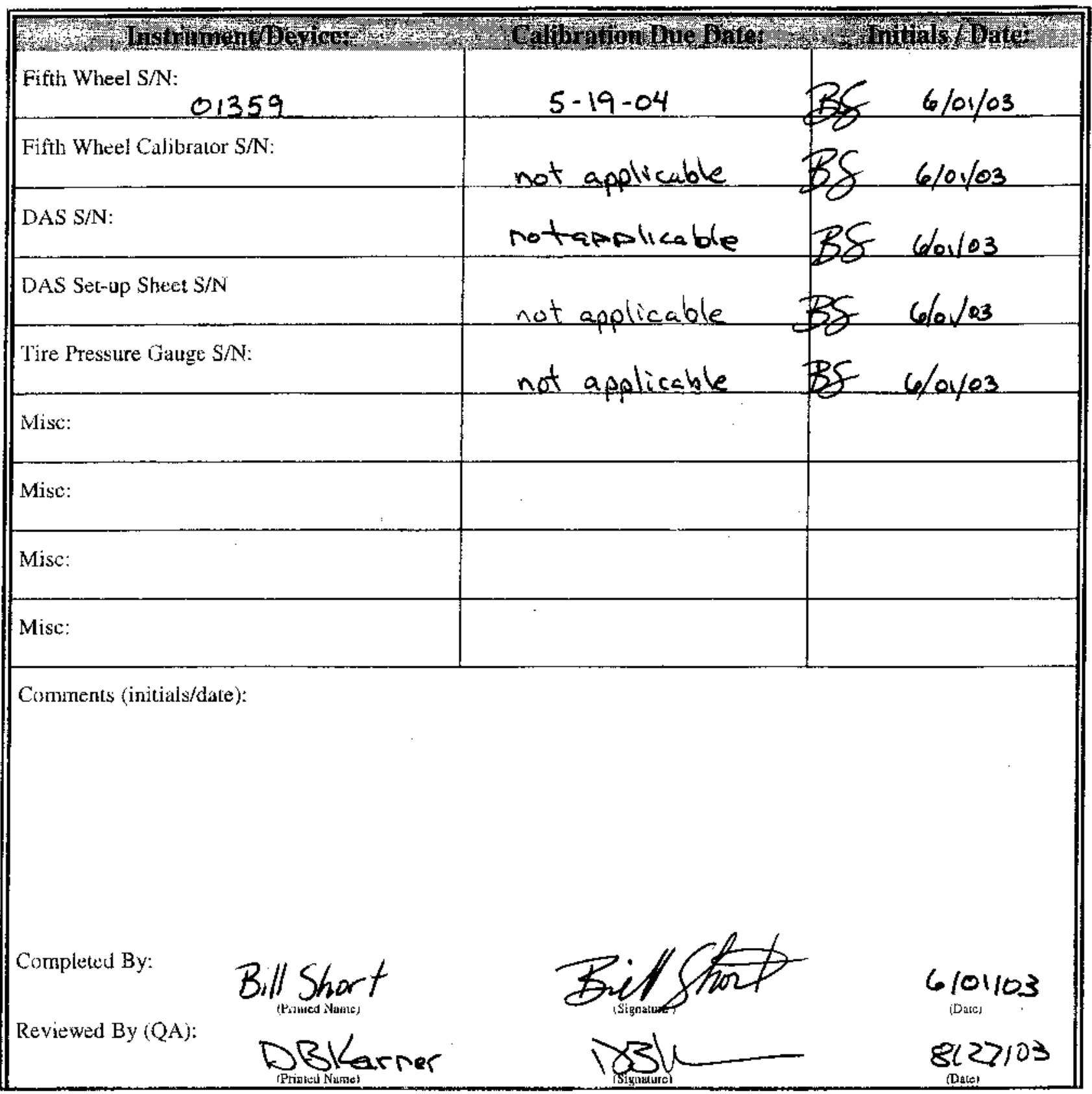

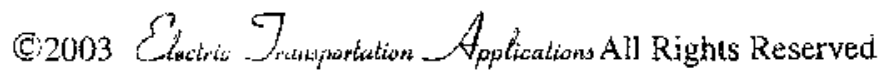




\title{
Attachment 4 - Hydrogen ICE Vehicle Constant Speed Fuel Economy
} Testing Data Sheets

\author{
Test Data Sheets Form \\ Conduct of ETA-YTP002, Revision 0
}




\section{APPENDIX-A \\ 45 mph Constant Speed Fuel Economy Test Data Sheet \\ (Page 1 of 2)}

VIN Number: IFTPF 17 M 8 YK B 39272

\begin{tabular}{|c|c|}
\hline Project No: ETA $-\alpha_{6}-25-\infty 2$ & Test Date(s): 6125103 \\
\hline Root File No.: & \\
\hline Test Driver Ziel Ghot & 6125103 \\
\hline Test Engineer: & (Dace) 6125703 \\
\hline
\end{tabular}

Vehicle Setup

\begin{tabular}{|c|c|c|c|}
\hline \multicolumn{4}{|c|}{$\begin{array}{l}\text { VEHICLE WEIGHTS AS TESTED WITH DRIVER \& INSTRUMENTATION } \\
\text { (Test Weight is Curb Weight plus } 332 \text { pounds) }\end{array}$} \\
\hline Left Front: $1363 \mathrm{Ibs}$. & Right Front: $144 / / \mathrm{bs}$ & Total Front: 2804 l6s. & Percent Front $53.7 \%$ \\
\hline 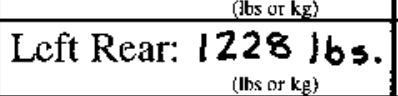 & 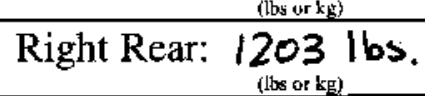 & Total Rear: $\underset{\text { (lls or kg) }}{243 \text { or kg) }}$ & Percent Rear: $46.3 \%$ \\
\hline & & Total Weight: 5235 & 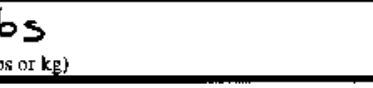 \\
\hline \multicolumn{4}{|c|}{$\begin{array}{l}\text { INSTALLED TRESS } \\
\text { (Placard or sidewall whichever is less) }\end{array}$} \\
\hline \multicolumn{4}{|c|}{ Preparation Area Temperature: } \\
\hline \multicolumn{2}{|c|}{ Left Front } & \multicolumn{2}{|c|}{ Right Front } \\
\hline 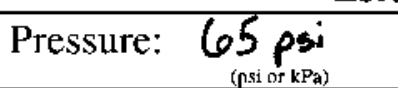 & & Pressure: 65 psi & \\
\hline \multicolumn{2}{|c|}{ Left Rear } & \multicolumn{2}{|c|}{ Right Rear } \\
\hline Pressure: 65 psi & & Pressure: 65 psi & \\
\hline
\end{tabular}

Track/Weather Conditions

\begin{tabular}{|c|c|c|}
\hline Test Track Location: $D$ & Track Grade: & 0 \\
\hline Ambient Temperature (initial): $\quad 78.1^{\circ} \mathrm{F}$ & \multicolumn{2}{|c|}{$\begin{array}{ll}\text { Ambient Temperature (final): } & 87 . \mathrm{F} \\
\left(40.100^{\circ} \text { or } 5.38^{\circ} \mathrm{C}\right)\end{array}$} \\
\hline Track Temperature (initial): & \multicolumn{2}{|c|}{\begin{tabular}{|ll} 
Track Temperature (final): & $96.5^{\circ} \mathrm{F}$ \\
\end{tabular}} \\
\hline Wind Velocity (initial): & \multicolumn{2}{|c|}{ Wind Velocity (final): $\quad \frac{10.7 \mathrm{mph}}{<<0 \mathrm{mphor} / 6 \mathrm{kmm} / \mathrm{h})}$} \\
\hline Wind Direction (initial): & \multicolumn{2}{|c|}{ Wind Direction (completion): $\quad 32^{\circ}$} \\
\hline
\end{tabular}

(1)2003 $\sum_{\text {lectric }} \mathcal{J}_{\text {ransportation Applications All Rights Reserved }}$ 


\section{Procedure ETA-YTP002 Revision 0}

\section{APPENDIX-A \\ 45 mph Constant Speed Fuel Economy Test Data Sheet \\ (Page 2 of 2)}

VIN Number IFTPF 17 M $8 Y K B 39272$

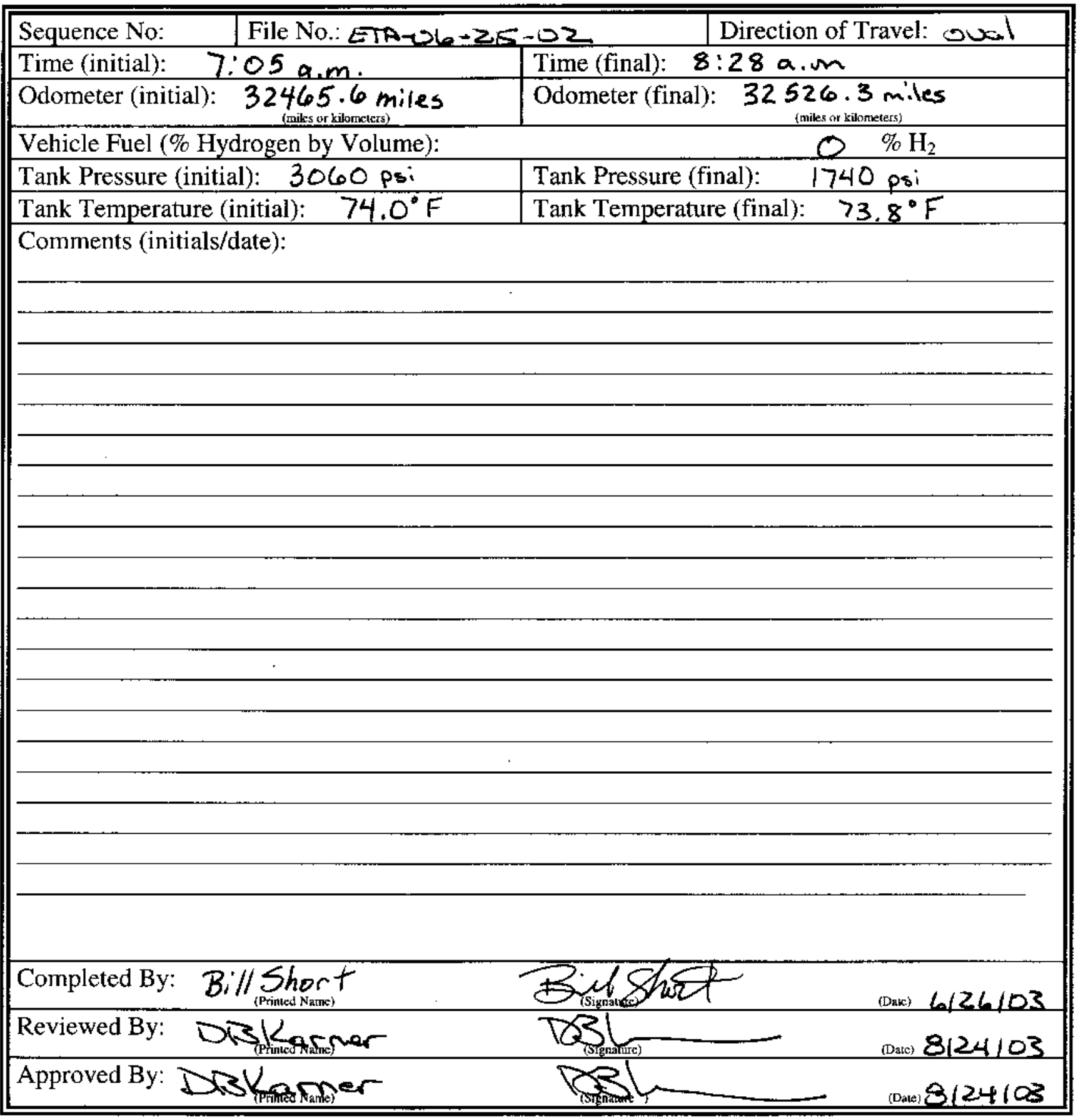


Procedore ETA-Y YP002 Revision 0

\section{APIENDTX-B \\ Vehicle Metrology Setup Sheets \\ (Page 1 of 1 )}

VIN Number: IFTPFI 7 M 8 YKB 39272

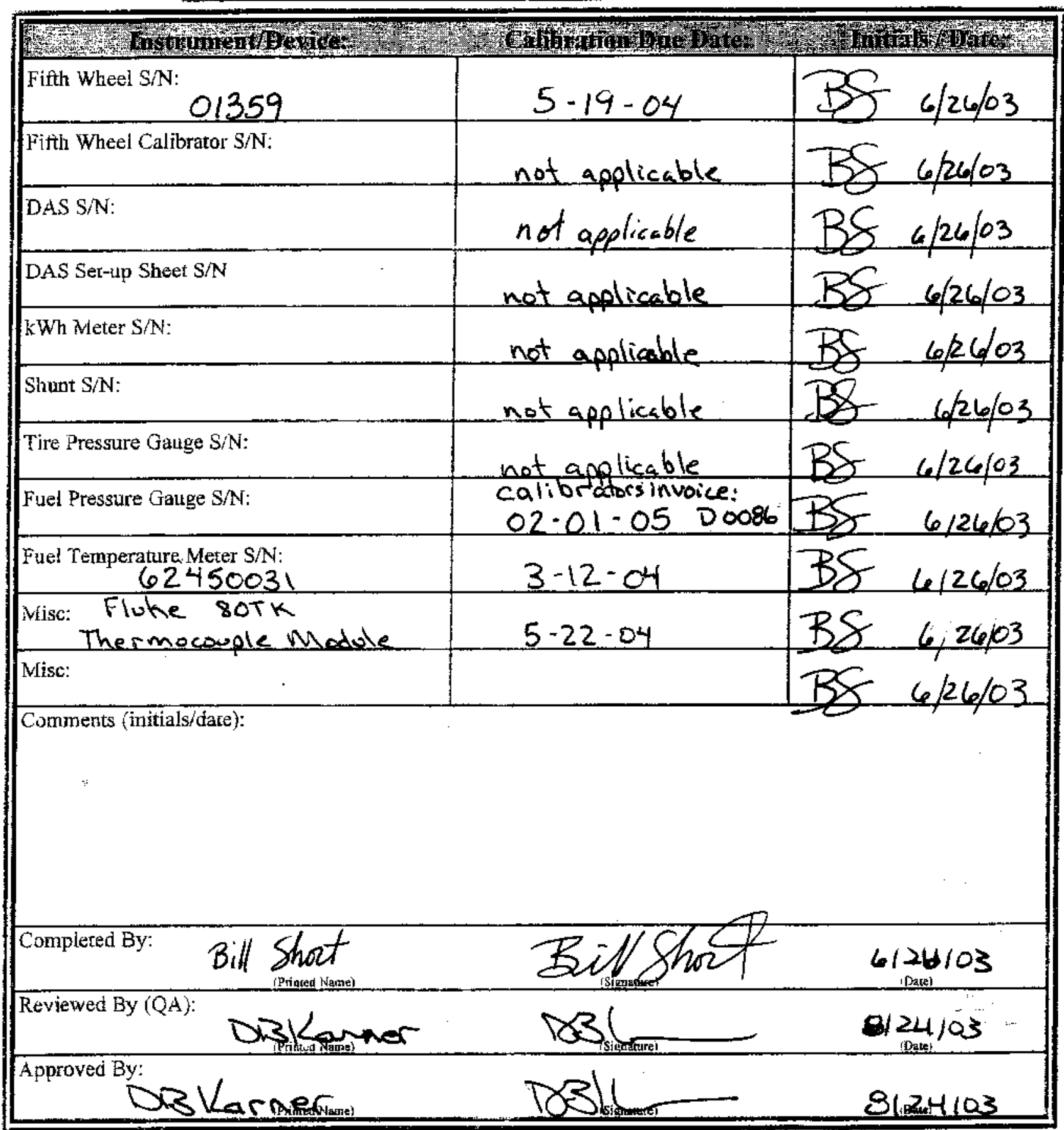




\section{APPENDIX-A \\ 45 mph Constant Speed Fuel Econony Test Data Sheet \\ (Page 1 of 2)}

VIN Number: JFTPF 17 M 8YK B 39272

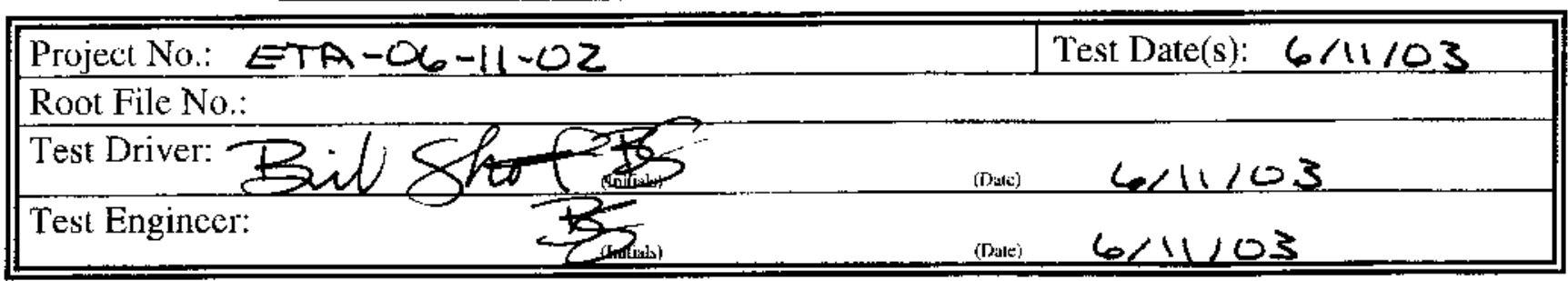

Vehicle Setup

\begin{tabular}{|c|c|c|c|}
\hline \multicolumn{4}{|c|}{ 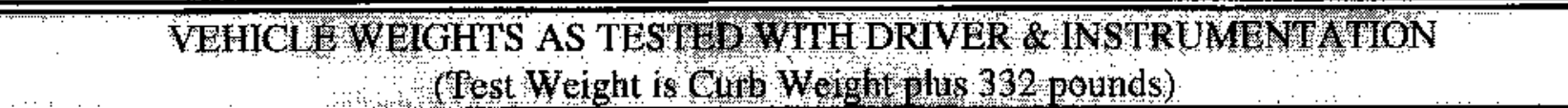 } \\
\hline Left Front: $1363 / 6 \mathrm{~s}$. & Right Front: 144||$_{(\mathrm{lbs} \text { in } \mathrm{kg})} \mid \mathrm{bs}_{\mathrm{s}}$. & Total Front: $28 \mathrm{Clbs}_{\text {(brks) }} \mathrm{lbs}$. & Percent Front: $53.7 \%$ \\
\hline Left Rear: $12228 / 6 s$. & Right Rear: $1203 / 6 \mathrm{~s}$. & Total Rear: $243 / 16 s$. & Percent Rear: $46.3 \%$ \\
\hline & & \multicolumn{2}{|c|}{ Total Weight: $5235 \mathrm{lbs}_{\text {(hsur } \mathrm{k} k \text { ) }}$} \\
\hline \multicolumn{4}{|c|}{$\begin{array}{l}\text { TNSTALED TRES } \\
\text { or sidewall wholeved }(\text {, } 1 \text { ess) }\end{array}$} \\
\hline \multicolumn{4}{|c|}{ Preparation Area Temperature: } \\
\hline \multicolumn{2}{|c|}{ Left Front } & \multicolumn{2}{|c|}{ Right Front } \\
\hline Pressure: 65 psi & and & Pressure: $65 \rho$ si $^{i}$ & \\
\hline \multicolumn{2}{|c|}{ Left Rear } & \multicolumn{2}{|c|}{ Right Rear } \\
\hline Pressure: 65 psi & 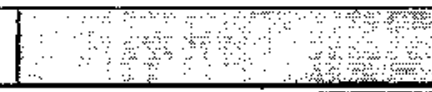 & Pressure: 65 psi & , \\
\hline
\end{tabular}

\section{Track/Weather Conditions}

\begin{tabular}{|c|c|}
\hline Test Track Location: DC APL Hahse & Track Grade: \\
\hline Ambient Temperature (initial): $\quad 76.4 \mathrm{~F}$ & Ambient Temperature (final): \\
\hline Track Temperature (initial): & Track Temperature (final): \\
\hline $5.9 \mathrm{mph}$ & Wind Velocity (final): \\
\hline Wind Direction (initial): & Wind Direction (completion): \\
\hline
\end{tabular}




\section{APPENDIX-A \\ 45 mph Constant Speed Fuel Economy Test Data Sheet \\ (Page 2 of 2)}

VIN Number $\perp$ FTPF $17 \mathrm{M} 8$ YKB 39272

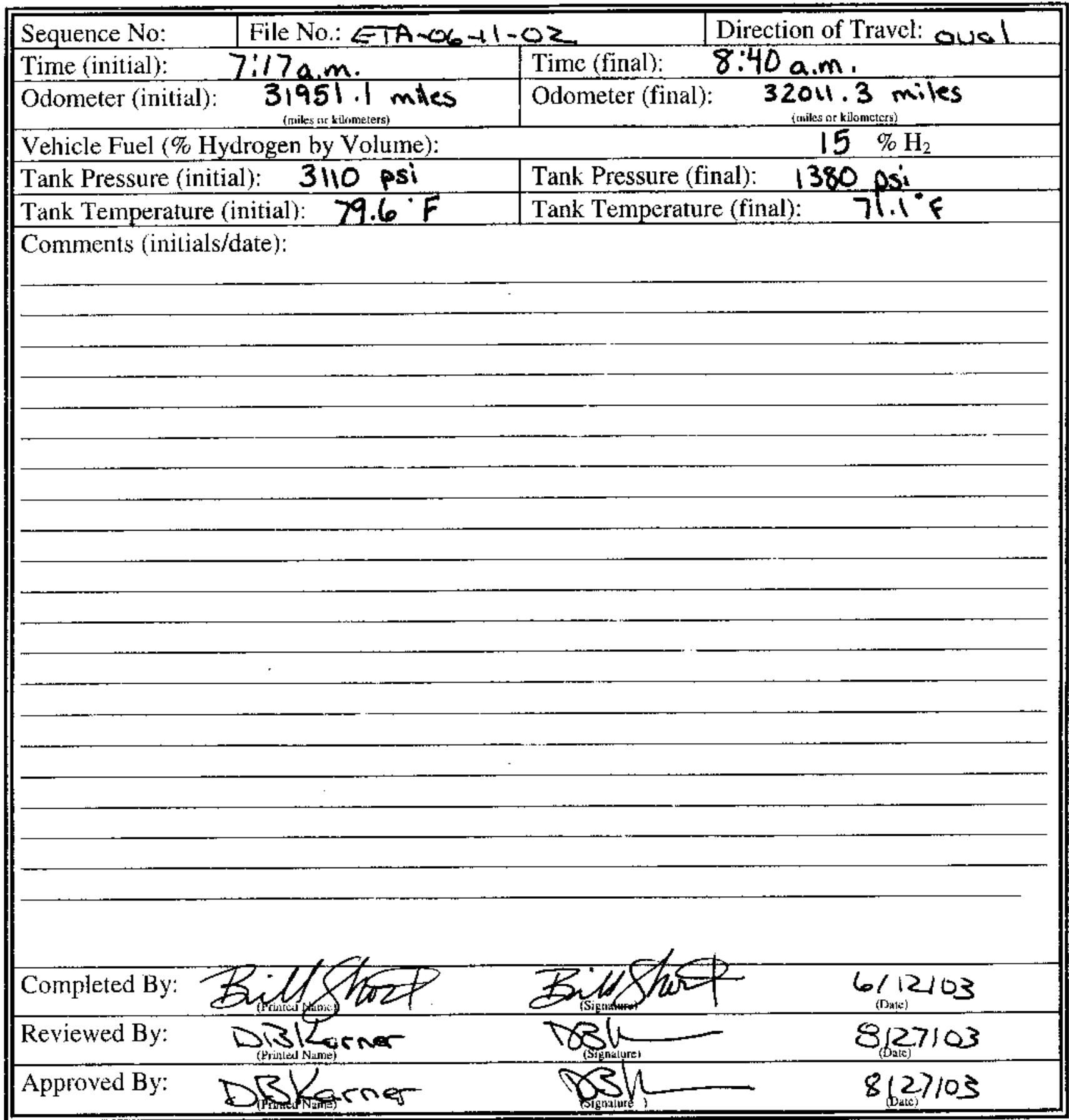

(C2003 Sfletriv Janiportation Applications All Rights Reserved 
Procedure ETA-YTP002 Revision 0

APYENDIX-B

Vehicle Metrology Setup Sheets

(Page 1 of 1 )

VIN Number: IFTPF17M 8YK B 39272

\begin{tabular}{|c|c|c|}
\hline Fifth Wheel S/N: 01359 & $5.19-04$ & BS $6 / 12 / 03$ \\
\hline Fiftin Wheel Calibrator $\mathrm{S} N$ : & not applicable & BS $6 / 12 / 03$ \\
\hline DAS S/N: & not apel & FBS $6 / 12 / 03$ \\
\hline DAS Set-up Sheet S/N & not applicable & BS 6/12/03 \\
\hline kWh Meter $\mathrm{S} / \mathrm{N}:$ & not apoliable & $B S \quad 6 / 12 / 03$ \\
\hline Shunt S/N: & not applicable & BS $6 / 12 / 03$ \\
\hline Tire Pressure Gauge $\mathrm{S} / \mathrm{N}$ : & not apf & BS $\quad 6 / 22 / 03$ \\
\hline Fuel Pressure Gauge $\mathrm{S} / \mathrm{N}$ : & $\begin{array}{l}\text { Calibratbrs invo.ce: } \\
02.01 .05\end{array}$ & BS $6 / 12 / 03$ \\
\hline $\begin{array}{r}\text { Fuet Temperature Meter S/N: } \\
62450031 \\
\end{array}$ & $3-12-04$ & BS $6 / 12 / 03$ \\
\hline $\begin{array}{l}\text { Misc: Fluthe 80TK } \\
\text { Thermocouple Madule }\end{array}$ & $5-22-04$ & BS $10 / 12 / 03$ \\
\hline Misc: & & \\
\hline \multicolumn{3}{|l|}{ Comments (initials/date): } \\
\hline Completed By: Bill Short & & $6 / 12103$ \\
\hline Dislifarner & a & 8127103 \\
\hline Approved By: DE & $x$ & 8127103 \\
\hline
\end{tabular}




\section{APl'ENDIX $A$ \\ Hydrogen ICE Vehicle Acceleration to a Pre-Determined Speed Test Data Sheet (Page 1 of 4 )}

VIN Number: IFTPEI7 $94 K B 39272$

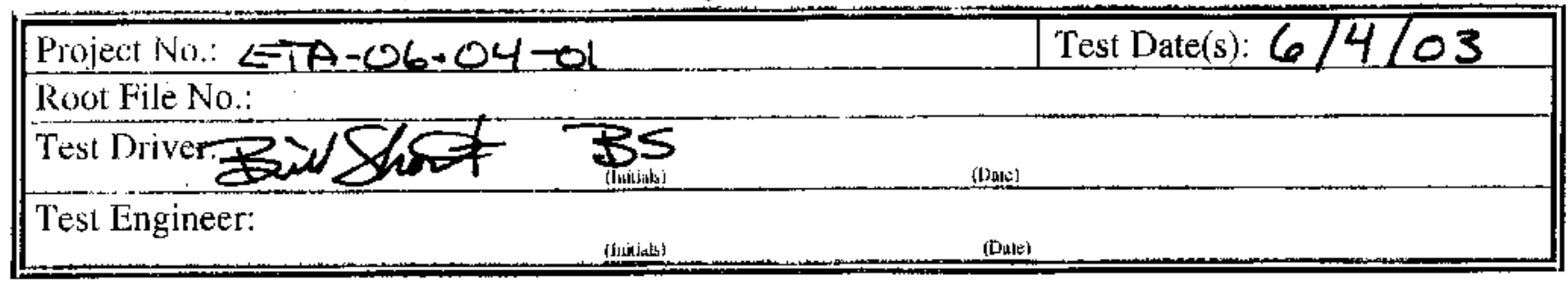

\begin{tabular}{|c|c|c|c|}
\hline \multicolumn{4}{|l|}{ Venticle Selin] } \\
\hline Left Tront: / $363 / 6 s$ & Right Front: $144 / 16 s$ & Total Front: $280416 \mathrm{~s}$ & Percent Front: $53.7 \%$ \\
\hline Left Rear: 1228 Hos & Right Rear: 1203 l6s & Total kear: $243116 \mathrm{~b}$ & Percent Rear. $46.3 \%$ \\
\hline & & Total Weight: 5235 & bs. \\
\hline \multicolumn{4}{|c|}{ 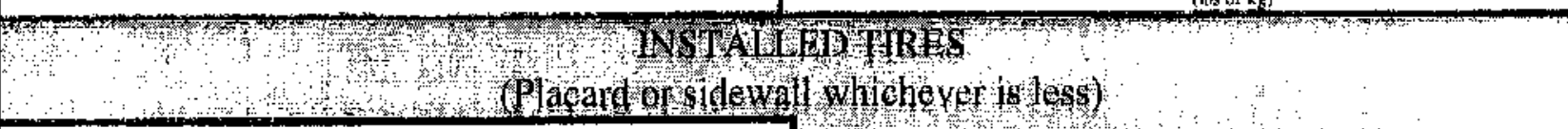 } \\
\hline \multicolumn{4}{|c|}{ Prepatation Ared Temperature: $\quad\left(\mathrm{FFur}^{\mathrm{a}} \mathrm{Cl}\right.$} \\
\hline \multicolumn{2}{|c|}{ Ieft Fiont } & \multicolumn{2}{|c|}{ Right Front } \\
\hline Pressure: 65 psi & 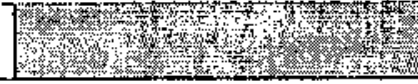 & 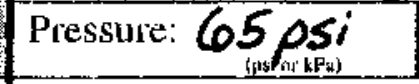 & Hents \\
\hline \multicolumn{2}{|c|}{$\begin{array}{l}\text { Left Rear } \\
\end{array}$} & \multicolumn{2}{|c|}{ Right Rear } \\
\hline Pressure: 65 psi & 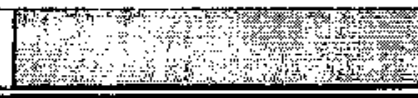 & Pres: & \\
\hline
\end{tabular}

Track/Weather Conditions

\begin{tabular}{|c|c|c|}
\hline \multicolumn{2}{|c|}{ Test Track Location: $D$ C APC Hoh Spend Oad } & $\sum_{1} \%$ \\
\hline Ambient Temperature (initial): $86.4^{\circ} \mathrm{F}$ & Ambient Temperature (final): & $4^{\circ} \mathrm{F}$ \\
\hline Track Temperature (initial): & Tratk Temperature (final): & $F$ \\
\hline Wind Velocity (initial): & Wind Velocily (final): & $n p^{n}$ \\
\hline Wind Direction (initial): & Wind Direction (completion): & $=$ \\
\hline
\end{tabular}




\section{APPENDIX-A \\ 45 mph Constant Speed Fuel Economy Test Data Sheet (Page 2 of 2 )}

VIN Number $\perp=T P 17$ M $84 K$ V3 39272

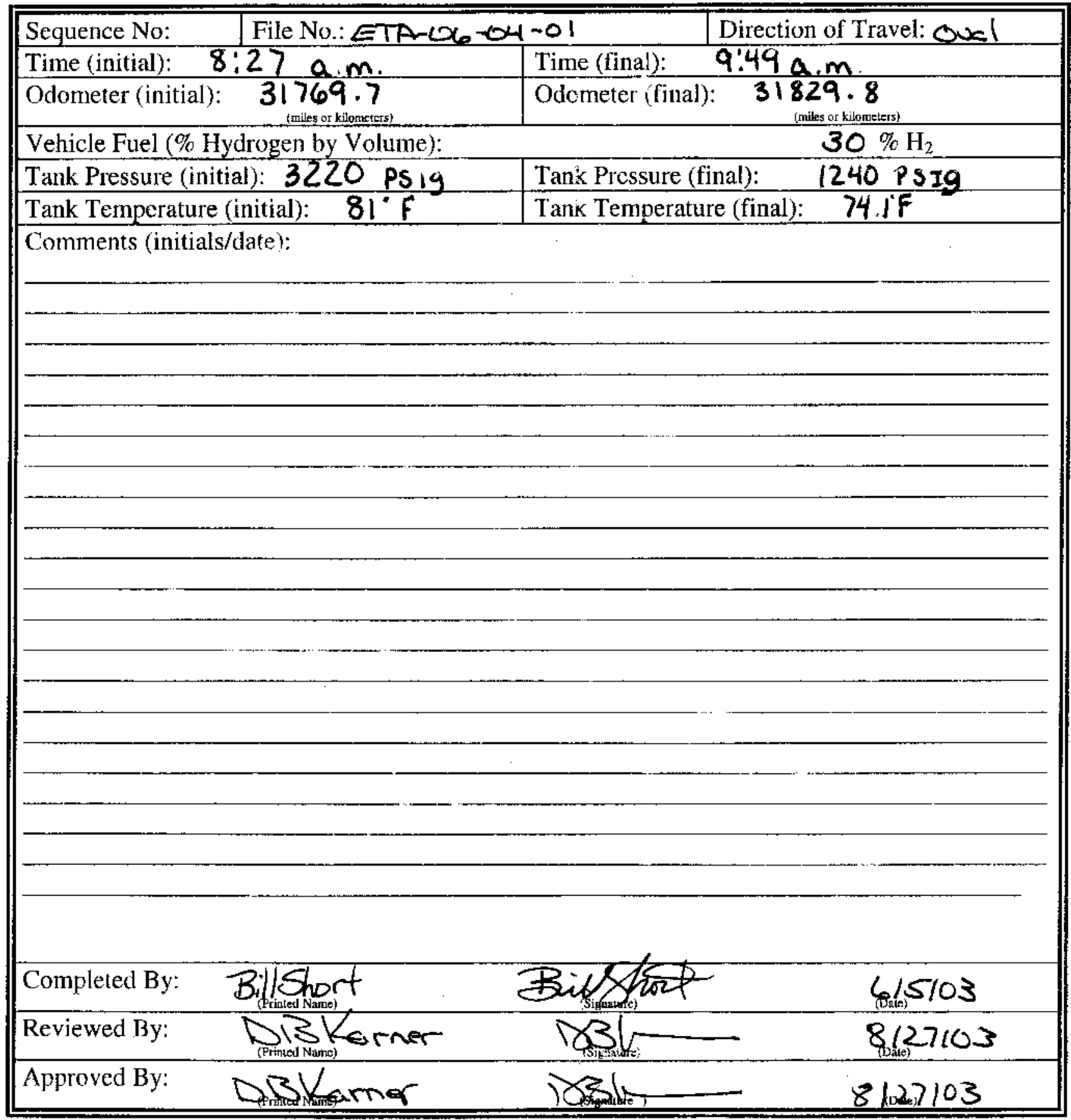


Procedure ETA-YTP002 Revision 0

\section{APPENDIX-B \\ Vehicle Metrology Setup Sheets \\ (Page 1 of 1)}

VIN Number: IFTPFI7M 8 YKB 39272

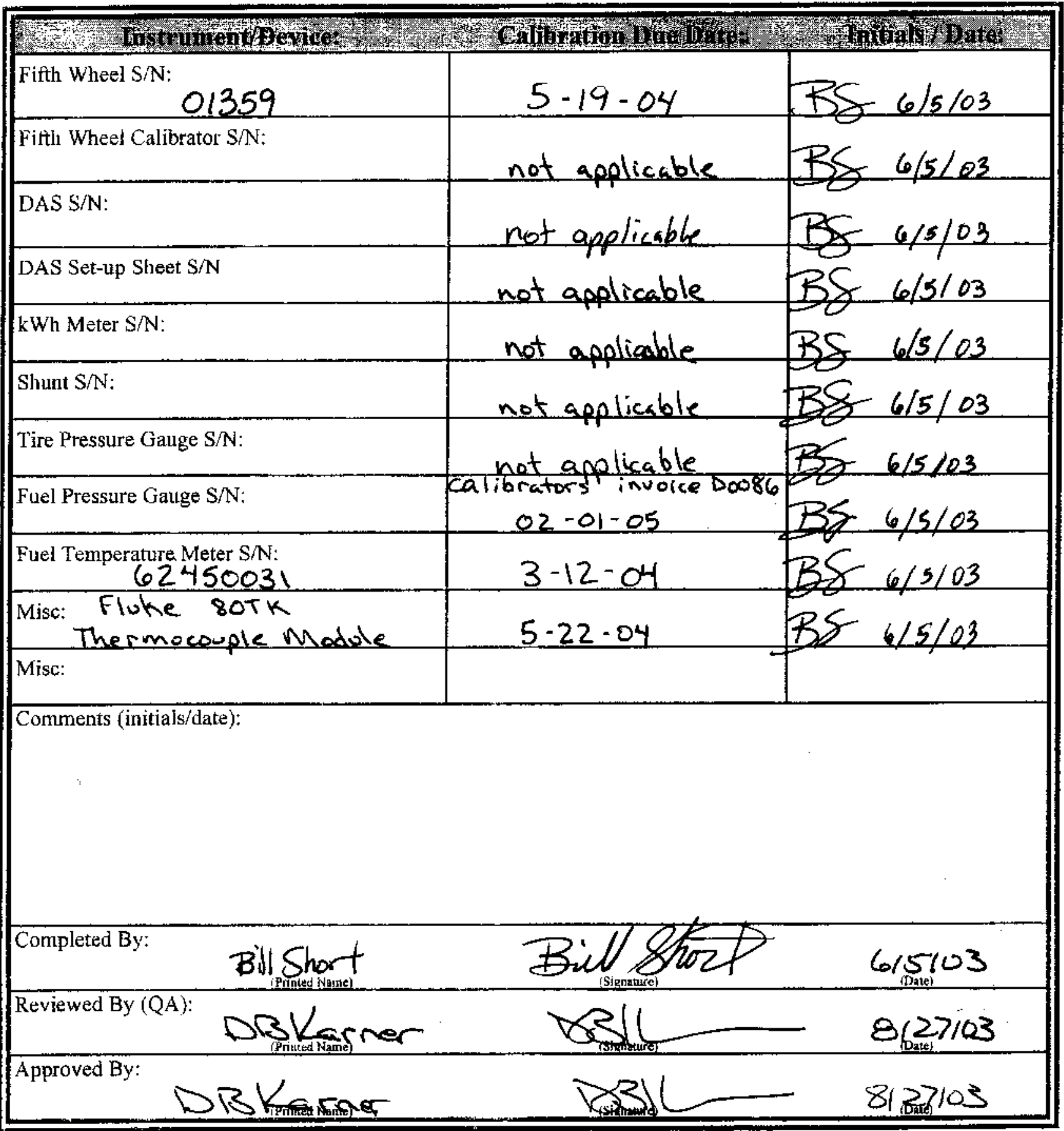




\section{Attachment 5 - Summary Emission Test Data Sheets}




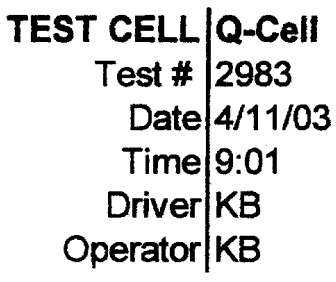

AMBIENT CONDITIONS...

\begin{tabular}{r|r|r|r|} 
Baro (inHg) & \multicolumn{1}{|c|}{28.72} \\
\hline PHASE \# & \multicolumn{1}{|c|}{1} & \multicolumn{1}{|c|}{2} & \multicolumn{1}{c}{$\mathbf{3}$} \\
\hline Temp ('F) & 76.0 & 76.1 & 76.8 \\
Wet blb ('F) & 54.3 & 54.3 & 54.6 \\
Humidity & $21.7 \%$ & $21.4 \%$ & $20.8 \%$ \\
Abs (gr/lb) & 29.9 & 29.6 & 29.5 \\
NOx K fac & 0.825 & 0.824 & 0.824
\end{tabular}

VEHICLE...

Model|F-150

Vehicle \# 72

Odometer 30045

Dyno Inertia 6500
FUEL...

$$
\begin{array}{r|l}
\text { ATL_Code } & \text { CNG } \\
\text { FE_num } & 1778 \\
\text { CWF } & 0.718 \\
\text { Spc Grv } & 0.5976 \\
\text { HC_density } & 18.75
\end{array}
$$

Comments...

Compressed Natural Gas

VARIABLES...

\begin{tabular}{r|r|r|r|}
\hline PHASE \# & \multicolumn{1}{|c|}{1} & \multicolumn{1}{c|}{$\mathbf{2}$} & \multicolumn{1}{c|}{3} \\
\hline VMIX (ft3) & 2863.7 & 4881.3 & 2845.7 \\
Distance & 3.58 & 3.861 & 3.59
\end{tabular}

Results...

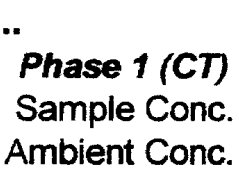

NMHC CHA

HC

co

NoX

ppm

ppm

ppm

$\mathrm{CO} 2$

ppm Ppm

36.050

83215

6.737

1.665

4.234

\begin{tabular}{ll}
\hline 4.443 & 1.961 \\
\hline
\end{tabular}

30.153

81.758

4.163

$\%$

DF

Net Conc.

$4.653 \quad 21.795$

30.153

7.719

2.156

$0.533 \quad 1709.033$

$0.149 \quad 477.383$

$(\mathrm{gm})$
$(\mathrm{gm} / \mathrm{mile})$

\begin{tabular}{|c|c|c|c|c|c|c|c|}
\hline Phase 2(CS) & ppm & ppm & ppm & ppm & ppm & $\%$ & DF \\
\hline Sample Conc. & 4.409 & 3.782 & 8.835 & 5.809 & 2.371 & 0.805 & 11.8 \\
\hline Ambient Conc. & 4.368 & 2.249 & 7.000 & 2.214 & 0.101 & 0.041 & \\
\hline Net Conc. & 0.406 & 1.721 & 2.419 & 3.779 & 2.278 & 0.767 & \\
\hline
\end{tabular}

0.065

0.329

\begin{tabular}{|c|c|c|c|c|c|c|c|}
\hline Phase 3 (HT) & ppm & ppm & ppm & ppm & ppm & $\%$ & \\
\hline Sample & 4.589 & 11.564 & 18.119 & 6.877 & 1.360 & 1.054 & 9.1 \\
\hline Ambient Conc. & 3.758 & 2.444 & 6.618 & 1.599 & 0.105 & 0.051 & \\
\hline Net Conc. & 1.242 & 9.387 & 12.225 & 5.453 & 1.266 & 1.009 & \\
\hline
\end{tabular}

0.452

m

\begin{tabular}{llllllrl}
$(\mathrm{gm})$ & 0.035 & 0.159 & 0.221 & 0.608 & 0.496 & 1940.372 & $\mathrm{mpg}$ \\
$(\mathrm{gm} / \mathrm{mile})$ & 0.009 & 0.041 & 0.057 & 0.158 & 0.129 & 502.557 & 13.05 \\
\hline
\end{tabular}

\begin{tabular}{llllllll}
$(\mathrm{gm})$ & 0.062 & 0.505 & 0.652 & 0.512 & 0.161 & 1487.364 & $\mathrm{mpg}$ \\
$(\mathrm{gm} / \mathrm{mile})$ & 0.017 & 0.141 & 0.182 & 0.143 & 0.045 & 414.308 & 15.82 \\
\hline
\end{tabular}

Composite ...

$\begin{array}{llllllll}\text { Grams/mile } & 0.023 & 0.128 & 0.173 & 0.567 & 0.110 & 473.113 & 13.84\end{array}$




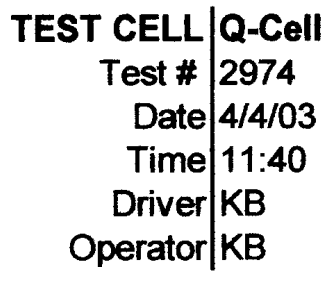

AMBIENT CONDITIONS...

\begin{tabular}{r|r|r|r|} 
Baro (inHg) & \multicolumn{1}{|c|}{28.75} & \multicolumn{1}{|c|}{ 2 } \\
\hline PHASE \# & \multicolumn{1}{|c|}{1} & \multicolumn{1}{|c|}{2} & \multicolumn{1}{|c}{} \\
\hline Temp ('F) & 76.0 & 76.2 & 75.3 \\
Wet blb ('F) & 57.0 & 56.7 & 57.0 \\
Humidity & $29.4 \%$ & $28.1 \%$ & $31.1 \%$ \\
Abs (gr/lb) & 40.7 & 39.1 & 42.0 \\
NOx K fac & 0.861 & 0.856 & 0.866
\end{tabular}

FUEL...

$$
\begin{array}{r|l}
\text { ATL Code } & \text { CNG } \\
\text { FE_num } & 1778 \\
\text { CWF } & 0.718 \\
\text { Spc Grv } & 0.5976 \\
\text { HC_density } & 18.75
\end{array}
$$

Comments...

FTP: (Hydrogen)

\begin{tabular}{l}
\hline Preliminary Results \\
\hline Pure CNG Fuel properties \\
\hline Target Hydrogen conc: $15 \%$ by volume \\
\hline Fuel economy correction factor: 95 \\
\hline Per request \\
\hline Vin \#1FTPF17M8YKB39272 \\
\hline
\end{tabular}

Pure CNG Fuel properties

Target Hydrogen conc: $15 \%$ by volume

Fuel economy correction factor: .95

VIn \# 1FTPF17MBYKB39272

VARIABLES...

\begin{tabular}{r|r|r|r|}
\hline PHASE \# & \multicolumn{1}{|c|}{1} & \multicolumn{1}{|c|}{$\mathbf{1}$} & \multicolumn{1}{c|}{3} \\
\hline VMIX (ft3) & 2860.8 & 4878.3 & 2843.5 \\
Distance & 3.631 & 3.857 & 3.552
\end{tabular}

Results...

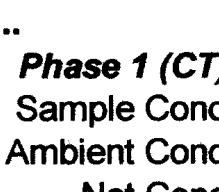

Net Conc.

NMHC

\begin{tabular}{|c|c|c|c|c|c|c|c|}
\hline Phase 2(CS) & ppm & ppm & ppm & ppm & ppm & $\%$ & DF \\
\hline Sample Conc. & 4.106 & 3.662 & 8.391 & 5.565 & 1.952 & 0.768 & 12.55 \\
\hline Ambient Conc. & 3.958 & 2.085 & 6.397 & 2.037 & 0.106 & 0.045 & \\
\hline Net Conc. & 0.463 & 1.744 & 2.503 & 3.690 & 1.854 & 0.727 & \\
\hline (gm) & 0.040 & 0.161 & 0.229 & 0.593 & 0.419 & 1837.419 & mpg \\
\hline (gm/mile) & 0.010 & 0.042 & 0.059 & 0.154 & 0.109 & 476.385 & 13.08 \\
\hline
\end{tabular}

ppm
VEHICLE...

Vehicle \# 72

Dyno Inertia 6500

\begin{tabular}{llllllrl|}
$(\mathrm{gm})$ & 0.220 & 1.203 & 1.632 & 6.183 & 0.440 & 1654.887 & $\mathrm{mpg}$ \\
\hline $\mathrm{gm} / \mathrm{mile})$ & 0.060 & 0.331 & 0.449 & 1.703 & 0.121 & 455.766 & 13.57 \\
\hline
\end{tabular}

Phase 3 (HT)

Sample Conc.

Ambient Conc.

ppm

ppm

co

Nox

\begin{tabular}{|c|c|c|c|c|c|c|}
\hline ppm & ppm & ppm & ppm & ppm & $\%$ & DF \\
\hline 4.813 & 11.949 & 18.794 & 6.262 & 4.221 & 1.016 & 9.48 \\
\hline 3.461 & 2.287 & 6.136 & 1.990 & 0.107 & 0.048 & \\
\hline 1.717 & 9.904 & 13.305 & 4.482 & 4.126 & 0973 & \\
\hline
\end{tabular}

DF

\begin{tabular}{|r|r|r|r|r|r|}
\hline 7.546 & 24.125 & 35.772 & 67.412 & 3.404 & 1.155 \\
\hline 3.598 & 2.127 & 6.086 & 2.119 & 0.1217 & 0.043 \\
\hline 4.382 & 22.254 & 30.420 & 65.548 & 3.297 & 1.117 \\
\hline
\end{tabular}

8.29

Net Conc.

(gm)

0.086

0.532

0.709

0.420

$\begin{array}{lll}0.550 & 1433.595 \quad \mathrm{mpg}\end{array}$

(gm/mile)

0.024

0.150

0.200

0.118

0.155

403.602 15.43

Composite ...

Grams/mile

0.025

0.132

0.179

0.467

0.124

452.197

MPG

13.76 


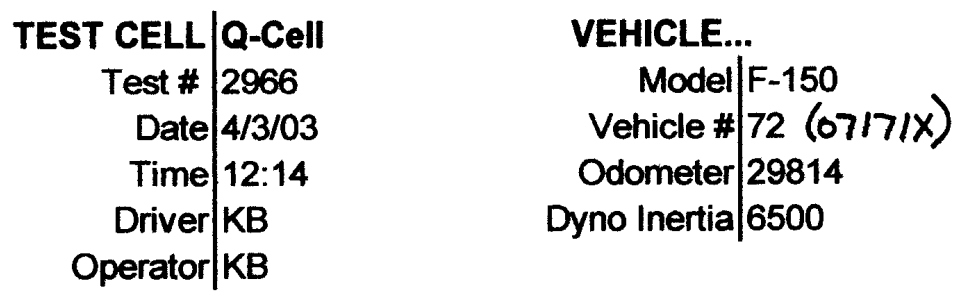

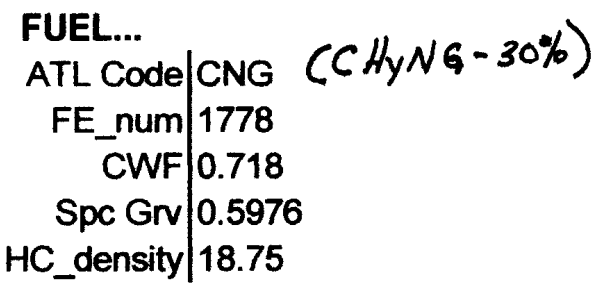

AMBIENT CONDITIONS...
\begin{tabular}{r|r|r|r|} 
Baro (inHg) & \multicolumn{1}{|c|}{28.71} \\
\hline PHASE \# & \multicolumn{1}{|c|}{1} & \multicolumn{1}{|c|}{2} & \multicolumn{1}{|c}{3} \\
\hline Temp ('F) & 75.7 & 76.5 & 76.3 \\
Wet blb ('F) & 56.1 & 56.6 & 56.6 \\
Humidity & $27.6 \%$ & $27.4 \%$ & $27.9 \%$ \\
Abs (gr/lb) & 37.7 & 38.4 & 38.9 \\
NOx K fac & 0.851 & 0.853 & 0.855
\end{tabular}

Comments...

FTP: (Hydrogen)

Preliminary Results

Pure CNG Fuel properties

Target Hydrogen conc: $30 \%$ by volume

Fuel economy correction factor: .95

Per request

Vin \# 1FTPF17M8YKB39272

VARIABLES...

\begin{tabular}{r|r|r|r|}
\hline PHASE \# & \multicolumn{1}{|c|}{1} & \multicolumn{1}{c|}{2} & \multicolumn{1}{c|}{3} \\
\hline VMIX (ft3) & 2861.2 & 4878.6 & 2845.2 \\
Distance & 3.585 & 3.859 & 3.586
\end{tabular}

Results...

Phase 1 (CT)

NMHC $\mathrm{CH}$

HC

co

Nox

ppm

ppm

ppm

DF

Sample Conc.

Ambient Conc.

\begin{tabular}{l|l}
4.681 & 23.61 \\
\hline
\end{tabular}

pm

32.309

58.424

3.720

\begin{tabular}{|l|r|r|r|r|r|}
\hline 2.714 & 1.991 & 5.043 & 2.010 & 0.068 & 0.043 \\
\hline
\end{tabular}

Net Conc.

$\begin{array}{llllll}2.295 & 21.862 & 27.873 & 56.656 & 3.660 & 1.118\end{array}$

(gm)

0.115

1.182

1.495

5.345

1.491

0.4831656 .971

$0.135462 .196 \quad 13.40$

(gm/mile)

0.032

0.330

0.417

(1)

Phase 2(CS)

Sample Conc.

Ambient Conc.

Net Conc.

\begin{tabular}{|r|r}
\hline 2.8 \\
\hline 2.7 \\
\hline
\end{tabular}

ppm ppm

ppm

\begin{tabular}{l|r|r|r|} 
& \multicolumn{1}{c}{ ppm } & \multicolumn{1}{c}{ ppm } & \multicolumn{1}{l}{$\%$} \\
\hline 7.466 & 5.575 & 1.924 & 0.758 \\
\hline 5.289 & 2.044 & 0.019 & 0.047 \\
\hline 2.593 & 3.692 & 1.907 & 0.714
\end{tabular}

\begin{tabular}{llllllll|}
$(\mathrm{gm})$ & 0.026 & 0.180 & 0.237 & 0.594 & 0.430 & 1805.680 & $\mathrm{mpg}$ \\
\hline$(\mathrm{gm} / \mathrm{mile})$ & 0.007 & 0.047 & 0.061 & 0.154 & 0.111 & 467.914 & 13.32 \\
\hline
\end{tabular}

Phase 3 (HT)

.

ppm

\begin{tabular}{l|l|}
2.878 & 3.922 \\
\hline
\end{tabular}

DF

Sample Conc.

Ambient Conc.

2.795

2.132

\begin{tabular}{|c|c|c|}
\hline 32 & 5.4 \\
\hline
\end{tabular}

Net Conc.

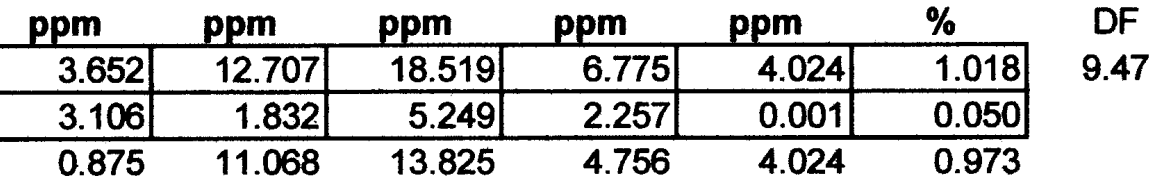

\begin{tabular}{llllllll|}
$(\mathrm{gm})$ & 0.044 & 0.595 & 0.738 & 0.446 & 0.530 & 1434.796 & $\mathrm{mpg}$ \\
\hline$(\mathrm{gm} / \mathrm{mile})$ & 0.012 & 0.166 & 0.206 & 0.124 & 0.148 & 400.111 & 15.56 \\
\hline
\end{tabular}

Composite ...
Grams/mile
0.013
0.138
0.175
0.423
$0.126 \quad 448.114$
13.89 
